\title{
Bipolar disorder in daily life : mood and cortisol responses to naturally occurring events
}

Citation for published version (APA):

Havermans, A. G. (2013). Bipolar disorder in daily life : mood and cortisol responses to naturally occurring events. [Doctoral Thesis, Maastricht University]. Maastricht University. https://doi.org/10.26481/dis.20130117ah

Document status and date:

Published: 01/01/2013

DOI:

10.26481/dis.20130117ah

Document Version:

Publisher's PDF, also known as Version of record

\section{Please check the document version of this publication:}

- A submitted manuscript is the version of the article upon submission and before peer-review. There can be important differences between the submitted version and the official published version of record. People interested in the research are advised to contact the author for the final version of the publication, or visit the DOI to the publisher's website.

- The final author version and the galley proof are versions of the publication after peer review.

- The final published version features the final layout of the paper including the volume, issue and page numbers.

Link to publication

\footnotetext{
General rights rights.

- You may freely distribute the URL identifying the publication in the public portal. please follow below link for the End User Agreement:

www.umlib.nl/taverne-license

Take down policy

If you believe that this document breaches copyright please contact us at:

repository@maastrichtuniversity.nl

providing details and we will investigate your claim.
}

Copyright and moral rights for the publications made accessible in the public portal are retained by the authors and/or other copyright owners and it is a condition of accessing publications that users recognise and abide by the legal requirements associated with these

- Users may download and print one copy of any publication from the public portal for the purpose of private study or research.

- You may not further distribute the material or use it for any profit-making activity or commercial gain

If the publication is distributed under the terms of Article $25 \mathrm{fa}$ of the Dutch Copyright Act, indicated by the "Taverne" license above, 


\section{Bipolar disorder in daily life \\ Mood and cortisol responses to naturally occurring events}


(C) Copyright Rob Havermans, Maastricht 2013.

All rights reserved. No part of this thesis may be reproduced of transmitted in any form of by any means, electronic or mechanical, including photocopying, recording, or any information storage or retrieval system without permission from the author, or when appropriate, from the publishers of the publications.

Alle rechten voorbehouden.

Niets uit deze uitgave mag worden verveelvoudigd, opgeslagen in een geautomatiseerd gegevensbestand en/of openbaar gemaakt in enige vorm of op enige wijze, hetzij elektronisch, mechanisch, door fotokopieën, opnamen of op enige andere manier zonder voorafgaande schriftelijke toestemming van de uitgever.

Omslagontwerp: Miranda Reijnders

Vormgeving en druk: Datawyse | Universitaire Pers Maastricht ISBN 9789461591814 


\title{
Bipolar disorder in daily life
}

\section{Mood and cortisol responses to naturally occurring events}

\author{
PROEFSCHRIFT \\ ter verkrijging van de graad van doctor aan de Universiteit Maastricht, \\ op gezag van de Rector Magnificus, Prof. dr. L.L.G. Soete, \\ volgens het besluit van het College van Decanen, \\ in het openbaar te verdedigen, \\ op donderdag 17 januari 2013 om 16.00 uur \\ door \\ Adrianus Gertruda (Rob) Havermans
}

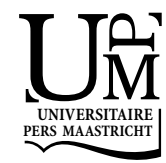




\section{Promotor}

Prof. dr. M. deVries

\section{Co-promotor}

Dr. N. Nicolson

\section{Beoordelingscommissie}

Prof. dr. J. van Os (voorzitter)

Prof. dr. R. Bentall (University of Liverpool, United Kingdom)

Prof. dr. Ph. Delespaul

Prof. dr. R.W. Kupka (VU Medisch Centrum, Amsterdam)

Prof. dr. M.L. Peters 


\section{Contents}

Chapter 1

Introduction - outline and aims of this thesis

Chapter 2

Daily hassles, uplifts, and time use in individuals with bipolar disorder in remission. Journal of Nervous and Mental Disease 195 (2007) 745-751.

Chapter 3

Mood reactivity to daily events in patients with remitted bipolar disorder.

Psychiatry Research 179 (2010) 47-52

Chapter 4

Patterns of salivary cortisol secretion and responses to daily events in patients with remitted bipolar disorder.

Psychoneuroendocrinology 36 (2011) 258-265

Chapter 5

Mood states and reactivity to positive daily events predict episode recurrence in patients with remitted bipolar disorder.

To be submitted

Chapter 6

Discussion and concluding remarks

Appendix

The influence of environmental factors on the course of bipolar disorder.

Adapted and translated from: Rob Havermans en Manon Hillegers (2008) Omgevingsfactoren. In: R.W. Kupka, E.A.M. Knoppert - van der Klein, W.A. Nolen (Eds.) Handboek Bipolaire Stoornissen.

Hoofdstuk 10. De Tijdstroom, Utrecht.

Samenvatting

Verantwoording en dankwoord

Curriculum vitae 

Chapter 1

Introduction outline and aims of this thesis 
CHAPTER 1 


\section{Introduction}

Bipolar disorder (BD) is a mood disorder that is defined by recurrent manic, hypomanic and depressive episodes. In the absence of identified specific pathophysiological processes, diagnosis of bipolar disorder is based on the nature, the number, the severity and the course of symptoms. According to the DSM-IV classification system, the typical and more severe forms of BD are Bipolar I Disorder (BD-I; full-blown manic episodes with or without alternating depressive episodes) and Bipolar II Disorder (BD-II; depressive episodes alternating with hypomanic episodes). BD has been conceptualised as a broad spectrum ranging from BD-I to subthreshold BD, including syndromes with depressive episodes with a positive family history of BD or alternating with milder subsyndromal or antidepressant-induced hypomanic states (Ghaemi et al., 2004). However, much controversy exists concerning the validity and usefulness of this concept (for a discussion, see Goodwin and Jamison, 2007, pp. 19-24). In this thesis we focus on BD-I and BD-II. The recent Nemesis-2 study, a representative Dutch survey of mental disorders using the CIDI, estimated a lifetime prevalence of BD-I and BD-II combined of $1.3 \%$, with a 12-month prevalence of $0.8 \%$. Slightly higher percentages were found in the National Comorbidity Survey Replication in the United States, with lifetime prevalence estimates of $1 \%$ for BD-I, $1.1 \%$ for BD-II, and $2.4 \%$ for subthreshold BD (Merikangas et al., 2007).

The course of BD is very dynamic and highly variable. Some patients succeed in a rapid and successful recovery from often severe episodes and are able to achieve long periods of remission and maintain acceptable levels of occupational and psychosocial functioning. In many patients, however, the course of the disorder is more chronic, with a high rate of episode recurrence, only partial recovery, and persistent impairments in cognitive and psychosocial functioning. Cohort studies have estimated the risk of episode recurrence in patients under treatment for BD at 0.4 episodes per year (Angst et al., 2003), with up to 73\% of patients experiencing a relapse over a period of five years (Gitlin et al., 1995). In addition, during periods of remission subsyndromal symptoms are often present (Judd et al., 2002), which in turn predict faster episode recurrence (Judd et al., 2008). Recurrent episodes and subsyndromal symptoms disrupt multiple domains of social functioning; as a result the large majority of patients with BD manifest problems with work and global functioning (Goldberg and Harrow, 2011). Moreover, the long-term course of BD is associated with a high prevalence of psychiatric and somatic comorbidity (Soreca et al., 2009), a high subjective burden in about half of the primary caregivers (Perlick et al., 2007), and high direct and indirect economic costs (Dilsaver, 2011).

It is thus important to identify factors (protective as well as hazardous) that affect the risk of recurrence and improve our understanding of the mechanisms that may be involved. In line with vulnerability-stress models of BD (Johnson 
and Roberts, 1995), cohort studies performed over the past 20 years have shown that psychosocial factors such as major life events, social support, and the affective climate within families influence the course and outcome of BD. A review of the main studies (published before 2007) on this topic is provided as an Appendix to this thesis. A major limitation of these studies is that they provide no information about the direct psychological and physiological consequences of environmental factors, and thus contribute little to a better understanding of the mechanisms through which these factors may exert their effects on the risk of episode recurrence. Information about how BD patients experience and react to naturally occurring events in daily life may help understand how individual differences in vulnerability to stress may arise, and can thus be useful in developing interventions aimed at preventing relapse.

Taking this assumption as its starting point, the present study was designed to provide a detailed description of the experience of daily events and their effects on mood states and salivary cortisol in patients with remitted BD and a healthy comparison group. We used an intensive sampling procedure, the experience sampling method (ESM; Csikszentmihalyi and Larson, 1987; deVries, 1992), in combination with frequent salivary cortisol sampling, to assess daily events, mood states and cortisol levels as close as possible to their time and place of occurrence. Such a daily process design has been typified as "the equivalent of a behavioral science microscope" (Eckenrode and Bolger, 1995), enabling the researcher "to capture the film rather than the snapshot of daily life reality" (Myin-Germeys et al., 2009). ESM has proven to be a particularly useful tool in the study of psychiatric disorders; in combination with appropriate statistical methods, it makes it possible to link within-day fluctuations in mood states and cortisol levels to daily experiences and contexts (Ebner-Priemer et al., 2009; Myin-Germeys et al., 2009).

Research on the structure of self-rated mood has revealed the presence of two major and fairly independent dimensions: negative affect (NA) and positive affect (PA) (Watson and Tellegen, 1985; Watson et al., 1999). High NA is linked to behavioral withdrawal and subsumes a range of negative mood states such as anger, fear, and sadness. High PA is characterized by feelings of enthusiasm, joy, and happiness and is associated with explorative behavior and active engagement with the environment. Whereas heightened NA and lowered PA (anhedonia) are key symptoms of depression, extreme high levels PA (euphoria) are present during manic states. In a previous ESM study, patients with unipolar depression reported smaller increases in NA en smaller decreases in PA following a negative daily event than healthy individuals, whereas responses to positive daily events were enhanced (Peeters et al., 2003). Within this patient group, reduced NA reactivity to negative daily events predicted a longer time until remission was achieved during the subsequent treatment period (Peeters et al., 2010). This study illustrates that experience sampling can provide better insight in affect regulation in everyday life and help predict the course of mood 
disorders. To our knowledge, levels of PA and NA and their responses to daily events have not yet been studied in patients with (remitted) BD.

We note that in the literature on mood regulation, the terms emotion, affect and mood are used with varying definitions. According to Russell's definitions (Russell, 2003; Russell, 2009), emotions are short-lived, intentional and presumed to be qualitatively distinct from each other. In contrast, affects are lasting, dimensional with fluctuating intensity, and either free-floating or responsive to internal and external influences (with mood being defined as prolonged affect). In the present study, we preferred to use the terms affect or mood state, because we did not investigate (reactivities of) particular emotions; our measures of PA and NA correspond with what Watson and Tellegen (1985) described as the two dominant dimensions in self-rated mood, and are also similar to Russell's two-dimensionally constructed concept of core affect (Russell, 2003).

The choice of salivary cortisol as a physiological indicator of the effects of daily events was based on both theoretical and practical grounds. Cortisol is the end product of the HPA axis, a hormonal system that is important in regulating the response of the organism to internal and environmental stressors. Cortisol feeds back on several levels of the HPA axis and thus plays an important role in the regulation of basal activity of this system, as well as in limiting the duration of the stress response. Previous studies suggest that HPA axis dysregulation with increased secretion of cortisol may be a trait characteristic of bipolar patients, but there is relatively little information on cortisol secretory patterns in remitted bipolar disorder (Daban et al., 2005). Salivary cortisol is a reliable indicator of the unbound, biologically active fraction of cortisol in plasma and can be collected stress-free by participants themselves, without disrupting normal daily activities (Hellhammer et al., 2009). It is therefore particularly suitable for intensive ambulatory assessments and can be easily combined with collecting information on daily events. ESM studies have demonstrated that negative daily events are associated with increased salivary cortisol levels in healthy individuals (van Eck et al., 1996; Smyth et al., 1998), whereas patients with major depression showed blunted responses (Peeters et al., 2003). Such studies have not been done on patients with BD.

\section{Aims of the present study}

The central aim of the present study was to investigate effects of daily events on mood states and salivary cortisol in a group of patients with remitted BD and healthy comparison group within the context of their normal daily lives, and to provide detailed descriptive information on the following topics: 
1. Nature, frequencies and subjective appraisals of naturally occurring negative (hassles) and positive (uplifts) daily events (Chapter 2). In addition, we examined whether individual differences in the experience of daily events were related to time use patterns, coping styles, and clinical features. Assuming that past and current symptoms in patients with BD could easily lead to the generation of stress and the loss of sources of positive experiences, we expected that patients with remitted bipolar would report more negative daily events and appraise them as more stressful, and would experience fewer positive events.

2. Levels of positive and negative affect and their reactivities to positive and negative daily events (Chapter 3). Questions that are addressed are: do mean levels and patterns of positive and negative affect differ between remitted BD patients and healthy individuals? Do patients and healthy individuals differ with respects to the effects of daily events on positive and negative affect? Are individual differences in mood reactivity among the patients related to clinical characteristics? We predicted that current subclinical hypomanic symptoms would be associated with increased PA reactivity to positive events, whereas a large number of previous episodes and the presence of current subclinical depressive symptoms would be associated with increased NA reactivity to negative events.

3. Levels and patterns of salivary cortisol and reactivity to daily events (Chapter 4). We hypothesized that levels of cortisol secretion in patients with remitted BD would be higher, more variable, and less responsive to daily events than in healthy individuals. We also investigated whether individual differences in cortisol secretion in the patient group could be explained by the number of previous episodes and the presence of subsyndromal symptoms.

From a clinical and theoretical point of view, it would be interesting to investigate whether the ESM and cortisol variables that were reported in the study, especially the reactivities of mood states and cortisol to daily events, are predictive of the future course of BD. To this end, the patient group was followed up for two years; life charts were used to document episode recurrences. Results will be presented in Chapter 5 .

Chapter 6 summarizes the main findings and provides a general discussion of the implications for future research and clinical practice. 


\section{References}

Angst, J., A. Gamma and J. Endrass (2003). Risk factors for the bipolar and depression spectra. Acta Psychiatr. Scand. Suppl.: 15-19.

Csikszentmihalyi, M. and R. Larson (1987). Validity and reliability of the Experience-Sampling Method. J. Nerv. Ment. Dis. 175: 526-536.

Daban, C., E. Vieta, P. Mackin and A. H. Young (2005). Hypothalamic-pituitary-adrenal axis and bipolar disorder. Psychiatr. Clin. North Am. 28: 469-480.

deVries, M. W., Ed. (1992). The Experience of Psychopathology: Investigating Mental Disorders in their Natural Settings. Cambridge, Cambridge University Press.

Dilsaver, S. C. (2011). An estimate of the minimum economic burden of bipolar I and II disorders in the United States: 2009. J. Affect. Disord. 129: 79-83.

Ebner-Priemer, U. W., M. Eid, N. Kleindienst, S. Stabenow and T. J. Trull (2009). Analytic strategies for understanding affective (in)stability and other dynamic processes in psychopathology. J. Abnorm. Psychol. 118: 195-202.

Eckenrode, J. and N. Bolger (1995). Daily and within-day event measurement. Measuring Stress: A Guide for Health and Social Scientists. S. Cohen, R. C. Kessler and L. Underwood Gordon. Oxford, Oxford University Press: 80-101.

Ghaemi, S. N., D. J. Hsu, J. Y. Ko, C. F. Baldassano, N. J. Kontos and F. K. Goodwin (2004). Bipolar spectrum disorder: a pilot study. Psychopathology 37: 222-226.

Gitlin, M. J., J. Swendsen, T. L. Heller and C. Hammen (1995). Relapse and impairment in bipolar disorder. Am. J. Psychiatry 152: 1635-1640.

Goldberg, J. F. and M. Harrow (2011). A 15-year prospective follow-up of bipolar affective disorders: comparisons with unipolar nonpsychotic depression. Bipolar Disord. 13: 155-163.

Goodwin, F. K. and K. R. Jamison (2007). Manic-depressive illness: bipolar disorders and recurrent depression. New York, N.Y., Oxford University Press.

Hellhammer, D. H., S. Wust and B. M. Kudielka (2009). Salivary cortisol as a biomarker in stress research. Psychoneuroendocrinology 34: 163-171.

Johnson, S. L. and J. E. Roberts (1995). Life events and bipolar disorder: implications from biological theories. Psychol. Bull. 117: 434-449.

Judd, L. L., H. S. Akiskal, P. J. Schettler, J. Endicott, J. Maser, D. A. Solomon, A. C. Leon, J. A. Rice and M. B. Keller (2002). The long-term natural history of the weekly symptomatic status of Bipolar I Disorder. Arch. Gen. Psychiatry 59: 530-537.

Judd, L. L., P. J. Schettler, H. S. Akiskal, W. Coryell, A. C. Leon, J. D. Maser and D. A. Solomon (2008). Residual symptom recovery from major affective episodes in bipolar disorders and rapid episode relapse/recurrence. Arch. Gen. Psychiatry 65: 386-394.

Merikangas, K. R., H. S. Akiskal, J. Angst, P. E. Greenberg, R. M. Hirschfeld, M. Petukhova and R. C. Kessler (2007). Lifetime and 12-month prevalence of bipolar spectrum disorder in the National Comorbidity Survey replication. Arch. Gen. Psychiatry 64: 543-552.

Myin-Germeys, I., M. Oorschot, D. Collip, J. Lataster, P. Delespaul and J. van Os (2009). Experience sampling research in psychopathology: opening the black box of daily life. Psychol. Med. 39: 1533-1547.

Peeters, F., J. Berkhof, J. Rottenberg and N. A. Nicolson (2010). Ambulatory emotional reactivity to negative daily life events predicts remission from major depressive disorder. Behav. Res. Ther. 48: 754-760.

Peeters, F., N. A. Nicholson and J. Berkhof (2003). Cortisol responses to daily events in major depressive disorder. Psychosom. Med. 65: 836-841.

Peeters, F., N. A. Nicolson, J. Berkhof, P. Delespaul and M. DeVries (2003). Effects of daily events on mood states in major depressive disorder. J. Abnorm. Psychol. 112: 203-211.

Perlick, D. A., R. A. Rosenheck, D. J. Miklowitz, C. Chessick, N. Wolff, R. Kaczynski, M. Ostacher, J. Patel and R. Desai (2007). Prevalence and correlates of burden among caregivers of patients with bipolar disorder enrolled in the Systematic Treatment Enhancement Program for Bipolar Disorder. Bipolar Disord. 9: 262-273. 


\section{CHAPTER 1}

Russell, J. A. (2003). Core affect and the psychological construction of emotion. Psychol. Rev. 110: 145-172.

Russell, J. A. (2009). Emotion, core affect and psychological construction. Cognition and Emotion 23: 1259-1283.

Smyth, J., M. C. Ockenfels, L. Porter, C. Kirschbaum, D. H. Hellhammer and A. A. Stone (1998). Stressors and mood measured on a momentary basis are associated with salivary cortisol secretion. Psychoneuroendocrinology 23: 353-70.

Soreca, I., E. Frank and D. J. Kupfer (2009). The phenomenology of bipolar disorder: what drives the high rate of medical burden and determines long-term prognosis? Depress. Anxiety 26: 73-82.

van Eck, M., H. Berkhof, N. Nicolson and J. Sulon (1996). The effects of perceived stress, traits, mood states, and stressful daily events on salivary cortisol. Psychosom. Med. 58: 447-58.

Watson, D. and A. Tellegen (1985). Toward a consensual structure of mood. Psychol. Bull. 98: 219235.

Watson, D., D. Wiese, J. Vaidya and A. Tellegen (1999). The two general activation systems of affect: structural findings, evolutionary considerations, and psychobiological evidence. J. Pers. Soc. Psychol. 76: 820-838. 


\section{Chapter 2}

\section{Daily hassles, uplifts, and time use in individuals with bipolar disorder in remission}


Abstract: Although life stress has been shown to trigger relapse in bipolar disorder, little is known about how bipolar patients perceive daily hassles or their positive counterparts, uplifts. We used the experience sampling method to investigate the daily experience of hassles and uplifts in 38 patients with remitted bipolar disorder and 38 healthy controls. Largely because of current unemployment, patients were more often alone and at home and spent less time working and more time in passive leisure activities. Contrary to expectations, the groups did not differ in total frequencies or appraisals of events. Within the patient group, however, those patients with current depressive symptoms and more previous depressive episodes experienced negative events as more stressful. These findings are consistent with hypothesized processes linking depressive symptoms to the generation of stressful conditions or to the reactivation of negative cognitive schemas.

Key Words: Bipolar disorder, stress, daily events, experience sampling method (ESM), time use. 


\section{Introduction}

In line with vulnerability-stress models of bipolar affective disorder (Johnson and Roberts, 1995), cohort studies have shown that major life events increase the risk of episode recurrence (Ellicott et al., 1990; Hunt et al., 1992) and impede recovery (Johnson and Miller, 1997). A major limitation of these studies is that they have focused exclusively on the role of major life events without examining more frequent sources of stress, such as daily hassles, which could also influence health outcomes (Kanner et al., 1981). The counterparts of daily hassles-so-called uplifts-may also be relevant because they are thought to prevent or attenuate the effects of stress (Kanner et al., 1981). The present study was designed to investigate the daily experience of hassles and uplifts in remitted bipolar disorder. Although we did not study the influence of daily events on the course of bipolar disorder, this information can help to understand how individual differences in vulnerability to stress may arise and can be useful in developing interventions to help patients find effective ways of coping with the threat of recurrent illness.

Although daily events have not previously been investigated in bipolar disorder, there are reasons to expect greater exposure to daily hassles and reduced experience of daily uplifts. The residual symptoms and sustained impairments that are common during periods of remission (Coryell et al., 1993; Gitlin et al., 1995; Goldberg et al., 1995; Judd et al., 2002; Paykel et al., 2006) may generate stressful situations and diminish availability of supportive social interactions, as have been reported in persons with unipolar depression (Hammen, 1991; Harkness et al., 1999; Rudolph et al., 2000). For example, 93\% of family caregivers of patients with bipolar disorder report moderate or severe levels of burden (Perlick et al., 1999). High levels of expressed emotion in family members increase the risk of relapse (Miklowitz et al., 1988), and the mechanism is likely to involve more frequent or intense daily stress in the form of negative social interactions (Simoneau et al., 1998). Moreover, as in unipolar depression (Teasdale, 1988), previous depressive episodes in bipolar disorder may generate negative cognitive schemas that are reactivated during mild dysphoric states, so that current experiences are interpreted more negatively.

Previous studies have shown that individuals currently undergoing a depressive episode tend to withdraw from daily activities, spend less time working and with friends and more time alone at home, and spend time in passive leisure activities rather than healthy controls (Barge-Schaapveld et al., 1995). Depressed patients are also reported to make more use of avoidance and supportseeking strategies when coping with the stresses of everyday life than do nondepressed individuals (Coyne et al., 1981). Episodes of depression continue to influence daily life activities and coping behaviors even after recovery. Focus groups of individuals recovered from a depressive episode indicated that they actively avoided the demands of work and close relationships out of fear of 
relapse (Coyne and Calarco, 1995), a result that has been replicated in questionnaire studies (Coyne et al., 1998; Kirk et al., 2000). Given the high risk of relapse and the often devastating effects of full-blown episodes, it can be expected that individuals with a history of bipolar disorder also develop adaptive strategies involving coping and time use to regulate exposure and responses to daily stress.

In the present study, we used the experience sampling method (ESM; Csikszentmihalyi and Larson, 1987; deVries, 1992) to investigate frequencies and subjective appraisals of negative and positive events in outpatients with remitted bipolar disorder compared with healthy controls. In addition, we examined whether individual differences in the experience of daily events were related to time use patterns, avoidant and support-seeking coping styles, and clinical features (number of previous episodes and current manic and depressive symptoms).

\section{Subjects and methods}

\section{Subjects}

Thirty-nine subjects with bipolar disorder were recruited among patients attending lithium clinics in Maastricht and Sittard, The Netherlands. The main inclusion was a primary diagnosis of Bipolar I or Bipolar II Disorder without rapid cycling, as assessed with the Structured Clinical Interview for DSM-IV (First et al., 1996) by a trained research psychiatrist (R.H.). Additional inclusion criteria were age between 18 and 65 years, in a state of partial or full remission for more than 2 months, and under regular treatment including appropriate pharmacotherapy for more than 4 months. On study entry, 16 patients received monotherapy with lithium; the others used various combinations of drugs as follows: lithium ( $n=20)$, carbamazepine $(n=4)$, valproate $(n=2)$, antidepressants $(n=4)$, neuroleptics $(n=7)$, and benzodiazepines $(n=6)$.

A control group of 39 healthy subjects in the same age range was recruited through a local newspaper advertisement and available subject pools (this was the same control group as in Peeters et al., 2003). Patients and controls were excluded if they had met DSM-IV criteria for alcohol or drug abuse or dependence within the preceding year. Additional exclusion criteria for the control group were current use of psychotropic drugs, any personal history of Axis I disorder, and any inpatient treatment for Axis I disorder in a firstdegree relative. One patient and 1 healthy control were later excluded from the analysis because they failed to meet ESM compliance criteria (see below). The protocol was approved by the local medical ethics committee, and written informed consent was obtained from all subjects. 


\section{Measures}

\section{Clinical Measures}

In the bipolar group, clinical measures were obtained by interview in the week preceding the ESM sampling. The Life Chart Method (Leverich and Post, 1996) provided a detailed history of the course of the disorder, from which the number and nature of previous episodes and the age of onset were determined. Subsyndromal depressive and manic symptoms were assessed with the 17-item Hamilton Rating Scale for Depression (HRSD; Hamilton, 1960) and the Young Mania Rating Scale (Young et al., 1978), administered by a trained research psychiatrist (R.H.). The Social Adjustment Scale - Self Report (Weissman and Bothwell, 1976) was used as an overall measure of social functioning.

\section{Questionnaires}

Coping styles were assessed with the Utrecht Coping List (Schreurs and Van de Willege, 1988), a 44-item selfreport questionnaire with 7-factor analytically derived subscales for assessing habitual coping styles. Reliability and validity of the Utrecht Coping List have been shown to be satisfactory (Sanderman and Ormel, 1992). Based on findings from studies of currently and previously depressed individuals (Coyne et al., 1981, 1998), the current analysis focused on the subscales seeking social support and avoidance. Subjects also filled in the Symptom Checklist (SCL-90; Derogatis et al., 1973; Dutch version: Arrindell and Ettema, 1981); the total score provides a general measure of psychological complaints.

\section{ESM Measures}

Daily events and time use in patients and controls were assessed with ESM during 6 consecutive days, including 2 weekend days. Subjects wore a wristwatch programmed to emit auditory signals ("beeps") 10 times a day, at semirandom intervals of approximately 90 minutes between 7:30 a.m. and 10:30 p.m. As soon as possible after each beep, subjects completed a brief ESM self-report form. Responses to open questions were later coded by trained research assistants. An earlier investigation of the reliability of this coding system showed high interrater reliability (Laundis and Koch, 1977), with Cohen's kappas for categories of events, current activities, social contexts, and locations ranging from 0.90 to 0.96 (van Eck, 1996). Time use patterns are described as the percentages of total ESM reports a subject reported to be engaged in specific categories of activities (work, household chores, social activities, active leisure like sports, passive leisure like watching television or reading, or other activities including "doing nothing"); social contexts (alone, with family members, friends, colleagues, or others); and physical locations (own home, homes of family or friends, workplace, public places, or other). At each beep, participants were asked briefly to describe a positive and negative 
event or situation that may have taken place since the last ESM report. Examples of reported negative events are "a squabble with my children," "arrived too late at work," and "favorite soccer team lost a game;" reported positive events included "nice phone call with friend," "pleasant dinner with partner," and "saw a good movie on TV." Although subjects were instructed to report only events or situations that actually took place in the preceding interval, some event reports clearly referred to internal states (e.g., ruminations about past events or anticipated events, physical symptoms) with no link to a current external situation. Such internal events were identified by team consensus following preestablished criteria; they represented 37 events of 1002 total events reported by bipolar patients and 52 events of the 1022 events in the control group. Internal events were excluded from the analysis. Subjects rated the valence (unpleasantness for negative events, pleasantness for positive events), stressfulness, and importance of events on 7-point scales (1, not at all to 7, very).

ESM forms completed more than 20 minutes after a beep were considered invalid. Subjects with fewer than 20 valid ESM reports (1 patient and 1 control) were excluded from the analyses. On average, patients completed somewhatfewer valid reports than controls (patients: $78 \%, S D=13 \%$; controls: $87 \%, S D=$ 9\%; Mann-Whitney $U$ test, $p=0.002$ ).

\section{Statistical Analysis}

ESM data were aggregated over each subject, with frequencies calculated as a percentage of total valid ESM reports. Differences between groups were assessed with the Mann-Whitney $U$ test. We next performed multiple regression analysis with forward stepwise selection to assess how time use, coping styles (avoidance and seeking support), and diagnosis of bipolar disorder were associated with the frequency and stressfulness of daily hassles and uplifts. Because distributions of event frequency data were skewed, data were first normalized by square root transformations. Additional regression analyses were done with the following clinical variables: the number of previous episodes (to reduce the influence of outlying values we used a median split: $\leq 7$ episodes vs. $>7$ episodes, with manic and depressive episodes combined); the severity of subclinical depressive symptoms; and the severity of subclinical manic symptoms. Age was included in the analyses to avoid possible confounding of the effects of number of previous episodes. Alpha was set at 0.05 for all tests (two-tailed). 


\section{Results}

\section{Sample Characteristics}

The ESM procedure was completed by 38 patients and 38 controls. As shown in Table 1, bipolar subjects had a lower mean level of education, were less often married or living with a partner, and were less frequently in paid employment. They also showed higher levels of psychological complaints (SCL-90) and reported more frequent use of both avoidant and support-seeking coping styles.

Table 1. Sociodemographic and Psychological Measures for Bipolar Patients and Controls

\begin{tabular}{lcccc}
\hline & $\begin{array}{c}\text { Patients } \\
\boldsymbol{N}=\mathbf{3 8}\end{array}$ & $\begin{array}{c}\text { Controls } \\
\boldsymbol{N}=\mathbf{3 8}\end{array}$ & $\begin{array}{c}\text { Test } \\
\text { Statistic }\end{array}$ & $\boldsymbol{p}$ \\
\hline Age, mean (SD) & $46.2(9.6)$ & $44.4(11.7)$ & $t=0.74$ & n.s. \\
Sex ratio (M/F) & $19 / 19$ & $15 / 23$ & $X^{2}=0.85$ & n.s. \\
Education, $N$ (\%) & & & $X^{2}=8.20$ & 0.01 \\
$\quad$ Elementary school & $11(29)$ & $3(8)$ & & \\
$\quad$ Secondary school & $14(37)$ & $11(29)$ & & \\
$\quad$ Higher education & $13(34)$ & $24(63)$ & & \\
Marital status, $N$ (\%) & & & $X^{2}=8.94$ & 0.02 \\
$\quad$ Married or living together & $20(53)$ & $31(82)$ & & \\
$\quad$ Never married & $11(18)$ & $2(13)$ & & \\
$\quad$ Divorced or widowed & & $5(5)$ & & \\
Work situation, $N$ (\%) & $12(32)$ & $3(8)$ & & \\
$\quad$ Household & $8(21)$ & $32(84)$ & & \\
$\quad$ Regular job or education & $18(47)$ & $3(8)$ & & \\
$\quad$ Disabled, unemployed, or retired & $137.6(46.9)$ & $110.2(22.3)$ & $t=3.15$ & $<0.01$ \\
SCL-90a & $18.5(3.8)$ & $13.9(3.6)$ & $t=5.45$ & $<0.001$ \\
Coping styles (scale range) & $22.9(2.8)$ & $14.9(3.0)$ & $t=12.03$ & $<0.001$ \\
\hline Seeking social support (6-24) & & & \\
Avoidance (8-32) & & & & \\
\hline
\end{tabular}

a Three patients had missing data on the SCL-90.

Of the patients, 31 had a bipolar I disorder and 7 a bipolar II disorder, with a mean age of onset of 29.6 years (median $=26.5$; range $16-61$ ). The median number of previous episodes (manic and depressive) was 7 , with a range from 1 to 38 (manic episodes: median $=2$, range $0-26$; depressive episodes: median $=$ 4 , range $0-17)$. Current age was unrelated to the number of previous episodes (Spearman $r=0.02, n=31, p=0.93$ ). Scores on the symptom scales indicated low levels of subsyndromal symptomatology (HRSD: mean $=2.9$, range $=0-8$; Young Mania Rating Scale: mean $=1.7$, range $=0-10$ ). Mean score on the Social 
Adjustment Scale - Self Report was $1.8(S D=0.5)$, indicating a moderate level of social impairment (Weissman et al., 1978).

\section{Time Use}

After each ESM beep, subjects described what they were doing, which other people were present, and where they were. As shown in Figure 1, patients spent significantly less time working than controls, more time on passive leisure activities, more time alone, and less time with colleagues. Bipolar subjects also spent significantly more time at home than controls and less time at the workplace. These categories are clearly interrelated; subjects who spent more time at home also spent more time alone, more time on passive leisure activities, less time working, less time with colleagues, and less time at the workplace (all $|r s|$ $>0.41, p s<0.001$ ).

Frequencies and Appraisals of Daily Hassles and Uplifts in Relation to Time Use and Coping

As shown in Table 2, bipolar patient and control groups did not differ significantly in total frequencies or mean appraisal scores for either negative or positive events. Patients, however, reported significantly fewer work-related events than controls.

In a series of regression analyses, we next examined whether individual differences in time use, coping styles (avoidance and seeking support), or age might help clarify the paucity of significant differences between patient and control groups in daily event frequencies and appraisals. To restrict the number of independent variables, time at home was the only time use variable used as a predictor in the regression analysis, because this variable showed substantial variability and was correlated with other time use variables (see above). Age, diagnosis of bipolar disorder, and avoidant coping had no significant effects and were excluded from the final models. Results indicated that negative events were more frequent in subjects who spent less time at home $\left(R^{2}\right.$ change $=13 \%$, $F$ change $=11.1, p=0.001$ ) and reported seeking social support more frequently as a coping style $\left(R^{2}\right.$ change $=6 \%, F$ change $\left.=5.8, p=0.02\right)$; the total model thus accounted for $19 \%$ of the variance in the frequency of negative events $(F=8.8$, $d f=2.73, p<0.001$ ). A similar pattern was observed for positive events, with more frequent events in subjects who scored higher on coping by seeking support $\left(R^{2}\right.$ change $=16 \%, F$ change $\left.=14.2, p<0.001\right)$ and who spent less time at home $\left(R^{2}\right.$ change $=8 \%, F$ change $\left.=7.9, p=0.006\right)$. Together these 2 variables explained $24 \%$ of the variance in positive event frequency $(F=11.7, d f=2.73, p$ $<0.001$ ). None of the independent variables contributed significantly to the regression models of the stressfulness of negative and positive events. In 
summary, time use and support-seeking coping were related to the number but not the stressfulness of daily events. However, even when corrected for differences in time use and coping, the number and appraised stressfulness of daily events in patients and controls were similar.

Table 2. Frequencies and Appraisals of Daily Events in Bipolar Patients and Controls

\begin{tabular}{|c|c|c|}
\hline ESM Measure & Patients & Controls \\
\hline \multicolumn{3}{|l|}{ Negative events } \\
\hline \multicolumn{3}{|l|}{ Frequencies ${ }^{\mathrm{a}}$} \\
\hline Total & $16.2(18.0)$ & $15.4(13.2)$ \\
\hline Work* & $2.0(4.5)$ & $3.9(5.2)$ \\
\hline Family and friends & $5.1(6.7)$ & $4.3(4.5)$ \\
\hline Household & $2.6(3.9)$ & $1.5(2.8)$ \\
\hline Leisure & $1.3(2.4)$ & $1.8(2.4)$ \\
\hline Other & $5.3(9.3)$ & $3.9(5.1)$ \\
\hline \multicolumn{3}{|l|}{ Appraisals ${ }^{b}$} \\
\hline Unpleasantness & $5.0(1.3)$ & $4.9(0.9)$ \\
\hline Importance & $4.2(1.5)$ & $4.2(1.2)$ \\
\hline Stressfulness & $4.0(1.7)$ & $3.6(1.4)$ \\
\hline \multicolumn{3}{|l|}{ Positive events } \\
\hline \multicolumn{3}{|l|}{ Frequencies ${ }^{\mathrm{a}}$} \\
\hline Total & $35.5(26.0)$ & $32.7(25.7)$ \\
\hline Work $^{\dagger}$ & $3.4(7.3)$ & $6.2(7.8)$ \\
\hline Family and friends & $12.9(10.2)$ & $12.0(10.9)$ \\
\hline Household & $4.1(6.9)$ & $3.2(4.2)$ \\
\hline Leisure & $9.4(10.9)$ & $7.1(8.1)$ \\
\hline Other & $5.7(7.5)$ & $4.2(4.7)$ \\
\hline \multicolumn{3}{|l|}{ Appraisals ${ }^{b}$} \\
\hline Pleasantness & $5.8(0.7)$ & $5.9(0.8)$ \\
\hline Importance & $5.6(1.1)$ & $5.3(1.0)$ \\
\hline Stressfulness & $2.0(0.9)$ & $1.9(0.8)$ \\
\hline
\end{tabular}

${ }^{a}$ Frequencies are expressed as mean $(S D)$ percentage of valid ESM responses.

${ }^{\mathrm{b}}$ Appraisals were rated on 7-point scales and are presented as mean $(S D)$. Mean appraisal scores were calculated on subgroups of participants because 2 patients and 2 controls reported no negative or positive events during the sampling period, and 3 additional patients reported no negative events. ${ }^{*} p<0.05$.

${ }^{\dagger} p<0.01$ (Mann-Whitney $U$ tests). 

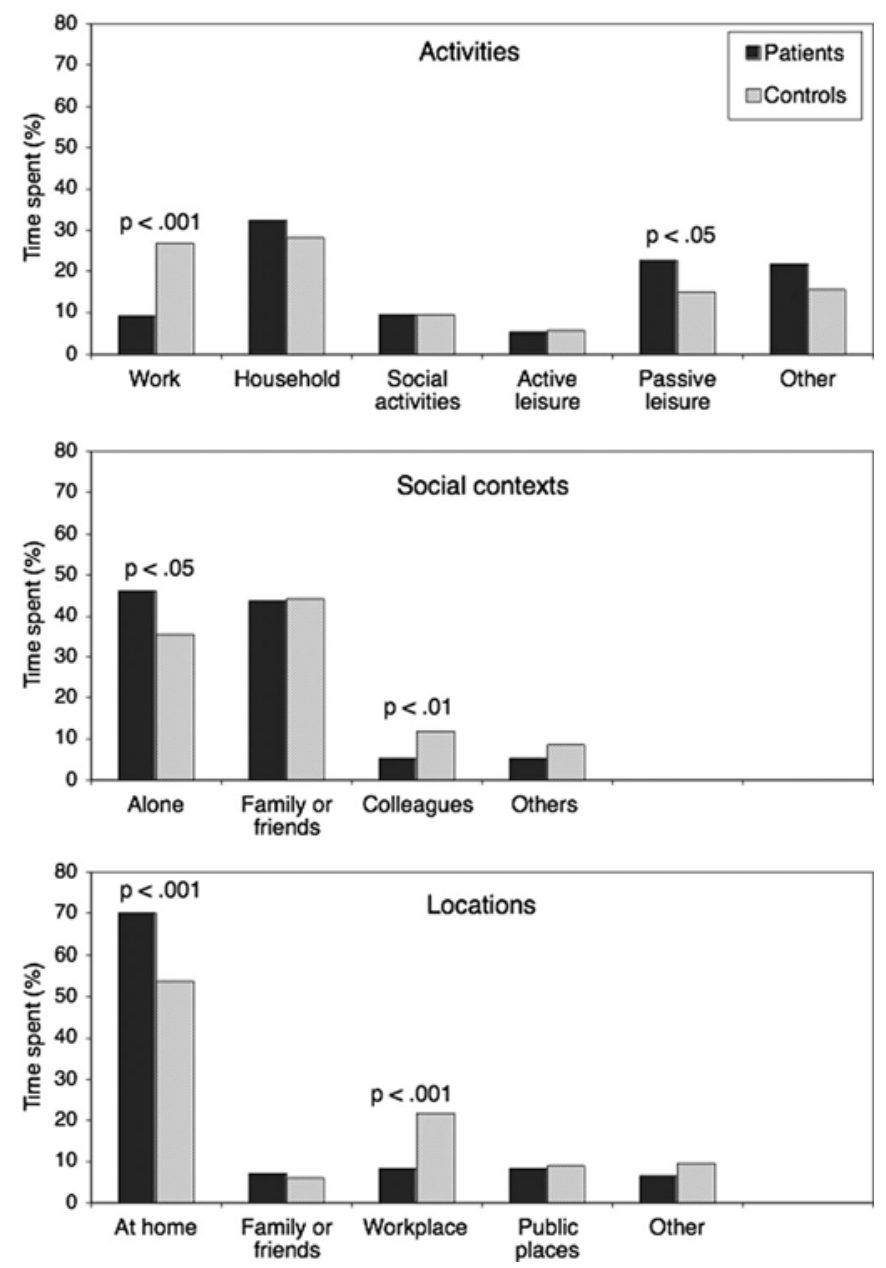

Figure 1. Time use in remitted bipolar patients and controls. Time spent in each category of activity, social context, and location was first calculated as a percentage of an individual subject's total valid experience sampling method reports. Bars indicate the mean percentages for bipolar $(n=38)$ and control $(n=38)$ groups. Between-group differences were assessed with Mann-Whitney $U$ tests.

\section{The Influence of Employment on Time Use and Experience of Daily Events}

Because it is plausible that differences in time use and exposure to work-related events between patients and controls may simply reflect differences in employment status, we performed additional analyses on employed (regular job or education) and unemployed subgroups (see Table 1). The resulting 4 subgroups were compared using Kruskal-Wallis tests on event frequencies, event appraisals, and activity patterns. No between-group differences were found for total 
frequencies of negative and positive events or mean appraisal scores. As expected, the 4 subgroups differed significantly on frequencies of negative and positive work-related events and on work-related time use variables (time spent working, time at the workplace, and time with colleagues) $(p<0.001)$. Moreover, significant differences were found for time spent on household chores $(p<0.05)$, passive leisure time $(p<0.05)$, and time spent at home $(p<$ 0.001). We next performed 2-sample Mann-Whitney tests to identify which subgroups differed from each other. The results indicated that all differences in work-related event exposure and time use were between employed and unemployed patients or between employed and unemployed controls. No differences were found between the 2 employed subgroups or between the 2 unemployed subgroups. These results suggest that patients, as a group, are less frequently exposed to work-related events than controls and have different time use patterns as a consequence of their being less frequently employed. To gain additional insight in potential factors that may influence employment status in bipolar patients, we performed additional analyses comparing employed and unemployed patients on clinical characteristics and coping styles. Although there was a trend towards more previous manic episodes in unemployed patients (median $=2.5$, range $=0-25$ vs. median $=1$, range $=0-5$; Mann-Whitney $U$ test; $p=0.051$ ), no significant differences were found with respect to age, the previous number of depressive episodes, illness duration, severity of current symptoms, social functioning, or use of avoidant and support-seeking coping styles.

\section{Relationship Between Daily Events and Clinical Variables in Bipolar Patients}

Failure to detect differences between patients and controls in most daily stress measures may have been due to the considerable heterogeneity in clinical characteristics within the patient group. We therefore conducted additional regression analyses to assess the influence of selected clinical variables on the frequency and stressfulness of daily events. None of these variables showed a significant association with the event frequencies or the stressfulness of positive events. However, the stressfulness of negative events was positively related to both HRSD-scores $\left(R^{2}\right.$ change $=38 \%, F$ change $\left.=18.7, p<0.001\right)$ and the number of previous episodes $\left(R^{2}\right.$ change $=8 \%, F$ change $\left.=5.5, p=0.04\right)$ (total model: $R^{2}=46 \%, F=12.7, p<0.001$ ). To determine whether the influence of previous episodes was polarity specific, we performed additional univariate regression analyses with the number of depressive episodes ( $\leq 4$ vs. $>4$ ) and the number of manic episodes ( $\leq 2$ vs. $>2$ ) entered separately. Patients with more than 4 previous depressive episodes experienced negative events as more 
stressful $\left(R^{2}=12 \%, F=4.2, p=0.05\right)$, whereas the number of previous manic episodes had no significant effect.

\section{Discussion}

Contrary to expectation, individuals with bipolar disorder in remission reported similar frequencies of daily hassles and uplifts compared with controls and did not differ in their perceptions of events in terms of intensity, importance, or stressfulness. Higher frequencies of daily hassles have been reported in current major depression (Ravindran et al., 1995) and subclinical cyclothymia (Lovejoy and Steuerwald, 1995). In these studies, events were assessed retrospectively with a checklist completed at the end of each day (Lovejoy and Steuerwald, 1995) or over the past 4 weeks (Ravindran et al., 1995), whereas the present ESM study measured events repeatedly over the day, a method that is less susceptible to recall biases (Eckenrode and Bolger, 1995). Interestingly, a recent ESM study in patients with current unipolar depression also found no differences from healthy controls in the frequency of negative daily events, but depressed patients did experience fewer positive events and rated both negative and positive events as more stressful (Peeters et al., 2003). Taken together, the results of these studies imply that both differences in study populations and differences in event assessment may have contributed to the discrepant results.

Subsyndromal symptoms and previous episodes seem to be related to stressful events; the findings indicate that these relations are polarity specific, as bipolar patients with higher scores on the HRSD and more than 4 previous depressive episodes rated negative events as more stressful, whereas current subsyndromal manic symptoms and previous manic episodes had no significant effects. These findings are consistent with the hypothesis that past and current depressive symptoms generate stressful events and conditions (Hammen, 1991; Harkness et al., 1999; Rudolph et al., 2000). However, because stressfulness ratings of events were based on subjective reports, we cannot rule out that similar daily events are appraised as more stressful in patients with more past and current depressive symptoms. This alternative explanation is in line with the hypothesis that individuals with previous depressive episodes have a dormant set of negative and depressogenic cognitions that become reactivated when the individuals are in a mildly depressed mood (Segal et al., 1996; Teasdale, 1988). Although this hypothesis was formulated for recovered patients with recurrent unipolar depression, it is reasonable to assume that similar processes occur in bipolar patients with recurrent depressive episodes. Both subsyndromal depressive symptoms and a high number of previous episodes have been associated with an increased risk of relapse in bipolar disorder (Coryell et al., 1998; Keller et al., 1992; Kessing et al., 1998). Future studies are needed to clarify whether the negative prognostic impact of these clinical 
variables might be mediated by the actual occurrence or the perception of stressful daily events.

Time use comparisons showed that bipolar subjects were more often alone and at home, worked less, and spent more time in passive leisure activities, which could be attributed to their being less frequently employed. The current study shows that this sheltered lifestyle may well reduce exposure to daily hassles but may simultaneously limit exposure to daily uplifts. These patterns could be the result of active avoidance of the potential demands and stresses of work and social relationships, as has been reported by individuals recovered from an episode of depression (Coyne and Calarco, 1995; Coyne et al., 1998; Kirk et al., 2000). However, the current finding that employed and unemployed patients had similar scores on avoidant coping points to the possibility that the sheltered lifestyle of remitted bipolar patients simply reflects the loss of work and close relationships that are common sequelae of bipolar disorder (Dion et al., 1988; Goldberg et al., 1995).

Results further indicated that seeking social support was associated with more frequent positive events, as well as with increased exposure to negative events. It seems plausible that the interaction between seeking support and daily hassles and uplifts will depend on the availability and quality of close relationships. This issue deserves further attention, as previous studies have shown that bipolar patients with high levels of perceived social support recover more quickly from the index episode and show fewer depressive symptoms during follow-up (Cohen et al., 2004; Johnson et al., 1999). The results of these studies did not support the hypothesis that social support buffers the negative impact of major life events on the course of bipolar disorder. The current findings suggest an alternative hypothesis: the beneficial influence of social support on the course of bipolar disorders may be based on its being an important source of positive daily experiences. Little is known, however, about the influence of daily uplifts on the course of mood disorders and its relation to social support levels.

The findings of the present study have possible implications for treatment. Recent studies have shown that mindfulness-based cognitive therapy (MBCT) is effective in preventing recurrence in recovered patients with unipolar depression with 3 or more previous episodes (Teasdale et al., 2000; Ma and Teasdale, 2004). MBCT is designed to teach patients to be aware of ruminative patterns of negative thinking reactivated by dysphoria and respond to them in an intentional and skillful manner (Segal et al., 2002). The present study suggests that negative thinking patterns may also be present in remitted bipolar patients with dysphoric mood; it would thus be interesting to investigate whether MBCT is also effective in preventing depressive recurrences in these patients. Other psychosocial treatment programs for patients with bipolar disorder contain elements intended to restore occupational functioning and counteract social isolation (for a review see Jones, 2004). The possibility that these interventions 
increase exposure to negative as well as to positive experiences underscores the importance of combining them with training in communication and stress management skills.

\section{Limitations}

The study had a number of limitations. First, an objective validation of the reported events was not feasible, and it was therefore not possible to evaluate the accuracy of an individual's perceptions. Second, although we have interpreted the regression results in terms of the influence of time use, coping, and clinical characteristics on the experience of daily events, causal relationships cannot be established given the cross-sectional design of the study. Third, statistical comparisons of employed versus unemployed subgroups may not have had adequate power to detect significant patterns, in particular due to the small numbers of employed bipolar patients $(N=8)$ and unemployed control subjects $(N=6)$.

\section{Conclusion and Future Directions}

Using the ESM to assess daily events, we found no evidence that outpatients with remitted bipolar disorder experienced more frequent daily hassles and fewer daily uplifts than healthy controls. These negative findings may reflect group differences in time use and coping styles. Bipolar patients with residual depressive symptoms and a higher number of previous depressive episodes found negative events to be particularly stressful, which may contribute to their vulnerability for recurrence. Prospectively designed studies, however, are needed to clarify whether daily events influence the course of bipolar disorder and the mechanisms through which this may occur. Finally, more information is needed about other aspects of daily stress, such as emotional and neuroendocrine reactivity to daily events, which might be more sensitive indicators of stress vulnerability. Other ESM studies have shown that mood responses to daily events in patients with schizophrenia (Myin-Germeys et al., 2001) or current depression (Peeters et al., 2003) differ from those in healthy controls. Future analyses of data collected in remitted bipolar disorder and control groups will therefore focus on differences in emotional and cortisol reactivity to daily events.

\section{Acknowledgments}

The authors thank T. Driesen, L. Finders, and F. van Goethem for research assistance and A. L. van Bemmel and P. Delespaul for advice on the study. This study was carried out with the support and collaboration of the following institutions: Maastricht University, Psychiatric Hospital Vijverdal Maastricht, Academic Hospital Maastricht, and Prins Claus Centre Sittard. 


\section{References}

Arrindell WA, Ettema H (1981) Dimensionele structuur, betrouwbaarheid en validiteit van de Nederlandse bewerking van de Symptom Checklist (SCL-90): Gegevens gebaseerd op een fobische en een 'normale' populatie. Ned Tijdschr Psychol. 36:77-108.

Barge-Schaapveld DQCM, Nicolson NA, Gerritsen van der Hoop R, deVries MW (1995) Changes in daily life experience associated with clinical improvement in depression. J Affect Disord. 34:139 -154 .

Cohen AN, Hammen C, Henry RM, Daley SE (2004) Effects of stress and social support on recurrence in bipolar disorder. J Affect Disord. 82:143-147.

Coryell W, Scheftner W, Keller M, Endicott J, Maser J, Klerman GL (1993) The enduring psychosocial consequences of mania and depression. Am J Psychiatry. 150:720 -727.

Coryell W, Turvey C, Endicott J, Leon AC, Mueller T, Solomon D, Keller M (1998) Bipolar I affective disorder: Predictors of outcome after 15 years. J Affect Disord. 50:109 -116.

Coyne JC, Aldwin C, Lazarus RS (1981) Depression and coping in stressful episodes. J Abnorm Psychol. 90:439 - 447.

Coyne JC, Calarco MM (1995) Effects of the experience of depression: Application of focus group and survey methodologies. Psychiatry. 58:149-163.

Coyne JC, Gallo SM, Klinkman MS, Calarco MM (1998) Effects of recent and past major depression and distress on self-concept and coping. J Abnorm Psychol. 107:86 -96.

Csikszentmihalyi M, Larson R (1987) Validity and reliability of the Experience-Sampling Method. J Nerv Ment Dis. 175:526 -536.

deVries MW (1992) The Experience of Psychopathology: Investigating Mental Disorders in Their Natural Settings. Cambridge: Cambridge University Press.

Derogatis LR, Lipman RS, Covi L (1973) SCL-90: An outpatient psychiatric rating scale-Preliminary report. Psychopharmacol Bull. 9:13-27.

Dion GL, Tohen M, Anthony WA, Waternaux CS (1988) Symptoms and functioning of patients with bipolar disorder six months after hospitalization. Hosp Community Psychiatry. 39:652- 657.

Eckenrode J, Bolger N (1995) Daily and within-day event measurement. In S Cohen, RC Kessler, L Underwood Gordon (Eds), Measuring Stress: A Guide for Health and Social Scientists (pp 80 101). Oxford: Oxford University Press.

Ellicott A, Hammen C, Gitlin M, Brown G, Jamison K (1990) Life events and the course of bipolar disorder. Am J Psychiatry. 147:1194 -1198.

First MB, Spitzer RL, Gibbon M, Williams JBW (1996) Structured Clinical Interview for DSM-4 Axis 1 Disorders-Patient Edition (SCID-I/P Version 2.0). New York: Biometrics Research Department.

Gitlin MJ, Swendsen J, Heller TL, Hammen C (1995) Relapse and impairment in bipolar disorder. Am J Psychiatry. 152:1635-1640.

Goldberg JF, Harrow M, Grossman LS (1995) Recurrent affective syndromes in bipolar and unipolar mood disorders at follow-up. Br J Psychiatry. 166:382-385.

Hamilton M (1960) A rating scale for depression. J Neurol Neurosurg Psychiatry. 23:56 - 62.

Hammen C (1991) Generation of stress in the course of unipolar depression. J Abnorm Psychol. 101:45-52.

Harkness KL, Monroe SM, Simons AD, Thase M (1999) The generation of life events in recurrent and non-recurrent depression. Psychol Med. 29:135-144.

Hunt N, Bruce-Jones W, Silverstone T (1992) Life events and relapse in bipolar affective disorder. J Affect Disord. 25:13-20.

Johnson SL, Miller I (1997) Negative life events and time to recovery from episodes of bipolar disorder. J Abnorm Psychol. 106:449 - 457.

Johnson SL, Roberts JE (1995) Life events and bipolar disorder: Implications from biological theories. Psychol Bull. 117:434 - 449.

Johnson SL, Winett CA, Meyer B, Greenhouse WJ, Miller I (1999) Social support and the course of bipolar disorder. J Abnorm Psychol. 108:558 -566.

Jones S (2004) Psychotherapy of bipolar disorder: A review. J Affect Disord. 80:101-114. 
Judd LL, Akiskal HS, Schettler PJ, Endicott J, Maser J, Solomon DA, Leon AC, Rice JA, Keller MB (2002) The long-term natural history of the weekly symptomatic status of Bipolar I Disorder. Arch Gen Psychiatry. 59:530 -537.

Kanner AD, Coyne JC, Schaefer C, Lazarus RS (1981) Comparison of two modes of stress measurement: Daily hassles and uplifts versus major life events. J Behav Med. 4:1-39.

Keller MB, Lavori PW, Kane JM, Gelenberg AJ, Rosenbaum JF, Walzer EA, Baker LA (1992) Subsyndromal symptoms in bipolar disorder: A comparison of standard and low serum levels of lithium. Arch Gen Psychiatry. 49:371-376.

Kessing LV, Andersen PK, Mortensen PB, Bolwig TG (1998) Recurrence in affective disorder I-Case register study. Br J Psychiatry. 172:23-28.

Kirk L, Haaga DAF, Solomon A, Brody C (2000) Perceptions of depression among never-depressed and recovered-depressed people. Cognit Ther Res. 24:585-594.

Laundis JR, Koch GG (1977) The measurement of observer agreement for categorical data. Biometrics. 33:396 -398.

Leverich GL, Post RM (1996) Life charting the course of bipolar disorder. Curr Rev Mood Anxiety Disord. 1:48 - 61.

Lovejoy MC, Steuerwald BL (1995) Subsyndromal unipolar and bipolar disorders: Comparison on positive and negative affect. J Abnorm Psychol. 104:381-384.

Ma SH, Teasdale JD (2004) Mindfulness-based cognitive therapy for depression: Replication and exploration of differential relapse prevention effects. J Consult Clin Psychol. 72:31- 40.

Miklowitz DJ, Goldstein MJ, Nuechterlein KH, Snyder KS, Mintz J (1988) Family factors and the course of bipolar affective disorder. Arch Gen Psychiatry. 45:225-231.

Myin-Germeys I, van Os JJ, Schwartz JE, Stone AA, Delespaul PA (2001) Emotional reactivity to daily life stress in psychosis. Arch Gen Psychiatry. 58:1137-1144.

Paykel ES, Abbott R, Morriss R, Hayhurst H, Scott J (2006) Sub-syndromal and syndromal symptoms in the longitudinal course of bipolar disorder. Br J Psychiatry. 189:118 -123.

Peeters F, Nicolson NA, Berkhof J, Delespaul P, deVries MW (2003) Effects of daily events on mood states in major depressive disorder.J Abnorm Psychol. 112:203-211.

Perlick D, Clarkin JF, Sirey J, Raue P, Greenfield S, Struening E, Rosenheck R (1999) Burden experienced by care-givers of persons with bipolar affective disorder. Br J Psychiatry. 175:56 62.

Ravindran AV, Griffiths J, Waddell C, Anisman H (1995) Stressful life events and coping styles in relation to dysthymia and major depressive disorder: Variations associated with alleviation of symptoms following pharmacotherapy. Prog Neuropsychopharmacol Biol Psychiatry. 19:637653.

Rudolph KD, Hammen C, Burge D, Lindberg N, Herzberg D, Daley SE (2000) Toward an interpersonal life-stress model of depression: The developmental context of stress generation. Dev Psychopathol. 12:215-234.

Sanderman R, Ormel J (1992) De Utrechtse Coping Lijst: Validiteit en betrouwbaarheid \{The Utrecht Coping List (UCL): Validity and reliability\}. Gedrag en Gezondheid. 20:32-37.

Schreurs PJG, van de Willige G (1988) De Utrechtse Copinglijst (UCL). Lisse, The Netherlands: Swets, Zeitlinger.

Segal ZV, Williams JM, Teasdale JD, Gemar M (1996) A cognitive science perspective on kindling and episode sensitization in recurrent affective disorder. Psychol Med. 26:371-380.

Segal ZV, Williams JMG, Teasdale JD (2002) Mindfulness-Based Cognitive Therapy for DepressionA New Approach to Preventing Relapse. New York: Guilford Press.

Simoneau TL, Miklowitz DJ, Saleem R (1998) Expressed emotion and interactional patterns in the families of bipolar patients. J Abnorm Psychol. 107:497-507.

Teasdale JD (1988) Cognitive vulnerability to persistent depression. Cogn Emot. 2:247-274.

Teasdale JD, Segal ZV, Williams JMG, Ridgeway VA, Soulsby JM, Lau MA (2000) Prevention of relapse/recurrence in major depression by mindfullness-based cognitive therapy. J Consult Clin Psychol. 68:615- 623. 
van Eck M (1996) Stress, Mood and Cortisol Dynamics in Daily Life. PhD dissertation, Maastricht University, The Netherlands.

Weissman MM, Bothwell S (1976) Assessment of social adjustment by patient self-report. Arch Gen Psychiatry. 33:1111-1115.

Weissman MM, Prusoff BA, Thompson WD (1978) Social adjustment by self-report in a community sample and in psychiatric outpatients. J Nerv Ment Dis. 166:317-326.

Young RC, Biggs JT, Ziegler VE, Meyer DA (1978) A rating scale for mania: Reliability, validity and sensitivity. Br J Psychiatry. 133:429 -435. 



\section{Chapter 3}

\section{Mood reactivity to daily events in patients with remitted bipolar disorder}

Rob Havermans, Nancy A. Nicolson, Johannes Berkhof, Marten W. deVries

Psychiatry Research 179 (2010) 47-52 
Abstract: Information about mood reactions to naturally occurring stress in remitted bipolar patients may help elucidate the mechanism by which stressors influence the propensity to manic or depressive relapse in these patients. Using the experience sampling method (ESM), we therefore investigated negative and positive mood states and their reactivity to daily hassles and uplifts in 38 outpatients with remitted bipolar disorder and 38 healthy volunteers. Multilevel regression analyses confirmed that mean levels of negative affect (NA) were higher and positive affect (PA) lower in bipolar patients. Reactivity of NA and PA to hassles and uplifts in bipolar patients was similar to controls and was unrelated to the number of previous episodes. Bipolar patients with subsyndromal depressive symptoms, however, showed particularly large NA responses to daily hassles, which they also rated as more stressful. Subsyndromal depressive symptoms in patients with remitted bipolar disorder thus appear to increase sensitivity to everyday stressors. 


\section{Introduction}

Bipolar disorder is characterized by profound, episodic disturbances in mood, and there is now substantial evidence that life events increase the risk of episode recurrence and impede recovery in patients with bipolar disorder (Alloy et al., 2005; Johnson, 2005). Information about mood reactions to naturally occurring stress in the daily life of remitted bipolar patients may help elucidate the mechanism through which stressors are linked with symptoms, and can be useful in developing interventions aimed at preventing relapse. Surprisingly little, however, is known about the dynamics of mood in daily life situations during either acute phases or periods of remission (Johnson et al., 2007). The present study was designed to provide a detailed description of mood regulation in patients with remitted bipolar disorder in comparison to a healthy control group. We used an intensive sampling procedure, the experience sampling method (ESM) (Csikszentmihalyi and Larson, 1987; deVries, 1992), to assess daily events and mood states as close as possible to their time and place of occurrence. In combination with appropriate statistical methods, such daily process designs make it possible to link mood fluctuations to daily experiences and contexts (Marco and Suls, 1993; van Eck et al., 1998; Bolger et al., 2003). Frequently repeated selfassessments may also be less prone to recall biases than retrospective end-of-day diary reports (Eckenrode and Bolger, 1995). ESM has proved to be a particularly useful tool in the study of psychiatric disorders (Johnson et al., 2009; Myin-Germeys et al., 2009).

Research on the structure of self-rated mood has revealed the presence of two major and fairly independent dimensions: negative affect (NA) and positive affect (PA) (Watson and Tellegen, 1985). High NA subsumes a range of negative mood states such as anger, fear, and sadness. High PA reflects pleasurable engagement with the environment: for example, feelings of enthusiasm, selfconfidence, and happiness. The presence of elevated NA in patients with remitted bipolar disorder is supported by studies that reported a higher level of neuroticism compared to healthy controls (Hirschfeld et al., 1986; Solomon et al., 1996), as NA is strongly correlated with neuroticism (Watson, 2000). An ESM study in a nonclinical population of young adults also reported that individuals with cyclothymia as well as individuals with intermittent depression have higher levels of negative affect than subjects with no affective disorder (Lovejoy and Steuerwald, 1995). Levels of PA in cyclothymic individuals were significantly higher than in individual with intermittent depression, but similar to the control subjects. In a recent study, patients with remitted bipolar disorder reported lower scores on various items of a positive mood scale than healthy controls (Gruber et al., 2009). Taken together, these studies consistently show that bipolar patients have higher levels of NA than healthy controls, whereas findings on PA levels are mixed. 
Several theories predict that patients with bipolar disorder and healthy controls differ in their mood responses to both negative and positive environmental stimuli. According to the kindling and behavioral sensitization hypothesis of recurrent affective disorders (Post, 1992), individuals with bipolar disorder become sensitized to psychosocial stress over the course of early affective episodes and subsequently display heightened affective and neurobiological responses to even minor stressors. An analogous cognitive process could take place if dysfunctional cognitive patterns are reactivated by psychosocial stress during subsyndromal dysphoric states in patients with previous depressive episodes (Segal et al., 1996). On the basis of these theories it is to be expected that remitted bipolar patients show larger NA reactivity to negative daily events than healthy controls, especially in patients with many previous episodes or current depressive symptoms. Nonetheless, previous studies have found no evidence of increased negative mood reactivity in remitted bipolar patients except when depressive symptoms are present (Johnson et al., 2007). For example, two recent studies demonstrated that patients with bipolar disorder in remission and healthy control subjects did not differ in their affective reactions to standardized laboratory stressors (Ruggero and Johnson, 2006; Cuellar et al., 2009). These findings are in line with the results of an earlier study on behavioral and mood changes following naturally occurring daily stressors in relation to affective symptoms in a nonclinical sample of young adults (Goplerud and Depue, 1985). Compared to non-symptomatic controls, cyclothymic and dysthymic participants had similar negative mood responses to stressful events, although they did show delayed mood recovery.

An additional hypothesis follows from neurobehavorial theory of affective and behavioural response tendencies. As originally formulated by Gray (1973), the behavioral activation system (BAS) regulates approach behavior and PA in response to cues of potential rewards. In bipolar disorder, the BAS is thought to be inadequately regulated, making the individual vulnerable to extreme states of BAS activity: deficient in the presence of depressive symptoms and excessively high in the presence of hypomanic/manic symptoms (Depue and Iacono, 1989; Depue and Zald, 1993). Studies using a selfreport BAS scale have provided some support for this theory (Meyer et al., 2001; Kasch et al., 2002). Further support comes from studies indicating that people with remitted bipolar disorder and those at risk for bipolar disorder show elevated reactivity of PA to specific positive stimuli involving potential reward (Johnson et al., 2007). Other studies, however, demonstrated elevated mood reactivity to several kinds of positive and even neutral stimuli in these groups (Gruber et al., 2008; M'Bailara et al., 2009).

Extending previous research to a clinical sample of patients with remitted bipolar sampled during their normal daily lives, the current study assessed mood states in terms of NA and PA dimensions and measured responses of these dimensions to both negative and positive daily events. In addition, we 
explored the contributions of selected clinical characteristics in the bipolar group to individual differences in mood reactivity. Bipolar disorder is known to be an extremely heterogeneous diagnostic category, with pronounced interand intra-individual variability in functioning and symptom expression, also in individuals receiving prophylactic treatment. Although untangling possible sources of individual differences in mood reactivity would require a much larger sample, the current study explores the influences of the number of previous episodes and the severity of subsyndromal symptoms, as these features of the disorder are highly variable and associated with increased risk of episode recurrence (Keller et al., 1992; Coryell et al., 1998; Kessing et al., 1998). We predicted that current subclinical hypomanic symptoms would be associated with increased PA reactivity to positive events, whereas a large number of previous episodes and the presence of current subclinical depressive symptoms would be associated with increased NA reactivity to negative events. Finally we explored whether the effects of bipolar disorder and clinical characteristics on mood reactivity could be explained by differences in how individuals experience events in terms of stressfulness. The appraised stressfulness of daily situations has been shown to influence mood responses (van Eck et al., 1998; Gunthert et al., 1999). As prior episodes and subclinical depressive symptoms may both reinforce negative cognitive schema and erode confidence in the ability to cope with daily events, they may increase the subjective stressfulness of events. We therefore expected that clinical characteristics might exert their effects on mood responses indirectly, through the appraised stressfulness of events.

\section{Methods}

\subsection{Participants}

Thirty-nine bipolar patients were recruited from lithium clinics in Maastricht and Sittard, The Netherlands. The main inclusion criterion was a primary diagnosis of bipolar I or bipolar II disorder, without rapid cycling, as assessed with the Structured Clinical Interview for Diagnostic and Statistical Manual of Mental Disorders, fourth edition (DSM-IV) (First et al., 1996) by a trained research psychiatrist (R.H.). Additional inclusion criteria were age between 18 and 65 years, in a state of partial or full remission for more than 2 months, and under regular treatment including pharmacotherapy in accordance with standard clinical practice for more than 4 months. Because the study also focused on salivary cortisol patterns (reported separately) the following exclusion criteria were applied: substance abuse in the last year, pregnancy, weight loss exceeding $15 \%$ in the previous 6 months, endocrine disorders, and insufficient fluency in Dutch. On study entry, 16 patients received monotherapy 
with lithium; the others used various combinations of psychotropic drugs as follows: lithium $(n=20)$, carbamazepine $(n=4)$, valproate $(n=2)$, antidepressants $(n=4)$, neuroleptics $(n=7)$ and benzodiazepines $(n=6)$. A control group of 39 healthy subjects in the same age range was recruited from available research pools and through a local newspaper advertisement. Additional exclusion criteria for the control group were current use of psychotropic drugs, any personal history of Axis I disorders, and any inpatient treatment for Axis I disorder in a first-degree relatives. One patient and one healthy control were later excluded from the analysis because they failed to meet ESM compliance criteria (see below). The local medical ethics committee approved the protocol, and all participants gave written informed consent.

\subsection{Experience sampling procedure and measures}

The ESM was used to assess daily events and mood states during everyday activities. In response to signals ("beeps") from a wristwatch, participants completed self-report forms 10 times a day for 6 days, including a weekend. The beeps were programmed to occur between 7:30 a.m. and 10:30 p.m., at semirandom intervals within each 90-min time block. Reports completed within 20 min after the beep were considered valid. Patients completed fewer valid ESM reports than controls (78\% versus $87 \%$; Mann-Whitney U test, $p=0.002)$. Subjects with fewer than 20 valid responses (one patient and one control) were excluded from the analyses. On average, bipolar patients took somewhat longer to complete their valid ESM reports than control subjects (5:53 $\mathrm{min}$, S.D. $=2: 48$ min versus 4:34 $\min$, S.D. $=2: 00 \mathrm{~min}$.; $p=0.02$, two-tailed $\mathrm{t}$-test).

\subsubsection{Event assessments}

Participants who responded affirmatively to the ESM question "Did you experience a positive event or situation since the previous beep?" were asked briefly to describe the event in their ESM booklet and to rate the event on several appraisal dimensions, including stressfulness ( 1 not at all to 7 extremely). These questions were repeated with respect to "a negative event or situation." Although subjects were instructed to report only external events or situations that actually took place in their daily environment in the preceding interval, some event reports clearly referred to internal states (e.g., ruminations about past events or anticipated events, personal health concerns). Following preestablished criteria, the research team identified such internal events by consensus and omitted them from subsequent analyses, to avoid confounding of event and mood measures. In the bipolar group, 3.7\% of the event reports referred to internal states, compared to $5.1 \%$ in the healthy control group. Altogether, participants reported 1317 external positive events (on 35\% of all valid ESM reports) and 618 external negative events (on 16\% of all valid ESM reports). 


\subsubsection{Mood assessments}

Momentary mood states were assessed with 17 adjectives rated on seven-point Likert scales ( 1 not at all, 7 very). We chose to include items typical of pleasantness- unpleasantness as well as activation or arousal dimensions, because these captured clinically relevant aspects of daily mood in bipolar disorder and have previously been used by our research group in different populations (e.g. Peeters et al., 2003). Both factor analyses (principal components analysis with oblique rotation) on subject mean scores and within-subject z-scores identified two mood factors. These factors accounted for $74 \%$ of the total variance in subject mean scores and $40 \%$ of the total variance in within-subject z-scores. Ratings on the items cheerful, enthusiastic, strong, energetic, satisfied, selfassured, happy, and talkative were averaged to form a PA scale. Ratings on the items tense, agitated, edgy, irritated, restless, sad, anxious, distractable, and guilty were averaged to form a negative affect (NA) scale. Pearson's correlations between PA and NA, calculated over all responses using within-subject z-scores, were low (patients: $\mathrm{r}=-0.24, p<0.001$; controls: $\mathrm{r}=-0.27, p<0.001$ ), supporting the notion that these two dimensions are relatively independent (Watson et al., 1999).

\subsection{Clinical measures}

In the week preceding the ESM sampling, we used the Life Chart Method (Leverich and Post, 1996) to obtain a detailed history of the course of the disorder, from which the number of previous episodes and the duration of the current remission were determined. Inter-episode depressive and manic symptoms were assessed with the 17-item Hamilton Rating Scale for Depression (HRSD; Hamilton, 1960) and the Young Mania Rating Scale (YMRS; Young et al., 1978), administered by a trained research psychiatrist (R.H.).

\subsection{Statistical analyses}

To assess the effects of remitted bipolar disorder and clinical characteristics on mood responses to daily events, we applied the multilevel or hierarchical linear model, a variant of multiple regression appropriate for nested data. In this study, momentary NA and PA ratings were nested within days within persons. To account for various dependencies among the mood ratings, we estimated day-level variance to account for day-to-day variability and modeled a random intercept to account for interindividual variability in NA and PA levels. A detailed mathematical description of a three-level model for mood states can be found in van Eck et al. (1998).

We estimated separate models for NA and PA, using the program MlwiN (Goldstein et al., 1998). Models were adjusted for diurnal variations in NA and 
PA (Watson et al., 1999) by including linear and quadratic time of day terms, with time centered around its mean. To test for differences between bipolar patients and controls in NA and PA levels and reactivity to daily events, the effects of bipolar disorder ( 1 patient; 0 control) and of variables representing the interactions between bipolar disorder and the event terms were estimated. Negative and positive events were dummy coded (1 event occurrence; 0 no event occurrence). To assess moderating effects of clinical characteristics in bipolar disorder, we included the following variables: number of previous episodes (to reduce the influence of outlying values we used a median split: $\leq 7$ episodes (coded 0) vs. > 7 episodes (coded 1), with manic and depressive episodes combined); severity of depressive symptoms (HRSD); and severity of manic symptoms (YMRS). Symptom measures were standardized. Clinical variables were modeled as interactions with bipolar disorder and thus measured effects of clinical characteristics within the patient group. Interactions between the three clinical variables and the two types of events (negative and positive) were also estimated. Gender and age effects on NA and PA levels and reactivity to events were estimated in preliminary models; although no significant effects for either variable were observed, age was included in the final models to avoid possible confounding of the effects of number of previous episodes. Lastly, we tested whether appraisal processes influenced the effects of events on NA and PA, and mediated the effects of clinical characteristics, by comparing regression models with and without adjustment for self-rated stressfulness of positive and negative events, with ratings centered around their grand means (Baron and Kenny, 1986). To test the statistical significance of the regression coefficients, z-scores were calculated by dividing the estimated effect by its standard error (Bryk and Raudenbush, 1992). Tests were two-tailed, with significance levels set at alpha $=0.05$.

\section{Results}

\subsection{Descriptive statistics}

The ESM procedure was completed by 38 patients (of whom 19 men) and 38 controls (of whom 15 men). As shown in Table 1, the two groups were similar in age, but bipolar subjects had a lower mean level of education, were less often married or living with a partner, and were less frequently in paid employment. Mann-Whitney U tests revealed no differences between groups in total frequencies (as a percentage of total ESM reports) of either negative events (patients: mean $=16.2 \%$, S.D. $=18.0 \%$; controls: mean $=15.4 \%$, S.D. $=13.2 \%$ ) or positive events (patients: mean $=35.5 \%$, S.D. $=26.0 \%$; controls: mean $=32.7 \%$, S.D. $=$ $25.7 \%$ ). Two patients and two controls reported no daily events during the 6- 
day sampling period; an additional three patients reported no negative events. For details concerning frequencies and appraisals of events, see Havermans et al. (2007). The bipolar group experienced significantly higher mean NA (1.6, S.D. $=0.7$ vs. 1.3, S.D. $=0.3 ; p=0.013$, two-tailed t-test) and lower mean PA (3.6, S. D. $=1.1$ vs. 4.5, S.D. $=0.9 ; p \leq 0.001$, two-tailed t-test) than the control group.

Table 1. Sociodemographic measures for bipolar patients and controls.

\begin{tabular}{|c|c|c|c|c|}
\hline & Patients & Controls & Test statistic & $P$ \\
\hline & $N=\mathbf{3 8}$ & $N=\mathbf{3 8}$ & & \\
\hline Age, mean (S.D.) & $46.2(9.6)$ & $44.4(11.7)$ & $\mathrm{t}=0.74$ & n.s. \\
\hline Sex ratio $(M / F)$ & $19 / 19$ & $15 / 23$ & $\chi^{2}=0.85$ & n.s. \\
\hline Education (N, \%) & & & $\chi^{2}=8.20$ & 0.01 \\
\hline Elementary school & $11(29 \%)$ & $3(8 \%)$ & & \\
\hline Secondary school & $14(37 \%)$ & $11(29 \%)$ & & \\
\hline Higher education & $13(34 \%)$ & $24(63 \%)$ & & \\
\hline Marital status (N, \%) & & & $\chi^{2}=8.94$ & 0.02 \\
\hline Married or living together & $20(53 \%)$ & $31(82 \%)$ & & \\
\hline Never married & $11(18 \%)$ & $2(13 \%)$ & & \\
\hline Divorced or widowed & 7 (29\%) & $5(5 \%)$ & & \\
\hline Work situation (N, \%) & & & $\chi^{2}=30.51$ & $<0.001$ \\
\hline Household & $12(32 \%)$ & $3(8 \%)$ & & \\
\hline Regular job or education & $8(21 \%)$ & $32(84 \%)$ & & \\
\hline Disabled, unemployed, or retired & $18(47 \%)$ & $3(8 \%)$ & & \\
\hline
\end{tabular}

Of the patients, 31 had bipolar I disorder and seven had bipolar II disorder, with a mean age of onset of 29.6 years (median $=26.5$; range 16-61). The median number of previous episodes (manic and depressive) was seven, with a range from 1 to 38 (manic episodes: median $=3$, range $0-26$; depressive episodes: median $=3$, range $0-17$ ). Scores on the symptom scales indicated low levels of subsyndromal symptomatology (HRSD: mean $=2.9$, range 0-8; YMRS: mean $=$ 1.7 , range $0-10)$. Current age was unrelated to the number of previous episodes (Spearman $\mathrm{r}=0.02, \mathrm{n}=31, p=0.93$ ).

\subsection{Predictors of mood states}

Results of the multilevel regression analyses are summarized in Table 2. The first data row shows estimated basal mood levels and responses to negative and positive events in healthy controls. As hypothesized, negative events were generally followed by an increase in NA and a decrease in PA. Positive events had the opposite effects, being associated with small decreases in NA and larger increases in PA.

In agreement with the previous univariate comparison, bipolar disorder (second data row) was associated with significantly elevated NA levels and 
lowered PA levels. The absence of significant interactions effects between bipolar disorder and daily events means that mood responses to both negative and positive events were similar in the two groups.

Table 2. Multilevel estimates of effects of bipolar disorder and clinical characteristics on mood levels and reactivity.

\begin{tabular}{|c|c|c|c|c|c|c|}
\hline & \multicolumn{2}{|c|}{ Mood level } & \multicolumn{2}{|c|}{ Response to negative events } & \multicolumn{2}{|c|}{ Response to positive events } \\
\hline & NA & PA & NA & PA & NA & PA \\
\hline Control group & $1.49^{a}(0.19)^{* * *}$ & $3.91^{\mathrm{a}}(0.47)^{* * *}$ & $+0.26(0.02)^{* * *}$ & $-0.19(0.04)^{* * *}$ & $-0.06(0.02)^{* *}$ & $+0.22(0.04)^{* * *}$ \\
\hline Bipolar disorder group & $+0.39(0.12)^{* *}$ & $-1.00(0.21)^{* * *}$ & $-0.01(0.05)$ & $+0.09(0.07)$ & $-0.02(0.04)$ & $-0.05(0.06)$ \\
\hline Previous episodes & $+0.24(0.11)^{*}$ & $-0.26(0.16)^{\#}$ & $-0.04(0.04)$ & $+0.07(0.06)$ & $-0.03(0.03)$ & $-0.04(0.04)$ \\
\hline Depressive symptoms & $+0.19(0.12)$ & $-0.43(0.17)^{*}$ & $+0.21(0.05)^{* * *}$ & $-0.11(0.06)^{\#}$ & $-0.05(0.03)$ & $+0.01(0.04)$ \\
\hline Manic symptoms & $+0.19(0.12)$ & $+0.16(0.17)$ & $-0.07(0.04)^{\#}$ & $+0.13(0.06)^{*}$ & $+0.02(0.03)$ & $-0.05(0.04)$ \\
\hline
\end{tabular}

Note. The analysis is based on 3776 valid ESM reports, including 618 negative events and 1317 positive events. Separate NA and PA models have been adjusted for time of day and age. Gender effects were non-significant and are not included in the final models.

a Modeled intercept, representing the estimated mean mood level in the control group. All other entries in the table are regression coefficients (SE in parentheses). These can be added to the intercept (value 1.49) to obtain specific estimates (e.g., mean NA in bipolar patients with a level of depressive symptoms that is one standard deviation above the mean: $1.49+0.39+0.19=2.07$; following a negative event, NA increases further in this subgroup: $2.07+0.26+(-0.01)+0.21=$ 2.53). $Z$ values can be computed by dividing $\beta$ by SE. P values: ${ }^{*} \leq 0.10,{ }^{*} \leq 0.05,{ }^{* *} \leq 0.01,{ }^{* * *} \leq 0.001$.

Patients with a high number of previous episodes (median split: $>7$ episodes) had greater elevations in NA and showed a trend toward further lowering of PA; however, contrary to our hypothesis, number of prior episodes had no significant effects on mood reactivity. Subsyndromal depressive symptoms, although they do not fulfill the criteria of a depressive episode, thus appear to have a substantial impact on mood regulation in daily life. Subsyndromal depressive symptoms, on the other hand, were strong predictors of mood measures. In particular, patients with more severe depressive symptoms showed further decrements in PA levels and markedly greater NA responses to negative events, as depicted in Fig. 1. Manic symptoms had no significant effects on mood, except for a diminished decrease in PA following a negative event. 


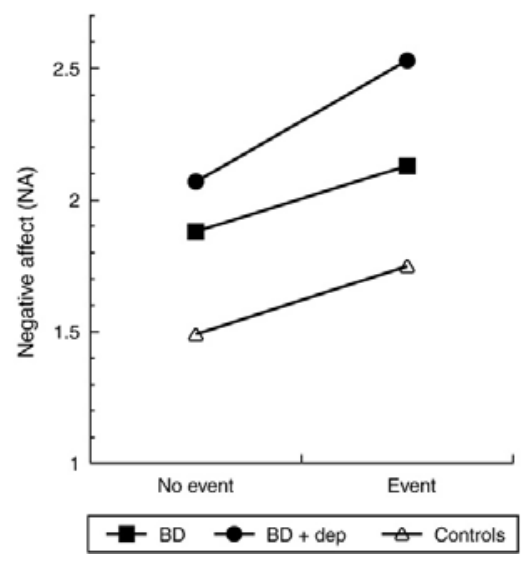

Fig. 1. Modeled changes in NA following negative daily events. Estimates are presented for the bipolar group at mean levels of subsyndromal symptoms (BD), for the bipolar group with severity of depressive symptoms 1 S.D. above the bipolar group mean (BD + dep), and for healthy controls (Controls).

Lastly, we examined the effects of rated stressfulness on mood responses to negative events. As expected, negative events that were more stressful than average were associated with further increases in NA $(\beta=0.14, \mathrm{SE}=0.01, \mathrm{Z}$ $=12.34, p<0.001)$ and decreases in PA $(\beta=-0.08, \mathrm{SE}=0.02, \mathrm{Z}=4.37, p<0.001)$. Interestingly, the estimated effect of depressive symptoms on the NA response to negative events was reduced after adjusting for rated stressfulness, although it remained significant $(\beta=0.13, \mathrm{SE}=0.05, \mathrm{Z}=2.79, p=0.01)$. This finding suggests that the effect of subsyndromal depressive symptoms on NA reactivity was partly mediated by appraisal processes.

\section{Discussion}

The observed combination of elevated NA and lowered PA previously described as a characteristic of symptoms and diagnosis of depression (Watson et al., 1988 ) is extended in the present study to a clinical sample of remitted bipolar patients, especially in the subgroup of patients with current depressive symptoms. Although the mood levels in the remitted bipolar group were not as abnormal as those observed in an ESM study of patients with current unipolar depression (Peeters et al., 2003), they may be clinically relevant in terms of general well-being and quality of life. Whereas elevated NA in this sample of bipolar patients is consistent with previous studies, the lowered PA is in contrast with the results of a previous ESM study on young adults with cyclothymia (Lovejoy and Steuerwald, 1995). As was pointed out by Gruber et al. (2009), who also reported lowered levels of positive affect in patients of remitted bipolar disorder, methodological difference may account for the divergent findings: a clinical sample of middle-aged bipolar patients may have endured more psychosocial problems that reduce opportunities for reward and other 
positive experiences compared to a younger, nonclinical sample of undergraduates.

In both bipolar and control groups, negative events were associated with increases in NA and decreases in PA, whereas positive events were followed by decreases in NA and increases in PA. The magnitude of mood changes was strongly associated with the appraised stressfulness of events. These findings replicate and extend the results of previous studies on the within-day effects of events and appraisal processes on mood states (Marco and Suls, 1993; van Eck et al., 1998; Marco et al., 1999; Myin-Germeys et al., 2003; Peeters et al., 2003).

In line with the results of previous studies we found no evidence for increased negative mood reactivity to daily events in the bipolar group as a whole. We had previously reported some evidence for larger decrements in PA in bipolar patients compared to healthy controls, during unpleasant daily activities or social situations (Myin-Germeys et al., 2003). ${ }^{1}$ This apparent discrepancy with the current results may indicate that bipolar patients have heightened sensitivity to these types of contexts only and not to daily events in general. Differences in how the daily stressors were operationalized may also be key: in the current analysis, stressors were concrete events that had occurred in the past 1-2 $\mathrm{h}$, whereas, in the earlier analysis, stressors were ongoing unpleasant situations, concurrent with the dependent measures of affect. Concurrent measurement is likely to result in higher associations, as mood responses to terminated events will generally decay over time. On the other hand, an association between appraised unpleasantness of the current situation and current affect is more difficult to interpret in terms of cause and effect; patients experiencing a dip in positive affect might, for example, find their current activity more demanding and less rewarding. Taken together, empirical studies to date provide insufficient evidence to conclude that mood reactivity to either naturally occurring or laboratory stressors in remitted bipolar patients, as a group, differs from reactivity in healthy controls.

It is important to note that the current analysis focused only on the magnitude of the mood response to daily stress. We were unable with these naturalistic data to assess other aspects of mood reactivity, such as the threshold for reactivity, the rise time to peak, and the recovery time (Davidson, 1998). Delayed recovery from negative daily events may be a more salient component of mood dysregulation than the magnitude of the immediate response (Goplerud and Depue, 1985). Moreover, our findings leave open the question whether mood states are inherently less stable in bipolar disorder, in the absence of environmental triggers, as other studies suggest (Ahearn and Carroll, 1996). Third, even if mood reactivity is normal, bipolar patients might show alterations in other aspects of the stress response, such as impaired cognitive performance, disturbed cortisol reactivity, or altered psychophysiological

\footnotetext{
${ }^{1}$ Same sample of bipolar patients but different healthy control group.
} 
responses (Depue et al., 1985; Ruggero and Johnson, 2006; Gruber et al., 2008; M'Bailara et al., 2009).

We investigated whether altered mood reactivity to daily events in bipolar patients might be confined to particular subgroups, specifically to those patients with many previous episodes or subsyndromal symptoms. Results provide no support for the hypothesis that prior episodes sensitize the individual to daily events. However, we included few patients with only one or two previous episodes, and it remains possible that the largest changes in stress reactivity occur early in illness course. A comparison with the results of prior studies is limited by the fact that they all focused on the association between major life events and subsequent episodes, and different sensitization processes with different mechanisms might be involved. The sensitization hypothesis needs further empirical evaluation in a longitudinal study, comparing mood reactivity over successive episodes.

We found no association between current manic symptoms and PA responses to positive events, in apparent contradiction to the hypothesis that these symptoms are related to increased BAS activity. It is important to note, however, that the range and variability of manic symptoms were restricted, as all patients were in a state of clinical remission. Moreover, the BAS is generally defined as a system that responds with increases in PA in situations offering potential rewards or incentives; such situations represent only a subset of positive events as measured in the current study. Interestingly, several longitudinal studies have reported that life events involving goal attainment, but not positive events in general, were associated with subsequent increases in manic symptoms in bipolar disorder (Johnson et al., 2000; Nusslock et al., 2007; Johnson et al., 2008).

Depressive symptoms in the bipolar patient group were related to greater increases of NA following negative daily events. As expected, this effect decreased after adjusting for event stressfulness. Although there was no overall significant difference between bipolar patients and controls in the average stressfulness of negative events, bipolar patients with more depressive symptoms did rate negative events as more stressful $(r=0.60, n=33, P<0.001)$. This finding is consistent with theories postulating maladaptive cognitive schemas in individuals with dysphoric mood, which cause them to interpret current experiences more negatively (Teasdale, 1988). Subsyndromal depressive symptoms, although they do not fulfill the criteria of a depressive episode, thus appear to have a substantial impact on mood regulation in daily life. A U.S. longitudinal study reported that subsyndromal depressive symptoms were nearly three times more frequent than subsyndromal manic or syndromal-level major depressive symptoms, occurring in $23 \%$ of follow-up weeks (Judd et al., 2002). Similar findings were obtained in a U.K. study (Paykel et al., 2006). Subsyndromal depressive symptoms are associated with increased risk of relapse and poor functional outcomes (Coryell et al., 1998; Bauer et al., 2001; 
Altschuler et al., 2002). We speculate that heightened stress reactivity may be one of the contributing factors. Future studies should investigate this hypothesis prospectively, ideally in samples of bipolar patients with a wider range of subsyndromal symptoms.

This study had some limitations. First, the registration of the presence and stressfulness of daily events was based on self-reports, and we have no way of checking the accuracy these reports. Second, our choice of pen and paper instead of electronic data collection means that we could not directly verify that participants completed ESM self-reports at the times they recorded. However, although poor compliance with fixed time paper diary protocols has been reported (Stone et al., 2002), other studies have shown that pen-and-paper compliance with more intensive and unpredictable ESM sampling schedules is high (as verified with electronic monitoring, Jacobs et al., 2005) and that paper and electronic diary studies generally yield similar empirical results (Green et al., 2006). Third, although we have interpreted the multilevel regression results in terms of mood reactivity to daily events, causal relationships cannot be firmly established with ESM data. Finally, as noted above, all patients were taking mood stabilizers, so that we could not assess whether similarities or differences between bipolar and control groups were due to the remitted disorder (either underlying vulnerability or 'scars') or to its treatment. Sample sizes precluded a comparison of mood patterns in patients receiving different types or combinations of pharmacologic treatments. Nevertheless, because treatment was in accordance with current practice and accepted guidelines, the results are broadly generalizable to outpatients with remitted bipolar disorder.

In summary, to our knowledge the present study is the first to examine positive and negative mood states and their relation to hassles and uplifts in the everyday life of a clinical sample of individuals with remitted bipolar disorder. Whereas previous studies have demonstrated that life events can trigger subsequent episode recurrences in these patients, the current study suggests that this vulnerability is not reflected by disturbances in the immediate effects of daily events on mood states. This finding adds to a growing literature, suggesting that mood reactions to laboratory stressors and naturally occurring daily events in these patients are similar to healthy controls. The present study, however, does indicate that bipolar patients with subsyndromal depressive symptoms are particularly sensitive to the impact of everyday stressors. It is attractive to speculate that this sensitivity may contribute to their vulnerability for episode recurrence but prospective studies are needed to verify this.

\section{Acknowledgments}

We thank Truda Driesen, Lilly Finders, and Frieda van Goethem for research assistance and Philippe Delespaul for advice on aspects of the study. 


\section{References}

Ahearn, E.P., Carroll, B.J., 1996. Short-term variability of mood ratings in unipolar and bipolar depressed patients. Journal of Affective Disorders 36, 107-115.

Alloy, L.B., Abramson, L.Y., Urosevic, S., Walshaw, P.D., Nusslock, R., Neeren, A.M., 2005. The psychosocial context of bipolar disorder: environmental, cognitive, and developmental risk factors. Clinical Psychology Review 25, 1043-1075.

Altschuler, L.L., Gitlin, M.J., Mintz, J., Leight, K.L., Frye, M.A., 2002. Subsyndromal depression is associated with functional impairment in patients with bipolar disorder. Journal of Clinical Psychiatry 63, 807-811.

Baron, R.M., Kenny, D.A., 1986. The moderator-mediator variable distinction in social psychological research: conceptual, strategic, and statistical considerations. Journal of Personality and Social Psychology 51, 1173-1182.

Bauer, M.S., Kirk, G.F., Gavin, C., Williford, W.O., 2001. Determinants of functional outcome and healthcare costs in bipolar disorder: a high-intensity follow-up study. Journal of Affective Disorders 65, 231-241.

Bolger, N., Davis, A., Rafaeli, E., 2003. Diary methods: capturing life as it is lived. Annual Review of Psychology 54, 579-616.

Bryk, A.S., Raudenbush, S.W., 1992. Hierarchical Linear Models: Applications and Data Analysis Methods. Sage Publications, London.

Coryell, W., Turvey, C., Endicott, J., Leon, A.C., Mueller, T., Solomon, D., Keller, M., 1998. Bipolar I affective disorder: predictors of outcome after 15 years. Journal of Affective Disorders 50, 109116.

Csikszentmihalyi, M., Larson, R., 1987. Validity and reliability of the Experience Sampling Method. Journal of Nervous and Mental Disease 175, 526-536.

Cuellar, A.K., Johnson, S.L., Ruggero, C.J., 2009. Affective reactivity in response to criticism in remitted bipolar disorder: a laboratory analog of expressed emotion. Journal of Clinical Psychology 65, 1-17.

Davidson, R.J., 1998. Affective style and affective disorders: perspectives from affective neuroscience. Cognition and Emotion 12, 307-330.

deVries, M.W. (Ed.), 1992. The Experience of Psychopathology: Investigating Mental Disorders in Their Natural Settings. Cambridge University Press, Cambridge.

Depue, R.A., Iacono, W.G., 1989. Neurobehavioral aspects of affective disorders. Annual Review of Psychology 40, 457-492.

Depue, R.A., Zald, D.H., 1993. Biological and environmental processes in nonpsychotic psychopathology: a neurobehavioral perspective. In: Depue, R.A., Zald, D.H. (Eds.), Basic Issues in Psychopathology. The Guilford Press, New York, pp. 127-237.

Depue, R.A., Kleiman, R.M., Davis, P., Hutchinson, M., Krauss, S.P., 1985. The behavioral high-risk paradigm and bipolar affective disorder, VIII: serum free cortisol in nonpatient cyclothymic subjects selected by the General Behavior Inventory. American Journal of Psychiatry 142, 175181.

Eckenrode, J., Bolger, N., 1995. Daily and within-day event measurement. In: Eckenrode, J., Bolger, N. (Eds.), Measuring Stress: A Guide for Health and Social Scientists. Oxford University Press, Oxford, pp. 80-101.

First, M.B., Spitzer, R.L., Gibbon, M., Williams, J.B.W., 1996. Structured Clinical Interview for DSM-4 Axis 1 Disorders - Patient Edition (SCID-I/P version 2.0). Biometrics Research Department, New York.

Goldstein, H., Rasbash, J., Plewis, I., Draper, D., Browne, W., Yang, M., Woodhouse, G., Healy, M., 1998. A User's Guide to MLwiN. Multilevel Models Project, Institute of Education, University of London, London.

Goplerud, E., Depue, R.A., 1985. Behavioral response to naturally occurring stress in cyclothymia and dysthymia. Journal of Abnormal Psychology 94, 128-139. 
Gray, J.A., 1973. Causal theories of personality and how to test them. In: Gray, J.A. (Ed.), Multivariate Analysis and Psychological Theory. Academic Press, New York, pp. 409-463.

Green, A., Rafaeli, E., Bolger, N., Shrout, P., Reis, H., 2006. Paper or plastic? Data equivalence in paper and electronic diaries. Psychological Methods 11, 87-105.

Gruber, J., Johnson, S.L., Oveis, C., Keltner, D., 2008. Risk for mania and positive emotional responding: too much of a good thing? Emotion 8, 23-33.

Gruber, J., Culver, J.L., Johnson, S.L., Nam, J.Y., Keller, K.L., Ketter, T.A., 2009. Do positive emotions predict symptomatic change in bipolar disorder? Bipolar Disorders 11,330-336.

Gunthert, K.C., Cohen, L.H., Armeli, S., 1999. The role of neuroticism in daily stress and coping. Journal of Personality and Social Psychology 77, 1087-1100.

Hamilton, M., 1960. A rating scale for depression. Journal of Neurology, Neurosurgery and Psychiatry 23, 56-62.

Havermans, R., Nicolson, N.A., deVries, M.W., 2007. Daily hassles, uplifts, and time use in individuals with bipolar disorder in remission. Journal of Nervous and Mental Disease 195, 745-751.

Hirschfeld, R.M.A., Klerman, G.L., Keller, M.B., Andreasen, N.C., Clayton, P.J., 1986. Personality of recovered patients with bipolar affective disorder. Journal of Affective Disorders 11, 81-89.

Jacobs, N., Nicolson, N.A., Derom, C., Delespaul, P., van Os, J., Myin-Germeys, I., 2005. Electronic monitoring of salivary cortisol sampling compliance in daily life. Life Sciences 76, 2431-2443.

Johnson, S.L., 2005. Life events in bipolar disorder: towards more specific models. Clinical Psychology Review 25, 1008-1027.

Johnson, S.L., Sandrow, D., Meyer, B., Winters, R., Miller, I., Solomon, D., Keitner, G., 2000. Increases in manic symptoms after life events involving goal attainment. Journal of Abnormal Psychology 109, 721-727.

Johnson, S.L., Gruber, J., Eisner, L.R., 2007. Emotion and bipolar disorder. In: Johnson, S.L., Gruber, J., Eisner, L.R. (Eds.), Emotion and Psychopathology: Bridging Affective and Clinical Science. American Psychological Association, Washington, DC, pp. 123-150.

Johnson, S.L., Cueller, A.K., Ruggero, C., Winett-Perlman, C., Goodnick, P., White, R., Miller, I., 2008. Life events as predictors of mania and depression in bipolar I disorder. Journal of Abnormal Psychology 117, 268-277.

Johnson, E.I., Grondin, O., Barrault, M., Faytout, M., Helbig, S., Husky, M., Granholm, E.L., Loh, C., Nadeau, L., Wittchen, H.U., Swendsen, J., 2009. Computerized ambulatory monitoring in psychiatry: a multi-site collaborative study of acceptability, compliance, and reactivity. International Journal of Methods in Psychiatric Research 18, 48-57.

Judd, L.L., Akiskal, H.S., Schettler, P.J., Endicott, J., Maser, J., Solomon, D.A., Leon, A.C., Rice, J.A., Keller, M.B., 2002. The long-term natural history of the weekly symptomatic status of bipolar I disorder. Archives of General Psychiatry 59, 530-537.

Kasch, K.L., Rottenberg, J., Arnow, B.A., Gotlib, I.H., 2002. Behavioral activation and inhibition systems and the severity and course of depression. Journal of Abnormal Psychology 111, 589597.

Keller, M.B., Lavori, P.W., Kane, J.M., Gelenberg, A.J., Rosenbaum, J.F., Walzer, E.A., Baker, L.A., 1992. Subsyndromal symptoms in bipolar disorder: a comparison of standard and low serum levels of lithium. Archives of General Psychiatry 49, 371-376.

Kessing, L.V., Andersen, P.K., Mortensen, P.B., Bolwig, T.G., 1998. Recurrence in affective disorder: I. Case register study. British Journal of Psychiatry 172, 23-28.

Leverich, G.S., Post, R.M., 1996. Life charting the course of bipolar disorder. Current Review of Mood and Anxiety Disorders 1, 48-61.

Lovejoy, M.C., Steuerwald, B.L., 1995. Subsyndromal unipolar and bipolar disorders: comparison on positive and negative affect. Journal of Abnormal Psychology 104, 381-384.

Marco, C.A., Suls, J., 1993. Daily stress and the trajectory of mood: spillover, response assimilation, contrast, and chronic negative affectivity. Journal of Personality and Social Psychology 64, 1053-1063. 
Marco, C.A., Neale, J.M., Schwartz, J.E., Shiffman, S., Stone, A.A., 1999. Coping with daily events and short-term mood changes: an unexpected failure to observe effects of coping. Journal of Consulting and Clinical Psychology 67, 755-764.

M’Bailara, K., Demotes-Mainard, J., Swendsen, J., Mathieu, F., Leboyer, M., Henry, C., 2009. Emotional hyper-reactivity in normothymic bipolar patients. Bipolar Disorders 11,63-69.

Meyer, B., Johnson, S.L., Winters, R., 2001. Responsiveness to threat and incentive in bipolar disorder: relations of the BIS/BAS scales with symptoms. Journal of Psychopathology and Behavioral Assessment 23, 133-143.

Myin-Germeys, I., Peeters, F., Havermans, R., Nicolson, N.A., DeVries, M.W., Delespaul, P., Van Os, J., 2003. Emotional reactivity to daily life stress in psychosis and affective disorder: an experience sampling study. Acta Psychiatrica Scandinavica 107, 124-131.

Myin-Germeys, I., Oorschot, M., Collip, D., Lataster, J., Delespaul, P., van Os, J., 2009. Experience sampling research in psychopathology: opening the black box of daily life. Psychological Medicine 39, 1533-1547.

Nusslock, R., Abramson, L.Y., Harmon-Jones, E., Alloy, L.B., Hogan, M.E., 2007. A goalstriving life event and the onset of hypomanic and depressive episodes and symptoms: perspective from the behavioral approach system (BAS) dysregulation theory. Journal of Abnormal Psychology 116, 105-115.

Paykel, E.S., Abbott, R., Morriss, R., Hayhurst, H., Scott, J., 2006. Sub-syndromal and syndromal symptoms in the longitudinal course of bipolar disorder. British Journal of Psychiatry 189, 118123.

Peeters, F., Nicolson, N.A., Berkhof, J., Delespaul, P., DeVries, M., 2003. Effects of daily events on mood states in major depressive disorder. Journal of Abnormal Psychology 112,203-211.

Post, R.M., 1992. Transduction of psychosocial stress into the neurobiology of recurrent affective disorder. American Journal of Psychiatry 149, 999-1010.

Ruggero, C.J., Johnson, S.L., 2006. Reactivity to a laboratory stressor among individuals with bipolar I disorder in full or partial remission. Journal of Abnormal Psychology 115, 539-544.

Segal, Z.V., Williams, J.M., Teasdale, J.D., Gemar, M., 1996. A cognitive science perspective on kindling and episode sensitization in recurrent affective disorder. Psychological Medicine 26, 371-380.

Solomon, D.A., Ristow, W.R., Keller, M.B., Kane, J.M., Gelenberg, A.J., Rosenbaum, J.F., Warshaw, M.G., 1996. Serum lithium levels and psychosocial function in patients with bipolar I disorder. American Journal of Psychiatry 153, 1301-1307.

Stone, A.A., Shiffman, S., Schwartz, J.E., Broderick, J.E., Hufford, M.R., 2002. Patient noncompliance with paper diaries. British Medical Journal 324, 1193-1194.

Teasdale, J.D., 1988. Cognitive vulnerability to persistent depression. Cognition and Emotion 2, 247274.

van Eck, M., Nicolson, N.A., Berkhof, J., 1998. Effects of stressful daily events on mood states: relationship to global perceived stress. Journal of Personality and Social Psychology 75, 15721585.

Watson, D., 2000. Mood and Temperament. The Guilford Press, New York.

Watson, D., Tellegen, A., 1985. Toward a consensual structure of mood. Psychological Bulletin 98, 219-235.

Watson, D., Clark, L.A., Carey, G., 1988. Positive and negative affectivity and their relation to anxiety and depressive disorders. Journal of Abnormal Psychology 97, 346-353.

Watson, D., Wiese, D., Vaidya, J., Tellegen, A., 1999. The two general activation systems of affect: structural findings, evolutionary considerations, and psychobiological evidence. Journal of Personality and Social Psychology 76, 820-838.

Young, R.C., Biggs, J.T., Ziegler, V.E., Meyer, D.A., 1978. A rating scale for mania: reliability, validity and sensitivity. British Journal of Psychiatry 133, 429-435. 



\section{Chapter 4}

\section{Patterns of salivary cortisol secretion and responses to daily events in patients with remitted bipolar disorder}

Rob Havermans, Nancy A. Nicolson, Johannes Berkhof, Marten W. deVries

Received 7 November 2009; received in revised form 21 July 2010; accepted 22 July 2010 Psychoneuroendocrinology 36 (2011) 258-265 
Summary: Previous studies on bipolar disorder revealed abnormalities in the function of the HPA axis, including disturbed patterns of cortisol secretion, during depressive and manic episodes. It is less clear whether these abnormalities persist after symptomatic recovery. In the present study we used the experience sampling method with intensive salivary cortisol sampling to study patterns of cortisol secretion in relation to negative and positive daily events during the normal daily life of a group of 36 patients with remitted bipolar disorder and 38 healthy controls. Results of multilevel regression analysis indicated that daytime cortisol levels and reactivity to daily events were similar in remitted bipolar patients and healthy controls, but bipolar patients showed flatter diurnal slopes and larger cortisol fluctuations over successive measures. Patients with many previous episodes had higher overall cortisol levels, reduced cortisol reactivity to negative daily events, and flatter diurnal slopes than patients with fewer episodes. These results provide additional evidence of subtle HPA axis dysregulation in remitted bipolar patients, especially in those with many recurrent episodes. 


\section{Introduction}

Many patients with bipolar disorders show evidence of increased activity at several levels of the hypothalamic- pituitary-adrenal (HPA) axis during depressive and manic episodes (Linkowski et al., 1994; Schmider et al., 1995; Cassidy et al., 1998; Rybakowski and Twardowska, 1999; Daban et al., 2005). Controversy exists whether these abnormalities are limited to the episodes themselves or might also be present before the onset of bipolar disorder or later, during periods of clinical remission. Offspring of parents with bipolar disorder have been reported to have elevated (Ellenbogen et al., 2006) or normal (Deshauer et al., 2006) basal cortisol levels; in general, studies of basal cortisol secretion in remitted bipolar patients provide little evidence of abnormalities (Cervantes et al., 2001; Watson et al., 2004; Thompson et al., 2005; Deshauer et al., 2006). However, evidence from challenge tests indicates persistent HPA dysfunction after clinical remission from bipolar episodes. For example, remitted bipolar patients have demonstrated intermittent cortisol non-suppression during monthly dexamethasone suppression tests (DSTs) (Deshauer et al., 1999). Moreover, a study using the combined dexamethasone/corticotropin releasing hormone (DEX/CRH) test reported an enhanced salivary cortisol response in symptomatic as well as in remitted bipolar patients, compared to healthy controls (Watson et al., 2004). These findings suggest that cortisol reactivity to psychosocial stressors might also be altered in remitted bipolar patients. Patients with unipolar depression tend to show decreased cortisol responses to laboratory as well as everyday psychosocial stressors (Peeters et al., 2003; Burke et al., 2005), whereas one study found that cyclothymic individuals showed heightened reactivity to a laboratory stressor (Depue et al., 1985). To our knowledge, cortisol reactivity to psychosocial stressors has not been studied in patients with bipolar disorder, either current or remitted. Furthermore, although basal cortisol secretion shows more random variability in individuals with cyclothymia (Depue et al., 1985) and in depressed patients under both naturalistic (Peeters et al., 2004) and controlled conditions (Posener et al., 2004), this indicator of dysregulated HPA activity has not previously been investigated in bipolar patients. In summary, although some studies suggest that HPA axis dysregulation precedes, accompanies and follows bipolar episodes and thus may be a trait characteristic (Daban et al., 2005), there is relatively little information on cortisol secretory patterns in remitted bipolar disorder. Better insight into these patterns may help elucidate whether HPA axis hyperactivity plays a role in the pathophysiology of bipolar disorders (Cousins and Young, 2005). Support for HPA involvement could in turn stimulate the development of therapeutic strategies that target this neuroendocrine system. The glucocorticoid receptor antagonist mifepristone, for example, has been shown to improve cognitive function and attenuate depressive symptoms in bipolar disorder (Young et al., 2004a). 
The first aim of the present study was to provide a more complete description of cortisol secretory patterns during the normal daily life of patients with remitted bipolar disorder, in comparison to healthy controls. We therefore conducted an intensive sampling of salivary cortisol with simultaneous registration of daily hassles and uplifts. In the present study, participants collected saliva samples and completed self-report forms 10 times a day for 6 days, which allowed us to examine not only overall cortisol levels, but also the diurnal decline in cortisol levels, short-term reactivity of this hormone to daily stressors, and the degree of apparent random variability. We hypothesized that levels of cortisol secretion in remitted patients would be higher, more variable, and less responsive to daily events than in healthy controls. Our second aim was to investigate whether individual differences in cortisol secretion in the patient group could be explained by the number of previous episodes and the presence of subsyndromal symptoms.

\section{Methods}

\subsection{Participants}

Thirty-nine bipolar patients were recruited from lithium clinics in Maastricht and Sittard, The Netherlands. The main inclusion criterion was a primary diagnosis of Bipolar I or Bipolar II Disorder, without rapid cycling, as assessed with the Structured Clinical Interview for DSM-IV (First et al., 1996). Additional inclusion criteria were age between 18 and 65 years, in a state of partial or full remission (according to DSMIV criteria) for more than 2 months, and under regular treatment including appropriate pharmacotherapy for more than 4 months. Exclusion criteria were substance abuse in the last year, pregnancy, weight loss exceeding 15\% in the previous 6 months, endocrine disorders, and insufficient fluency in Dutch. On study entry, 16 patients received monotherapy with lithium; the others used various combinations of psychotropic drugs. A control group of 39 healthy subjects in the same age range was recruited from available research pools and through a local newspaper advertisement. Additional exclusion criteria for the control group were current use of psychotropic drugs, current use of medication (other than oral contraceptives) known to affect the HPA axis, any personal history of Axis I disorders, and any inpatient treatment for Axis I disorder in first degree relatives. Three patients and one healthy control were later excluded from the analysis because they failed to meet protocol compliance criteria (see below). Subjects completed a questionnaire concerning marital status (married or living together; unmarried; divorced or widowed), employment (household; education or paid employment; unemployed) and education obtained (primary education; secondary education; 
university degree). The local medical ethics committee approved the protocol, and written informed consent was obtained from all participants.

\subsection{Experience sampling procedure and measures}

The experience sampling method (ESM) was used for the selfassessment of daily events in the context of everyday life (Csikszentmihalyi and Larson, 1987; deVries, 1992). Subjects were sampled repeatedly over the day during six consecutive days, including a weekend. Subjects wore a wristwatch programmed to emit auditory signals ('beeps') 10 times a day, at an unpredictable moment roughly centered in each 90-min time block between 07:30 and 22:30 h. As soon as possible after each beep, subjects completed a brief ESM selfreport form and simultaneously collected a saliva sample. A response was defined as valid when the delay between a beep signal and both the completion of an ESM form and the collection of a saliva sample was no more than 30 min. Subjects with fewer than 20 valid responses were excluded from the analyses.

Participants who responded affirmatively to the ESM question "Did you experience a positive event or situation since the previous beep?," were asked briefly to describe the event in their ESM booklet and to rate the event on how stressful is was ( 1 not at all to 7 extremely). These questions were then repeated with respect to "a negative event or situation." At every beep, participants could thus report no event, a positive event, a negative event, or both a positive and a negative event. Although subjects were instructed to report only external events or situations that actually took place in their daily environment in the preceding interval, some event reports clearly referred to internal states (e.g., ruminations about past events or anticipated events, personal health concerns). Following pre-established criteria, the research team identified such internal events by consensus and omitted them from subsequent analyses. In the bipolar group, $3.7 \%$ of the event reports referred to internal states, compared to $5.4 \%$ in the healthy control group. Altogether, participants reported 1278 external positive events (on 36\% of all valid ESM reports) and 601 external negative events (on $17 \%$ of all valid ESM reports).

\subsection{Clinical measures}

In the week preceding the ESM sampling, we used the Life Chart Method (Leverich and Post, 1996) to obtain a detailed history of the course of the disorder, from which the number of previous episodes and the duration of the current remission were determined. Inter-episode depressive and manic symptoms were assessed with the 17-item Hamilton Rating Scale for Depression (HRSD) (Hamilton, 1960) and the Young Mania Rating Scale (YMRS) (Young et al., 1978). 


\subsection{Salivary cortisol}

Salivary cortisol is a reliable indicator of the unbound, biologically active fraction of cortisol in plasma and can be easily collected without disrupting normal daily activities (Kirschbaum and Hellhammer, 1994). Subjects collected saliva by holding a cotton dental roll in their mouth for a few minutes and then sealed the saturated roll into a plastic tube ('Salivette', Sarstedt), which was stored in the home freezer that evening, until the end of the ESM sampling period. Salivettes were kept frozen in the laboratory at $-20{ }^{\circ} \mathrm{C}$ until analysis. Cortisol levels were determined in duplicate by direct radioimmunoassay at the laboratory of Dr. J. Sulon, University of Liege, Belgium. Briefly, $100 \mathrm{ml}$ of saliva were incubated overnight at $4{ }^{\circ} \mathrm{C}$ with 125 iodohistamine-cortisol and anticortisol serum made against the 3-CMO-BSA conjugate. Separation of free and antibody-bound 125 -cortisol was then performed by a conventional 'second antibody' method. The lower detection limit was $10 \mathrm{ng} / \mathrm{dl}$. The mean intra- and inter-assay coefficients of variation were 7.8 and $9.0 \%$, respectively. All samples from an individual were analyzed in the same assay to reduce sources of variability. Ten extreme cortisol values (>1600 ng/dl) were considered physiologically abnormal and deleted from the dataset before statistical analysis (two samples from one patient and eight samples from four control subjects).

\subsection{Statistical analyses}

Because experience sampling observations are nested within days within participants, we estimated the effects of daily events and clinical characteristics on cortisol secretion with multilevel or hierarchical linear regression methods, using the program MLwiN (Goldstein et al., 1998). A natural log transformation of the raw cortisol values yielded an unskewed response variable. The regression equation for cortisol at the beep level can be expressed as follows:

$$
(\text { Log Cort })_{i j t}=b_{0}+\sum_{q=1}^{Q} b_{q} x_{q i j t}+e_{i j t}
$$

where Log Cort $_{i j t}$ is the log-transformed cortisol level of participant $i$ at the $t$-th beep on day $\mathrm{j}$. The intercept is denoted by $\mathrm{b}_{0}, \mathrm{x}_{\mathrm{qijt}}$ is an entry of explanatory variable $x_{q}, b_{q}$ is the corresponding regression coefficient, and $e_{i j t}$ is an error term. The error term $e_{i j t}$ is itself a function of error terms that capture the dependencies among the cortisol measurements. Such dependencies occur because two observations tend to be more similar if (a) taken at points closer in time on the same day, (b) taken on the same day rather than on two different days, and (c) taken from one participant rather than from different participants. To account for these sources of dependency, we (a) modelled the autocorrelation between two subsequent observations as an exponentially decaying function of the time interval between these observations, (b) estimated day level 
variance to account for day-to-day variability, and (c) estimated person level variance to account for interindividual variability in cortisol levels.

We fitted the diurnal pattern of cortisol secretion by a fourth-degree time polynomial. Fixed effects estimated at the beep level controlled for potential confounders; these were included in the final model only if their effect on cortisol was statistically significant. The secretory peak in cortisol that occurs after morning awakening was modelled by including a variable coded as 1 if the sample was collected less than $60 \mathrm{~min}$ after awakening and 0 otherwise. The other potential confounders at the beep level (food intake, physical exertion, smoking, alcohol, coffee) were also dummy-coded (code 1 if present in the interval preceding the beep).

To test our main hypotheses, we included the following independent variables: group ( 1 if bipolar patient, 0 if healthy control), age (centered around overall mean), gender ( 1 if female, -1 if male), negative event ( 1 if a negative event had occurred, and 0 otherwise), and positive event ( 1 if a positive event had occurred, and 0 otherwise). To examine differences between groups in cortisol diurnal slopes and cortisol reactivity we estimated the interaction effects of group with time (linear), with negative events, and with positive events.

The intra-individual error was used as a measure of the within-person variability of cortisol secretion in bipolar patients and healthy controls. In the multilevel model, intra-individual error is characterized by two components: beep-level variance (which reflects the spread of cortisol values around an individual's mean at each time of the day) and autocorrelation (which reflects the strength of sampleto-sample cortisol associations within the day). Likelihood ratio tests were applied to investigate whether patients differed from controls on these measures.

To assess moderating effects of clinical characteristics in bipolar disorder, we next included the following three variables: number of previous episodes (centered around overall mean); severity of depressive symptoms; and severity of manic symptoms (both symptom scores standardized within the sample). Clinical variables were modelled as interactions with bipolar disorder; results thus represent effects of clinical characteristics within the patient group. Interactions of the three clinical variables with linear time (diurnal slope effects) and with positive and negative events (reactivity effects) were also estimated. The various medications used by the bipolar patients could potentially confound the effects of clinical characteristics on cortisol; this was partially controlled for by adding type of medication ( 1 if lithium only, -1 if otherwise) to the model.

To test the significance of the regression coefficients, zscores were calculated by dividing the estimated effect by its standard error. This ratio is approximately normally distributed. Two-tailed tests were used even when hypotheses were directional. Significance levels were set at alpha $=0.05$. 


\section{Results}

\subsection{Descriptive characteristics}

Of the 78 initial participants (39 patients and 39 controls), four (three patients and one control) were excluded from the analyses due to drop-out or inadequate volume of saliva. None of the participants was excluded from the study because of one of the other exclusion criteria. The final sample thus consisted of 36 patients (of whom $18 \mathrm{men}$ ) and 38 controls (of whom $15 \mathrm{men}$ ). Use of medication in the patient group was as follows: 15 patients received only lithium; the others used various combinations of drugs as follows: lithium ( $\mathrm{n}=$ 19), carbamazepine $(n=3)$, valproate $(n=3)$, serotonin reuptake inhibitors $(n=$ $5)$, neuroleptics $(n=5)$, benzodiazepines $(n=6)$, oral contraceptives $(n=3)$, antihypertensive drugs $(\mathrm{n}=4)$ and others. Of the 36 patients, 19 reported using tobacco. In the control group there were six oral contraceptive users and ten smokers. As shown in Table 1, the two groups were similar in age, but bipolar subjects had a lower mean level of education, were less often married or living with a partner, and were less frequently in paid employment. Remitted bipolar patients did not differ from control subjects in total frequencies and appraised stressfulness of either negative events or positive events. For details concerning frequencies and appraisals of events, see Havermans et al. (2007). In total, the subjects completed 3574 valid responses ( $80 \%$ of all programmed beeps) with both a complete ESM report and a cortisol measure. 
Table 1. Descriptive measures for bipolar patients and controls.

\begin{tabular}{|c|c|c|c|c|}
\hline & Patients & Controls & Test statistic & $\boldsymbol{P}$ \\
\hline & $N=36$ & $N=\mathbf{3 8}$ & & \\
\hline Age, mean (SD) & $45.9(9.7)$ & $44.4(11.7)$ & $t=0.61$ & 0.55 \\
\hline Sex ratio $(M / F)$ & $18 / 18$ & $15 / 23$ & $x^{2}=0.83$ & 0.36 \\
\hline Education $(\mathrm{N}, \%)$ & & & $x^{2}=8.08$ & 0.02 \\
\hline Elementary school & $10(28 \%)$ & $3(8 \%)$ & & \\
\hline Secondary school & $14(39 \%)$ & $11(29 \%)$ & & \\
\hline Higher education & $12(33 \%)$ & $24(63 \%)$ & & \\
\hline Marital status (N, \%) & & & $x^{2}=7.75$ & 0.02 \\
\hline Married or living together & $20(56 \%)$ & $31(82 \%)$ & & \\
\hline Never married & $10(28 \%)$ & $2(13 \%)$ & & \\
\hline Divorced or widowed & $6(17 \%)$ & $5(5 \%)$ & & \\
\hline Work situation (N, \%) & & & $x^{2}=28.85$ & $<0.001$ \\
\hline Household & $10(28 \%)$ & $3(8 \%)$ & & \\
\hline Regular job or education & $8(22 \%)$ & $32(84 \%)$ & & \\
\hline Disabled, unemployed, or retired & $18(50 \%)$ & $3(8 \%)$ & & \\
\hline Negative event frequencies ${ }^{a}$ & $17.0(18.1)$ & $15.4(13.2)$ & $t=0.43$ & 0.67 \\
\hline Positive event frequencies ${ }^{a}$ & $37.3(25.6)$ & 32.7 (25.7) & $t=0.77$ & 0.45 \\
\hline Stressfulness of negative events ${ }^{b}$ & $4.1(1.6)$ & $3.6(1.4)$ & $t=1.46$ & 0.15 \\
\hline Stressfulness of positive events ${ }^{b}$ & $1.9(0.9)$ & $1.9(0.8)$ & $t=0.007$ & 0.99 \\
\hline
\end{tabular}

a Event frequencies are expressed as mean (SD) percentage of valid ESM responses.

b Appraised stressfulness of events were rated on 7-point scales and are presented as mean (SD), scores were calculated on subgroups of participants because two patients and two controls reported no negative or positive events during the sampling period, and three additional patients reported no negative events.

\subsection{Diurnal cortisol levels and reactivity to daily events}

Results of the multilevel regression analysis are summarized in Table 2. Mean cortisol levels in patients did not differ from healthy controls, but the slope of the diurnal curve was less steep in the patient group (as indicated by the significant group by time interaction). As expected, negative events were associated with higher cortisol levels, with larger increases when the event was appraised as more stressful. Cortisol reactivity to negative daily events was similar in patients and controls. 
Table 2. Multilevel regression estimates for effects of remitted bipolar disorder diagnosis and clinical characteristics on daily salivary cortisol levels, diurnal slopes, and reactivity to negative daily events.

\begin{tabular}{|c|c|c|c|c|c|}
\hline & $\beta$ & SE & $\mathbf{Z}$ & $\mathbf{p}$ & Interpretation (raw cortisol levels) ${ }^{a}$ \\
\hline Constant (model intercept) & 4.842 & 0.059 & 82.49 & $<0.001$ & $127 \mathrm{ng} / \mathrm{dl}$ at mean sampling time in controls \\
\hline Time of day (diurnal slope) & -0.081 & 0.006 & 13.33 & $<0.001$ & $8.4 \%$ decrease per hour in controls \\
\hline Recent awakening & 0.157 & 0.044 & 3.58 & $<0.001$ & $17 \%$ increase if awakening $<60 \mathrm{~min}$ ago \\
\hline Food intake & 0.090 & 0.015 & 5.92 & $<0.001$ & $9.4 \%$ increase if food intake $<90 \mathrm{~min}$ ago \\
\hline Negative event reactivity & 0.137 & 0.031 & 4.50 & $<0.001$ & $14.7 \%$ increase after daily event \\
\hline Age & 0.00084 & 0.0049 & 0.17 & 0.87 & Age unrelated to cortisol levels \\
\hline Bipolar disorder (BD) & 0.048 & 0.081 & 0.60 & 0.55 & BD diagnosis unrelated to cortisol levels \\
\hline BD $x$ time of day & 0.014 & 0.0046 & 2.92 & 0.004 & $\begin{array}{l}6.9 \% \text { decrease per hour (diurnal slope flatter } \\
\text { than controls) }\end{array}$ \\
\hline $\mathrm{BD} \times$ negative event & -0.066 & 0.047 & 1.40 & 0.16 & $\begin{array}{l}\text { No difference from controls in cortisol } \\
\text { reactivity }\end{array}$ \\
\hline \multicolumn{6}{|l|}{ Clinical characteristics } \\
\hline Number previous episodes & 0.019 & 0.0088 & 2.18 & 0.03 & $\begin{array}{l}10.0 \% \text { increase in cortisol level for each five } \\
\text { episodes }\end{array}$ \\
\hline $\begin{array}{l}\text { Number previous } \\
\text { episodes } \mathrm{x} \text { time of day }\end{array}$ & 0.00098 & 0.00048 & 2.06 & 0.04 & $\begin{array}{l}\text { Decrease per hour } 0.5 \% \text { less for each five } \\
\text { episodes (flatter slope) }\end{array}$ \\
\hline $\begin{array}{l}\text { Number previous } \\
\text { episodes } \mathrm{x} \text { negative event }\end{array}$ & -0.010 & 0.0047 & 2.23 & 0.02 & Reactivity $5.1 \%$ less for each five episodes \\
\hline Depressive symptoms (HRSD) & 0.022 & 0.024 & 0.89 & 0.38 & $\begin{array}{l}\text { No effect of residual symptoms on cortisol } \\
\text { levels }\end{array}$ \\
\hline HRSD $x$ time of day & 0.0075 & 0.0015 & 5.13 & $<0.001$ & $\begin{array}{l}\text { Decrease per hour } 0.75 \% \text { less per SD } \\
\text { increase HRSD (flatter slope) }\end{array}$ \\
\hline HRSD $x$ negative event & -0.014 & 0.017 & 0.83 & 0.41 & No effect of residual symptoms on reactivity \\
\hline
\end{tabular}

Note: Model estimates are based on 3574 log cortisol measurements nested within 74 participants. Regression coefficients are unstandardized. The variable time (h) is centered around the grand mean, so that the model intercept represents log cortisol in healthy controls at the midpoint of the sampling times (3:10 p.m.). All time polynomials $\left(\mathrm{time}^{2}, \mathrm{time}^{3}\right.$, and time $\left.{ }^{4}\right)$ were highly significant ( $\mathrm{p}$ $<0.001$ ). Diurnal slope refers to the linear effect of the variable time; the main effect refers to diurnal slope in the control group, whereas interaction effects model diurnal slope in the patient group and in relation to clinical variables. In preliminary models, the following variables had no significant effects (all $p$ values $>0.10$ ) and were therefore excluded from the final model: (beep level) recent positive event, physical exertion, smoking, alcohol, coffee; (person level) gender, type of medication, manic symptoms. Although its effects were non-significant, age was retained in the model to rule out possible confounding of the effects of number of episodes.

The estimated relative effects of clinical characteristics are cumulative. As an example, remitted bipolar patients as a group had flatter diurnal cortisol slopes than the control group, but patients with many previous episodes were estimated to display even flatter diurnal cortisol slopes than bipolar patients with few previous episodes. Similarly, higher depressive symptoms in such participants would result in an even flatter diurnal slope estimate.

a $\%$ Change in raw cortisol per unit change in predictor $=[\exp (\beta)-1]$. 
Food intake and recent awakening were included in the final model due to their association with higher cortisol levels. None of the other potential confounders had statistically significant effects. Positive daily events, gender, and the interactions of age with group, with negative event and with positive event were also excluded from the final model because they had no significant effects on cortisol levels.

\subsection{Relationship between clinical variables and cortisol secretion}

We next examined whether cortisol levels and cortisol reactivity to daily events within the patient group were related to clinical characteristics (see lower part of Table 2). Patients with more previous episodes had higher mean cortisol levels, flatter cortisol diurnal slopes, and a blunted response to negative events compared to patients with fewer episodes. Multilevel regression results also revealed flatter diurnal slopes in patients with greater depressive symptomatology (HRSD score). Subsyndromal manic symptoms (YMRS score) and type of medication had no significant effects and were excluded from the final multilevel model.

We next performed a series of post hoc analyses to further investigate the possibility that the relation between previous episodes and salivary cortisol was confounded by the different medications patients used. If such a confounding effect is present, one would expect that patients using a specific medication would have a different number of previous episodes than patients not using that medication. Using twotailed Mann-Whitney U-tests, we found no significant differences $(p s \geq 0.40)$ in the number of previous episodes between the following subgroups: the 15 patients using lithium only (median $=6$; range $1-18$ ) compared to the 21 patients on various kinds of medication (median $=8$; range 1-38); the five patients using an SSRI (median = 6; range 5-12) compared to the 31 patients not using an SSRI (median $=7$; range 1-38); the five patients using a neuroleptic drug (median $=7$; range $5-38$ ) compared to the 31 patients not using a neuroleptic drug (median $=7$; range 1-18); and the three female patients using oral contraception (median $=7$; range $1-10$ ) compared to the 15 female patients not using oral contraception (median $=7$; range 1-17). These results indicate that the relation between previous episodes and cortisol variables is not explained by differences in the use of medication or oral contraception.

\subsection{Intra-individual variability of cortisol secretion}

Patients showed significantly lower autocorrelations than controls $(p<0.001)$, but the within-person variance was similar in the two groups. To assess the robustness of these multilevel model findings, we also estimated person-specific 
beep-level variances and autocorrelation coefficients (Diggle et al., 2002) by running a separate regression for each subject. We tested whether the personspecific beep-level variances and autocorrelations differed for the two groups by two-tailed Mann-Whitney U-tests. Again, the autocorrelation in the patient group was significantly lower than in the controls (patients: mean $=0.09$, range -0.34 to 0.52 ; controls: mean $=0.21$, range -0.21 to $0.73 ; p=0.03$ ), whereas the individual variance estimates were similar (patients: mean $=.18$, range $0.07-$ 0.51 ; controls: mean $=0.17$, range $0.05-0.38$ ). These findings indicate that cortisol secretion in bipolar patients was less stable over successive measures within a day, although the spread of cortisol values over the 6-day period was similar.

Because many previous episodes and (to a lesser extent) current depressive symptoms were associated with cortisol secretion, we examined whether these two clinical variables were also related to differences in cortisol variance and autocorrelation estimates in the patient group. However, no significant associations were found.

\section{Discussion}

The main findings of the present study point to subtle alterations in cortisol secretory patterns in remitted bipolar disorder: although daytime cortisol levels and reactivity to daily stressors appeared to be normal, patients showed flatter diurnal slopes and lower autocorrelation between successive cortisol measures than the healthy comparison group. In patients with many previous episodes, disturbances in cortisol secretory patterns appeared to be more widespread, with higher overall cortisol levels, even flatter diurnal slopes, and reduced cortisol reactivity to daily stressors.

The normal daytime levels of cortisol observed in the present study add to the body of evidence that hypercortisolism is not a characteristic of remitted bipolar patients as a group. The findings replicate and extend those of Deshauer et al. (2006), who found no differences in basal salivary cortisol levels in a small sample of remitted bipolar patients and healthy controls, sampled six times a day on three separate weekend days. It should be noted that we measured cortisol only during the daytime and thus were not able to chart cortisol levels during sleep. Cervantes et al. (2001) studied 24-h plasma cortisol secretion under laboratory conditions in three groups of bipolar patients (depressed, hypomanic and remitted) and healthy controls. In this case, bipolar patients showed significant cortisol hypersecretion during both depressed and hypomanic phases; in remitted patients, however, overall cortisol levels (as estimated by the area under the curve) were not significantly different from healthy controls (Cervantes et al., 2001). Taken together, these findings provide no firm evidence of cortisol hypersecretion in remitted bipolar disorder. 
Contrary to expectation, cortisol reactivity to daily negative events was similar in patients and healthy controls. In this respect, the HPA axis in remitted bipolar patients appears to be functionally intact. It is possible, however, that other relevant parameters of the stress response, such as delayed recovery, may be more sensitive measures of cortisol dysregulation than the size of the cortisol response itself. A meta-analysis of studies examining cortisol responses to psychological stressors in depressed patients demonstrated that these patients had slower recovery of cortisol levels following stress than healthy controls (Burke et al., 2005). This was most pronounced in more severely depressed individuals. Because determining the speed with which cortisol levels return to pre-stress levels following an acutely stressful event is virtually impossible in the context of an ESM study, studies of response to experimental psychosocial stressors in remitted bipolar disorder are needed. Another potential indicator of disturbed cortisol reactivity is the cortisol awakening response. This response may be either blunted (Stetler and Miller, 2005) or heightened (Vreeburg et al., 2009) in individuals with current or remitted depressive disorder, and it is possible that this aspect of HPA axis reactivity might have revealed differences between remitted bipolar patients and controls. To our knowledge, however, only one study has investigated the cortisol awakening response in remitted bipolar patients in comparison to healthy controls, and no differences between the two groups were found (Deshauer et al., 2006). Another interesting topic would be the impact of chronic stressors on the HPA axis. Increased levels of chronic stress have been reported in the offspring of parents with bipolar disorder (Ostiguy et al., 2009), and chronic stress has been reported to moderate the impact of stressful events on cortisol secretion in healthy young women (Marin et al., 2007). The possible influence of chronic stressors on cortisol secretion in remitted bipolar patients, however, was beyond the scope of the present study.

Bipolar patients showed some flattening of the diurnal cortisol slope, especially in individuals with many previous episodes or current depressive symptoms. Although the effect we observed was subtle (reflected in the small absolute value of the interaction term in the multilevel regression analysis), this may indicate a partial loss of regulatory control over the normal circadian rhythmicity in cortisol secretion. Naturalistic studies on individuals with depressive symptoms also point to disturbances in circadian cortisol rhythmicity, with some studies reporting a flatter diurnal secretory slope, reflecting lower morning levels or, more frequently, higher evening levels (van den Bergh and van Calster, 2009); in other outpatient samples, diurnal curves appeared to be normal (Peeters et al., 2004).

Patients also had lower mean autocorrelations, indicating that cortisol secretion was less stable over successive measurements. This could not be attributed to the influence of daily stressors, as this was controlled for in the analysis. Moreover, both exposure to these stressors as well as their effects on 
cortisol were similar in patient and control groups. The pathophysiological significance of a more fluctuating pattern of cortisol secretion remains to be determined. More information is needed, for example, about patterns of cortisol pulsatility in this disorder; the sampling frequency in the present study was too low for this level of analysis (Posener et al., 2004; Young et al., 2004b).

The most extensive signs of HPA dysregulation were found in patients with many previous episodes. Studies have shown that the risk of recurrence increases with the number of previous episodes (Kessing et al., 1998). This progressive course might be a manifestation of the illness process itself, with each episode lowering the threshold for developing the next episode, as has been proposed in the sensitization and kindling theory (Post, 1992). The mechanism by which episodes have a long-lasting influence on vulnerability for recurrence remains to be elucidated. The current findings are consistent with the hypothesis that progressive HPA dysregulation is part of the pathophysiology of bipolar affective disorder (Cousins and Young, 2005). Alternatively, some preexisting vulnerability, stemming for example from genetic factors or childhood adversity, might underly both a more pernicious illness course and more profound HPA axis dysregulation. Prospective studies are needed to clarify this.

This study had some limitations. First, we have no way of checking the accuracy of subjective daily event reports. Second, although we have interpreted the multilevel regression results in terms of cortisol reactivity to daily events, causal relationships cannot be firmly established with ESM data. Third, as noted under Section 2.1, all patients were taking mood stabilizers and other medications in accordance with standard clinical practice. Many pharmaceutical agents are capable of directly or indirectly affecting the HPA axis and the secretion of salivary cortisol, among them serotonin reuptake inhibitors, neuroleptics, and oral contraception (Granger et al., 2009). The sample size of the present study did not allow us to add all the various kinds of medication as potential confounding factors to the analysis, and thus we cannot rule out the possibility that they influenced cortisol secretion. This would be of the greatest concern if the bipolar patients with the most previous episodes were currently receiving different medications than those with fewer previous episodes, and this was not the case. Most patients used lithium, which is unlikely to have masked existing hypercortisolism in the patient group; an early study showed no effect of longterm lithium treatment on cortisol levels (Sachar et al., 1970), and lithium has been reported to increase rather than decrease HPA axis activity in the first weeks following administration (Bschor et al., 2002). Moreover, we found no differences between patients who used lithium as monotherapy and patients who used various combinations of medication in the secretion of salivary cortisol. To elucidate the effects of medication on the HPA axis in remitted bipolar patients, prospective studies are needed.

In summary, the results of the present study provide additional evidence of subtle HPA axis dysregulation in remitted bipolar affective disorder. Findings 
also indicate that some measures may be more sensitive to detect HPA axis abnormalities than others. Specifically, among remitted bipolar patients, increased basal cortisol levels and blunted responses to daily stressors were demonstrated only in patients with many previous episodes, a subgroup known to be particularly vulnerable to relapse. Other indicators of HPA axis dysregulation, such as delayed recovery of cortisol levels following experimental psychosocial stressors (Burke et al., 2005), disturbed response to DEX/CRH tests (Watson et al., 2004), a flattened diurnal cortisol rhythm (present study), or a more fluctuating pattern of cortisol secretion (present study) may be more widespread. Our findings suggest that treatments targeting HPA axis dysregulation in bipolar disorder warrant further exploration, especially in patients with many previous episodes.

Role of funding source

None.

Conflict of interest

There are no conflicts of interest.

Acknowledgements

We thank Dr. José Sulon, University of Liège, Belgium, for performing the cortisol assays, and Truda Driesen, Lilly Finders, and Frieda van Goethem for research assistance. 


\section{References}

Bschor, T., Adli, M., Baethge, C., Eichmann, U., Ising, M., Uhr, M., Modell, S., Künzel, H., MüllerOerlinghausen, B., Bauer, M., 2002. Lithium augmentation increases the ACTH and cortisol response in the combined DEX/CRH test in unipolar major depression. Neuropsychopharmacology 27, 470-478.

Burke, H.M., Davis, M.C., Otte, C., Mohr, D.C., 2005. Depression and cortisol responses to psychological stress: a meta-analysis. Psychoneuroendocrinology 30, 846-856.

Cassidy, F., Ritchie, J., Carroll, B., 1998. Plasma dexamethasone concentration and cortisol response during manic episodes. Biol. Psychiatry 43, 747-754.

Cervantes, P., Gelber, S., Ng Ying Kin, F., Nair, V., Schwartz, G., 2001. Circadian secretion of cortisol in bipolar disorder. J. Psychiatry Neurosci. 26, 411-416.

Cousins, D.A., Young, A.H., 2005. Is the hypothalamic-pituitary- adrenal axis at last paying dividends? In: Cousins, D.A., Young, A.H. (Eds.), Bipolar Disorder: The Upswing in Research and Treatment. Taylor \& Francis, London, pp. 115-122.

Csikszentmihalyi, M., Larson, R., 1987. Validity and reliability of the experience-sampling method. J. Nerv. Ment. Dis. 175, 526-536.

Daban, C., Vieta, E., Mackin, P., Young, A.H., 2005. Hypothalamic- pituitary-adrenal axis and bipolar disorder. Psychiatr. Clin. North Am. 28, 469-480.

deVries, M.W. (Ed.), 1992. The Experience of Psychopathology: Investigating Mental Disorders in their Natural Settings. Cambridge University Press, Cambridge.

Depue, R.A., Kleiman, R.M., Davis, P., Hutchinson, M., Krauss, S.P., 1985. The behavioral high-risk paradigm and bipolar affective disorder. VIII. Serum free cortisol in nonpatient cyclothymic subjects selected by the General Behavior Inventory. Am. J. Psychiatry 142, 175-181.

Deshauer, D., Grof, E., Alda, M., Grof, P., 1999. Patterns of DST positivity in remitted affective disorders. Biol. Psychiatry 45, 1023-1029.

Deshauer, D., Duffy, A., Meaney, M.S.S, Grof, P., 2006. Salivary cortisol secretion in remitted bipolar patients and offspring of bipolar patients. Bipolar Disord. 8, 345-349.

Diggle, P.J., Heagerty, P.J., Liang, K.Y., Zeger, S.L., 2002. Analysis of Longitudinal Data. Oxford University Press, New York.

Ellenbogen, M., Hodgins, S., Walker, C.-D., Couture, S., Adam, S., 2006. Daytime cortisol and stress reactivity in the offspring of parents with bipolar disorder. Psychoneuroendocrinology 31, 1164-1180.

First, M.B., Spitzer, R.L., Gibbon, M., Williams, J.B.W., 1996. Structured Clinical Interview for DSM-4 Axis 1 Disorders--Patient Edition (SCID-I/P version 2.0) Biometrics Research Department, New York.

Goldstein, H., Rasbash, J., Plewis, I., Draper, D., Browne, W., Yang, M., Woodhouse, G., Healy, M., 1998. A User's Guide to MLwiN. Multilevel Models Project. Institute of Education, University of London, London.

Granger, D.A., Hibel, L.C., Fortunado, C.K., Kapelewski, C.H., 2009. Medication effects on salivary cortisol: tactics and strategy to minimize impact in behavioral and developmental science. Psychoneuroendocrinology 34, 1437-1448.

Hamilton, M., 1960. A rating scale for depression. J. Neurol. Neurosurg. Psychiatry 23, 56-62.

Havermans, R., Nicolson, N.A., deVries, M.W., 2007. Daily hassles, uplifts, and time use in individuals with bipolar disorder in remission. J. Nerv. Ment. Dis. 195, 745-751.

Kessing, L.V., Andersen, P.K., Mortensen, P.B., Bolwig, T.G., 1998. Recurrence in affective disorder. I. Case register study. Br. J. Psychiatry 172, 23-28.

Kirschbaum, C., Hellhammer, D.H., 1994. Salivary cortisol in psychoneuroendocrine research: recent developments and applications. Psychoneuroendocrinology 19, 313-333.

Leverich, G.S., Post, R.M., 1996. Life charting the course of bipolar disorder. Curr. Rev. Mood Anxiety Disord. 1, 48-61.

Linkowski, P., Kerkhofs, M., van Onderbergen, A., 1994. The 24-hour profiles of cortisol, prolactin, and growth hormone secretion in mania. Arch. Gen. Psychiatry 51, 616-624. 
Marin, T.J., Martin, T.M., Blackwell, E., Stetler, C., Miller, G.E., 2007. Differentiating the impact of episodic and chronic stressors on hypothalamic-pituitary-adrenocortical axis regulation in young women. Health Psychol. 26, 447-455.

Ostiguy, C.S., Ellenbogen, M.A., Linnen, A.M., Walker, E.F., Hammen, C., Hodgins, S., 2009. Chronic stress and stressful life events in the offspring of parents with bipolar disorder. J. Affect. Disord. 114, 74-84.

Peeters, F., Nicholson, N.A., Berkhof, J., 2003. Cortisol responses to daily events in major depressive disorder. Psychosom. Med. 65, 836-841.

Peeters, F., Nicolson, N.A., Berkhof, J., 2004. Levels and variability of daily life cortisol secretion in major depression. Psychiatry Res. 126, 1-13.

Posener, J.A., DeBattista, C., Veldhuis, J.D., Province, M.A., Williams, G.H., Schatzberg, A.F., 2004. Process irregularity of cortisol and adrenocorticotropin secretion in men with major depressive disorder. Psychoneuroendocrinology 29, 1129-1137.

Post, R.M., 1992. Transduction of psychosocial stress into the neurobiology of recurrent affective disorder. Am. J. Psychiatry 149, 999-1010.

Rybakowski, J., Twardowska, K., 1999. The dexamethasone/corticotropin-releasing hormone test in depression in bipolar and unipolar affective illness. J. Psychiatr. Res. 33, 363-370.

Sachar, E.J., Hellman, L., Kream, J., Fukushima, D.K., Gallagher, T.F., 1970. Effects of lithium-carbonate therapy on adrenocortical activity. Arch. Gen. Psychiatry 22, 304-307.

Schmider, J., Lammers, C.H., Gotthardt, U., Dettling, M., Holsboer, F., Heuser, I.J.E., 1995. Combined dexamethasone/corticotropinreleasing hormone test in acute and remitted manic patients, in acute depression, and in normal controls: I. Biol. Psychiatry 38, 797-802.

Stetler, C., Miller, G.E., 2005. Blunted cortisol response to awakening in mild to moderate depression: regulatory influences of sleep patterns and social contacts. J. Abnorm. Psychol. 114, 697-705.

Thompson, J.M., Gallagher, P., Hughes, J.H., Watson, S., Gray, J.M., Ferrier, I.N., Young, A.H., 2005. Neurocognitive impairment in euthymic patients with bipolar affective disorder. Br. J. Psychiatry 186, 32-40.

van den Bergh, B.R.H., van Calster, B., 2009. Diurnal cortisol profiles and evening cortisol in postpubertal adolescents scoring high on the Children's Depression Inventory. Psychoneuroendocrinology 34, 791-794.

Vreeburg, S.A., Hoogendijk, W.J., van Pelt, J., Derijk, R.H., Verhagen, J.C., van Dyck, R., Smit, J.H., Zitman, F.G., Penninx, B.W., 2009. Major depressive disorder and hypothalamic-pituitary- adrenal axis activity: results from a large cohort study. Arch. Gen. Psychiatry 66, 617-626.

Watson, S., Galagher, P., Ritchie, J.C., Ferrier, I.N., Young, A.H., 2004. Hypothalamic-pituitary-adrenal axis function in patients with bipolar disorder. Br. J. Psychiatry 184, 496-502.

Young, A.H., Gallagher, P., Watson, S., Del-Estal, D., Owen, B.M., Ferrier, I.N., 2004a. Improvements in neurocognitive function and mood following adjunctive treatment with mifepristone (RU-486) in bipolar disorder. Neuropsychopharmacology 29, 1538-1545.

Young, E.A., Abelson, J., Lightman, S.L., 2004b. Cortisol pulsatility and its role in stress regulation and health. Front. Neuroendocrinol. 25, 69-76.

Young, R.C., Biggs, J.T., Ziegler, V.E., Meyer, D.A., 1978. A rating scale for mania: reliability, validity and sensitivity. Br. J. Psychiatry 133, 429-435. 



\section{Chapter 5}

\section{Mood states and reactivity to positive daily events predict episode recurrence in patients with remitted bipolar disorder}

Rob Havermans, Nancy A. Nicolson, Johannes Berkhof, Wolfgang Viechtbauer, Marten W. deVries 
CHAPTER 5 


\section{Introduction}

Bipolar disorder (BD) is characterized by recurring depressive, manic, and hypomanic mood episodes, which often lead to residual symptoms and significant impairments in social functioning even during remitted states (Judd et al., 2002; Paykel et al., 2006; Goldberg and Harrow, 2011). Despite advances in treatment, follow-up studies have estimated the risk of episode recurrence in patients under treatment for BD at 0.4 episodes per year (Angst et al. 2003), with up to $73 \%$ of patients experiencing a relapse over a period of five years (Gitlin et al., 1995). The most robust clinical predictors of recurrence in patients with remitted bipolar disorder are the number of previous episodes and the presence of subsyndromal symptoms (Kessing et al., 1998; Perlis et al., 2006; Tohen et al., 2006; Judd et al., 2008). To better identify and treat patients at high risk for recurrence, it is important to identify additional predictors and improve our understanding of the mechanisms that may be involved.

In a previous paper we reported that the reactivity of negative affect (NA) and positive affect (PA) to daily hassles and uplifts in patients with remitted BD was similar to healthy controls, although mean levels of NA were higher and mean levels of PA were lower (Havermans et al., 2010). Interestingly, within the patient group, the severity of subsyndromal depressive symptoms was associated with increased negative reactivity. Subsyndromal depressive symptoms in $\mathrm{BD}$ are associated with increased risk for depressive relapse (Perlis et al., 2006; Tohen et al., 2006), and we speculated that heightened reactivity to negative daily events may be a contributing factor. Such a reactivity pattern has been demonstrated to predict future increase in depressive symptoms in longitudinal studies of healthy individuals (Wichers et al., 2009), as well as faster recovery in a treated sample of patients with current unipolar depression (Peeters et al., 2010). Such follow-up studies have not been done in BD patients, but preliminary evidence comes from the finding that higher scores on a rating scale for neuroticism in patients with BD were associated with an increased risk for depressive recurrence (Lozano and Johnson, 2001).

Two current theories highlight the importance of PA and its reactivity to environmental stimuli in the course of BD. According to the first theory, as originally formulated by Gray (1973), the behavioral activation system (BAS) regulates approach behavior and PA in response to cues of potential rewards. The BAS is thought to be inadequately regulated in BD, with a trait-like hyperresponsivity making the individual vulnerable to extreme fluctuations of PA (Depue and Iacono, 1989; for a recent formulation, see Urosevic et al., 2008). More recently, Gruber (2011a) has developed an alternative theory, which posits that BD is associated with heightened and persistent positive affect (and associated reward and achievement specific emotions) in response to a variety of contexts. Both theories are supported by a growing number of empirical studies (for reviews, see Alloy and Abramson, 2010; Gruber, 2011b), which are, 
however, constrained by several major limitations. First, most studies have been done on individuals at risk for BD or on nonclinical samples of college students, and results may not apply to middle-aged patients with remitted BD. Second, most reports of heightened positive reactivity are based on laboratory studies or self-reported trait levels of PA reactivity, and may not generalize to PA responses to naturally occurring situations. Third, few studies have explored whether such reports predict future manic recurrence in patients with remitted BD (for a review, see Alloy et al., 2009, pp. 215-216).

To our knowledge, no study has investigated whether affective responses to naturally occurring daily events predict the onset of a manic or depressive recurrence, in a clinical sample of treated patients with remitted BD. We hypothesized that higher levels of NA and heightened reactivity of NA to negative events would predict shorter time to depressive recurrences, whereas higher levels of PA and heightened reactivity of PA to positive daily events would predict shorter time to manic recurrences - over and above established clinical predictors such as the number of previous episodes and the presence of subsyndromal symptoms.

\section{Method}

\subsection{Participants}

Thirty-nine outpatients were recruited from lithium clinics in Maastricht and Sittard, The Netherlands. The main inclusion criterion was a primary diagnosis of Bipolar I or Bipolar II Disorder, without rapid cycling, as assessed with the Structured Clinical Interview for DSM-IV (SCID; First et al., 1996). Additional inclusion criteria were age between 18 and 65 years, in a state of partial or full remission (according to DSM-IV criteria) for more than two months, and under regular treatment including appropriate pharmacotherapy for more than four months. Exclusion criteria were substance abuse in the last year, pregnancy, weight loss exceeding $15 \%$ in the previous six months, endocrine disorders, and insufficient fluency in Dutch. On study entry, 16 patients received monotherapy with lithium; the others used various combinations of psychotropic drugs as follows: lithium ( $n=20)$, carbamazepine $(n=4)$, valproate $(n=2)$, antidepressants $(n=4)$, neuroleptics $(n=7)$, and benzodiazepines $(n=6)$. One patient was later excluded from the analysis because he failed to meet protocol compliance criteria (see below). Participants completed a questionnaire concerning marital status (married or living together; unmarried; divorced or widowed), employment (household; education or paid employment; unemployed), and completed education (primary; secondary; university). The local medical ethics committee 
approved the protocol, and written informed consent was obtained from all participants.

\subsection{Experience sampling procedure and measures}

The Experience Sampling Method (ESM) was used for the self-assessment of daily events and mood states in the context of everyday life (Csikszentmihalyi and Larson, 1987; deVries, 1992; Myin-Germeys et al., 2009). Participants were sampled repeatedly over the day during six consecutive days, including a weekend. A programmed wristwatch emitted auditory signals ('beeps') 10 times a day, at an unpredictable moment roughly centered in each 90-minute time block between 7:30 a.m. and 10:30 p.m. As soon as possible after each beep, participants completed a brief ESM self-report form. A response was defined as valid when the delay between a beep signal and the completion of an ESM form was no more than 20 minutes. All but one of the participants completed 20 or more valid responses, the criterion set for inclusion in the analysis.

Participants who responded affirmatively to the ESM question " Did you experience a positive event or situation since the previous beep?" were asked briefly to describe the event in their ESM booklet. These questions were then repeated with respect to "a negative event or situation." At every beep, participants could thus report no events, a positive event, a negative event, or both a positive and a negative event. Momentary mood states were assessed with 17 adjectives rated on 7-point Likert scales ( 1 not at all, 7 very). Factor analyses (principal components analysis with oblique rotation) on subject mean scores and within-subject $z$-scores both identified two mood factors. Ratings on the items cheerful, enthusiastic, strong, energetic, satisfied, self-assured, happy, and talkative were averaged to form a positive affect (PA) scale. Ratings on the items tense, agitated, edgy, irritated, restless, sad, anxious, distractible, and guilty were averaged to form a negative affect (NA) scale. For more detailed description and validation of the ESM measures, see Havermans et al. (2010).

\subsection{Procedure and assessment of illness course}

In the week preceding the ESM sampling, we used the Life Chart Method (Leverich and Post, 1996) to obtain a detailed history of the course of the disorder, from which the age of onset, the number of previous episodes, and the duration of the current remission were determined. Baseline depressive and manic symptoms were assessed with the 17-item Hamilton Rating Scale for Depression (HRSD; Hamilton, 1960) and the Young Mania Rating Scale (YMRS; Young et al., 1978). After the ESM week, patients entered a two-year longitudinal study, during which they were treated according to standard clinical guidelines. Every six months patients were interviewed, life charts were completed, 
and the mood episode section of the SCID was administered to determine whether a depressive or manic episode had occurred in the previous six months, and to calculate the time from entering the longitudinal study to the onset of any of these episodes. Compliance with the protocol was excellent: all 38 patients who were included in the ESM study also completed the longitudinal study.

\subsection{Statistical analysis}

NA reactivities to negative events and PA reactivities to positive events were derived from a two-level (beeps within persons) multilevel regression model, performed with the MLwiN package (Goldstein et al., 1998). Reactivities were composed of an overall reactivity estimate and a person-specific estimate and fitted as randomly varying slopes and intercepts. Next, person-specific reactivities were obtained using empirical Bayes estimation of the random slopes (Morris, 1983). Thus, we derived for each participant four ESM variables: mean NA level, mean PA level, NA reactivity to negative events and PA reactivity to positive daily events. Separate Cox regression analyses were performed to determine whether these ESM variables predicted time to: (1) a depressive episode, and (2) a manic episode. NA and PA reactivity estimates were standardized. The number of previous episodes and baseline severity of depressive symptoms were controlled for in the analyses by entering them as covariates in a first step. To restrict the number of predictors, baseline severity of subsyndromal manic symptoms was not included in the analyses; statistical control for this variable did not appear necessary in the current sample, due to minimal manic symptoms (with half of the participants showing no subsyndromal manic symptoms: YMRS score $=0$ ). Survival analyses were conducted with SPSS 16.0 (SPSS Inc., Chicago, IL, USA). Statistical significance was assessed with the Wald test, with $p<.05$ considered significant. All tests were two-tailed.

\section{Results}

\subsection{Descriptive statistics}

The ESM procedure was completed by 38 patients (of whom 19 were men). Mean age was 46.2 years $(S D=9.6) ; 11$ had completed only elementary school, 14 had finished secondary school, and 13 had a higher education. Only 8 patients were employed or studying; the others were fulltime homemakers, disabled, unemployed, or retired. Of the patients, 31 had Bipolar I Disorder and 7 Bipolar II Disorder, with a mean age of onset of 29.6 years (range $16-61$ ). The median number of previous episodes (manic and depressive) was 7, ranging from 1 to 38 (manic episodes: median $=3$, range $0-26$; depressive episodes: 
median $=3$, range $0-17$ ). Scores on the symptom scales indicated low levels of subsyndromal symptomatology (depressive (HRSD): mean $=2.9$, range $0-8$; manic $($ YMRS): mean $=1.7$, range $0-10$ ). Correlations between ESM measures and clinical characteristics are shown in Table 1.

Table 1. Correlations (Spearman's rho) between ESM Measures and Clinical Characteristics

\begin{tabular}{lllll}
\hline & Mean NA & Mean PA & $\begin{array}{l}\text { NA } \\
\text { reactivity }\end{array}$ & $\begin{array}{l}\text { PA } \\
\text { reactivity }\end{array}$ \\
\hline Mean PA & $-0.47^{* *}$ & - & - & - \\
NA reactivity & $0.56^{* * *}$ & -0.08 & - & - \\
PA reactivity & -0.27 & -0.18 & -0.12 & - \\
Number of previous episodes & $0.41^{*}$ & $-0.34^{*}$ & 0.09 & -0.10 \\
HRSD score & $0.50^{* *}$ & -0.30 & $0.42^{* *}$ & -0.26 \\
Age of onset & -0.13 & 0.12 & -0.07 & -0.06 \\
Number of months in remission & -0.07 & -0.24 & 0.15 & -0.16 \\
\hline
\end{tabular}

HRSD $=17$-item Hamilton Rating Scale for Depression.

${ }^{*} p<0.05,{ }^{* *} p<0.01,{ }^{* * *} \mathrm{p}<0.001$.

In total, participants completed 1791 valid ESM reports (mean $=47$; range 27 60). Mean frequencies (as a percentage of total valid ESM reports) of negative and positive events were $16.2 \%(S D=18.0 \%)$ and $35.5 \%(S D=26.0 \%)$, respectively. Two patients reported no daily events during the six-day sampling period; an additional three patients reported no negative events but did report positive events. Mean level of NA was 1.6 ( $S D=0.7$ ); mean level of PA was 3.6 $(S D=1.1)$. As expected, positive events were related to subsequent increases in $\mathrm{PA}$, and negative events were followed by increases in NA (for more detailed descriptions and analyses of daily events and mood reactivity patterns, see Havermans et al., 2007; Havermans et al., 2010). During follow-up, 16 of the 38 patients had one or more recurrent mood episodes: of these, 12 patients had one or more depressive episodes (median number of days without depressive recurrence in these patients $=247$, range $66-714$ ), 9 patients had one or more manic episodes (median number of days $=471$, range $30-729$ ).

\subsection{Baseline mood reactivity and prediction of recurrence}

As shown in Table 2, Cox regression analyses revealed that a shorter time to depressive recurrence was predicted by higher mean NA levels (an increase of 1 point on the 7-point Likert scale increased the hazard ratio more than fivefold), whereas higher PA reactivity predicted onset of manic episodes (with an increase of 1 SD in PA reactivity corresponding to a hazard ratio of 2.5). As reported above, a small number of patients reported no positive events $(n=2)$ or no negative events $(n=5)$ during the ESM week. Because, in the absence of 
positive events, the PA reactivity estimates of these patients took the value of the overall estimate, their inclusion in the Cox regression model was not expected to influence the relation between PA reactivity and time to manic recurrence. Repeating the analyses with these two subjects excluded yielded similar results, with PA reactivity remaining a significant predictor of manic recurrence: $(\operatorname{Exp}(B)=2.419, C I 1.047-5.333, p=.03)$.

Table 2. Predictors of depressive and manic episodes (Cox regression)

\begin{tabular}{lllll}
\hline \multirow{2}{*}{ Predictors } & \multicolumn{2}{l}{ Time to depressive episode } & \multicolumn{2}{l}{ Time to manic episode } \\
\cline { 2 - 5 } & Exp (B) & $\mathbf{9 5 \%}$ CI & Exp (B) & $\mathbf{9 5 \% ~ C I ~}$ \\
\hline Number of previous episodes & 0.989 & $0.908-1.077$ & 1.006 & $0.908-1.115$ \\
HRSD score & 1.260 & $0.986-1.609$ & 1.019 & $0.707-1.470$ \\
Mean NA & $5.117^{*}$ & $1.539-17.010$ & 2.706 & $0.700-10.464$ \\
Mean PA & 0.780 & $0.395-1.539$ & 0.746 & $0.338-1.645$ \\
NA reactivity & 0.393 & $0.136-1.139$ & 0.801 & $0.288-2.226$ \\
PA reactivity & 1.586 & $0.835-3.013$ & $2.494^{\dagger}$ & $1.197-5.197$ \\
\hline
\end{tabular}

HRSD = 17-item Hamilton Rating Scale for Depression.

NA and PA reactivity estimates were standardized.

${ }^{*} p<0.01 .{ }^{\dagger} p=0.015$

\section{Discussion}

Results show that intensive sampling of affects and their reactivities to daily events contributed significantly to the prediction of clinical course in patients with remitted BD. In particular, levels of NA and reactivity of PA to daily positive events during the experience sampling week better explained the variance in time to future recurrence than baseline clinical characteristics such as the number of prior episodes and baseline severity of subsyndromal depressive symptoms. Moreover, the present paper adds to the increasing evidence that manic and depressive episodes in $\mathrm{BD}$ are related to different predictors and different pathways (Johnson et al., 2008).

A high level of NA has been characterized as an index of psychological distress and a general characteristic of psychiatric disorders (Watson et al., 1988). The present study suggests that the level of NA is a better predictor than residual symptoms in predicting the course of bipolar disorder. If this finding can be replicated in a larger sample, it would also suggest that high NA levels are more closely related to the mechanism leading to recurrence than a disturbed responsivity of NA to daily events, as this responsivity was not different from healthy individuals (Havermans et al., 2010) and not associated with future recurrences. Our finding that reactivity of PA predicted manic recurrence is in line with the growing literature on the role of PA in bipolar disorder (Alloy and 
Abramson, 2010; Gruber, 2011b). As noted above, most of the research on this topic has been done in nonclinical populations using single-measurement selfreport scales or laboratory tasks. To our knowledge this is the first study that has demonstrated that the regulation of mood under naturalistic conditions is a predictor of clinical course in a clinical sample. This makes ESM a potentially valuable tool in the prediction of the future course of bipolar disorders. Recent technical advances have made this method more feasible for use in clinical practice (Wichers et al., 2011). Information generated by this approach could help to improve current psychosocial treatments aimed at improving the course of bipolar disorders (Nusslock et al., 2007; Johnson and Fulford, 2009).

The strengths of the present study are inherent in the ESM methodology. The intensive sampling of affect ratings and naturally occurring events within the context of normal daily life provides a more reliable and ecologically valid assessment of levels and reactivities of affect than studies using self-report scales or experiments performed under laboratory conditions. The study also had some limitations. Although we have interpreted the multilevel regression results in terms of reactivity of affects to daily events, causal relationships cannot be firmly established with ESM data. Moreover, as noted above, all patients were using various medications in accordance with current practice and accepted guidelines. Although this sample may have been representative of treated outpatients, these medications could have had various effects on the regulation of affect. Sample size precluded a comparison of patterns of affect in patients receiving different types or combinations of pharmacologic treatments. Future studies in larger samples might compare patients with BD taking different classes of medication. Such studies should also allow for the inclusion of other variables that may influence the course of BD, such as treatment compliance, major life events, and cognitive schemas. 


\section{References}

Alloy, L. B. and L. Y. Abramson (2010). The Role of the Behavioral Approach System (BAS) in Bipolar Spectrum Disorders. Curr. Dir. Psychol. Sci. 19: 189-194.

Alloy, L. B., L. Y. Abramson, S. Urosevic, R. E. Bender and C. A. Wagner (2009). Longitudinal Predictors of Bipolar Spectrum Disorders: A Behavioral Approach System (BAS) Perspective. Clin Psychol (New York) 16: 206-226.

Csikszentmihalyi, M. and R. Larson (1987). Validity and reliability of the Experience-Sampling Method. J. Nerv. Ment. Dis. 175: 526-536.

Depue, R. A. and W. G. Iacono (1989). Neurobehavioral aspects of affective disorders. Annu. Rev. Psychol. 40: 457-492.

deVries, M. W., Ed. (1992). The Experience of Psychopathology: Investigating Mental Disorders in their Natural Settings. Cambridge, Cambridge University Press.

First, M. B., R. L. Spitzer, M. Gibbon and J. B. W. Williams (1996). Structured Clinical Interview for DSM-4 axis 1 disorders - Patient edition (SCID-I/P version 2.0). New York, Biometrics Research Department.

Gitlin, M. J., J. Swendsen, T. L. Heller and C. Hammen (1995). Relapse and impairment in bipolar disorder. Am. J. Psychiatry 152: 1635-1640.

Goldberg, J. F. and M. Harrow (2011). A 15-year prospective follow-up of bipolar affective disorders: comparisons with unipolar nonpsychotic depression. Bipolar Disord. 13: 155-163.

Goldstein, H., J. Rasbash, I. Plewis, D. Draper, W. Browne, M. Yang, G. Woodhouse and M. Healy (1998). A User's Guide to MLwiN. London, Multilevel Models Project, Institute of Education, University of London.

Gray, J. A. (1973). Causal theories of personality and how to test them. Multivariate analysis and psychological theory. J. R. Royce. New York, Academic Press: 409-463.

Gruber, J. (2011a). Can feeling too good be bad? Positive emotion persistence (PEP) in bipolar disorder. Curr. Dir. Psychol. Sci. 20: 217-221.

Gruber, J. (2011b). A review and synthesis of positive emotion and reward disturbance in bipolar disorder. Clinical Psychology and Psychotherapy 18: 356-65.

Hamilton, M. (1960). A rating scale for depression. J. Neurol. Neurosurg. Psychiatry 23: 56-62.

Havermans, R., N. A. Nicolson, J. Berkhof and M. W. deVries (2010). Mood reactivity to daily events in patients with remitted bipolar disorder. Psychiatry Res. 179: 47-52.

Havermans, R., N. A. Nicolson and M. W. deVries (2007). Daily hassles, uplifts, and time use in individuals with bipolar disorder in remission. J. Nerv. Ment. Dis. 195: 745-51.

Johnson, S. L., A. K. Cueller, C. Ruggero, C. Winett-Perlman, P. Goodnick, R. White and I. Miller (2008). Life events as predictors of mania and depression in Bipolar I Disorder. J. Abnorm. Psychol. 117: 268-277.

Johnson, S. L. and D. Fulford (2009). Preventing mania: a preliminary examination of the GOALS Program. Behav Ther 40: 103-13.

Judd, L. L., H. S. Akiskal, P. J. Schettler, J. Endicott, J. Maser, D. A. Solomon, A. C. Leon, J. A. Rice and M. B. Keller (2002). The long-term natural history of the weekly symptomatic status of Bipolar I Disorder. Arch. Gen. Psychiatry 59: 530-537.

Judd, L. L., P. J. Schettler, H. S. Akiskal, W. Coryell, A. C. Leon, J. D. Maser and D. A. Solomon (2008). Residual symptom recovery from major affective episodes in bipolar disorders and rapid episode relapse/recurrence. Arch. Gen. Psychiatry 65: 386-394.

Kessing, L. V., P. K. Andersen, P. B. Mortensen and T. G. Bolwig (1998). Recurrence in affective disorder: I. Case register study. Br. J. Psychiatry 172: 23-28.

Leverich, G. S. and R. M. Post (1996). Life charting the course of bipolar disorder. Curr. Rev. Mood Anxiety Disord. 1: 48-61.

Lozano, B. E. and S. L. Johnson (2001). Can personality traits predict increases in manic and depressive symptoms? J. Affect. Disord. 63: 103-11.

Morris, C. (1983). Parametric empirical Bayes inference: theory and applications. Journal of the American Statistical Association 78: 47 - 65. 
Myin-Germeys, I., M. Oorschot, D. Collip, J. Lataster, P. Delespaul and J. van Os (2009). Experience sampling research in psychopathology: opening the black box of daily life. Psychol. Med. 39: 1533-1547.

Nusslock, R., L. Y. Abramson, E. Harmon-Jones, L. B. Alloy and M. E. Hogan (2007). A goal-striving life event and the onset of hypomanic and depressieve episodes and symptoms: perspective from the behavioral approach system (BAS) dysregulation theory. J. Abnorm. Psychol. 116: 105-115.

Paykel, E. S., R. Abbott, R. Morriss, H. Hayhurst and J. Scott (2006). Sub-syndromal and syndromal symptoms in the longitudinal course of bipolar disorder. Br. J. Psychiatry 189: 118-123.

Peeters, F., J. Berkhof, J. Rottenberg and N. A. Nicolson (2010). Ambulatory emotional reactivity to negative daily life events predicts remission from major depressive disorder. Behav. Res. Ther. 48: 754-760.

Perlis, R. H., M. J. Ostacher, J. K. Patel, L. B. Marangell, H. Zhang, S. R. Wisniewski, T. A. Ketter, D. J. Miklowitz, M. W. Otto, L. Gyulai, N. A. Reilly-Harrington, A. A. Nierenberg, G. S. Sachs and M. E. Thase (2006). Predictors of recurrence in bipolar disorder: primary outcomes from the Systematic Treatment Enhancement Program for Bipolar Disorder (STEP-BD). Am. J. Psychiatry 163: 217-24.

Tohen, M., C. L. Bowden, J. R. Calabrese, D. Lin, T. D. Forrester, G. S. Sachs, A. Koukopoulos, L. Yatham and H. Grunze (2006). Influence of sub-syndromal symptoms after remission from manic or mixed episodes. Br. J. Psychiatry 189: 515-9.

Urosevic, S., L. Y. Abramson, E. Harmon-Jones and L. B. Alloy (2008). Dysregulation of the behavioral approach system (BAS) in bipolar spectrum disorders: review of theory and evidence. Clin. Psychol. Rev. 28: 1188-205.

Watson, D., L. A. Clark and G. Carey (1988). Positive and negative affectivity and their relation to anxiety and depressive disorders. J. Abnorm. Psychol. 97: 346-353.

Wichers, M., C. J. Simons, I. M. Kramer, J. A. Hartmann, C. Lothmann, I. Myin-Germeys, A. L. van Bemmel, F. Peeters, P. Delespaul and J. van Os (2011). Momentary assessment technology as a tool to help patients with depression help themselves. Acta Psychiatr. Scand. 124: 262-72.

Wichers, M. C., D. Q. Barge-Schaapveld, N. A. Nicolson, F. Peeters, M. deVries, R. Mengelers and J. van Os (2009). Reduced stress-sensitivity or increased reward experience: the psychological mechanism of response to antidepressant medication. Neuropsychopharmacology 34: 923-31.

Young, R. C., J. T. Biggs, V. E. Ziegler and D. A. Meyer (1978). A rating scale for mania: reliability, validity and sensitivity. Br. J. Psychiatry 133: 429-435. 

Chapter 6

Discussion and concluding remarks 
CHAPTER 6 


\section{Discussion}

The central theme of this thesis was the experience of daily events and their effects on mood states and cortisol in patients with remitted BD, compared to healthy individuals, within the context of normal daily life. We used the experience sampling method (ESM) in combination with intensive salivary cortisol sampling to study the experience of naturally occurring negative and positive daily events, the levels and patterns of mood states and salivary cortisol, and the dynamic interplay between them. Our starting point was that this approach would (1) enrich our understanding of the experience of daily events and their contextual determinants, (2) provide better insight in the psychological and physiological mechanisms that may play a role in the reactivity to environmental stressors, and (3) contribute to better prediction of risk of recurrences. The main findings and their implications for future research are discussed below.

\section{Experience of hassles and uplifts and time use patterns in the context of daily life}

We expected that patients with remitted BD would report more negative daily events and appraise them as more stressful, and would experience fewer positive events, as has been reported in patients with other mood disorders. This expectation was based on the assumption that the experience of past episodes and current subsyndromal symptoms could lead to the generation of stressors, the loss of sources of positive experiences, and the development of a negative cognitive style. Patients and healthy subjects, however, reported similar frequencies of daily hassles and uplifts and did not differ in their perceptions of events in terms of intensity, importance, or stressfulness (Chapter 2). Another study, published in the same year, also found no differences between remitted bipolar patients and a healthy comparison group in the appraisals of daily events, rated at the end of each day during one week (Knowles et al., 2007). There is thus currently no evidence that remitted bipolar patients experience daily events differently from healthy individuals.

In our study, daily events were measured simultaneously with the contexts (activities, social situations, places) in which they occurred. Time use analyses showed that patients were more often alone and at home and spent less time working and more time in passive leisure activities. We also found that this time use pattern was associated with reduced exposure to daily (negative as well as to positive) events. Such a life style could simply reflect the loss of work (as a consequence of previous episodes) and the presence of obstacles to regaining work (e.g., subsyndromal symptoms, cognitive dysfunctions, loss of established work skills, stigma). Its association with daily event frequencies, however, 
suggests that active avoidance of the potential demands of stresses of work and social relationships out of fear for recurrences, reduction in self-esteem or internalised lowered expectations may also play a role. Such negative perceptions have been reported by individuals recovered from an episode of depression (Coyne et al., 1998). In contrast, bipolar patients often report high achievement motivation and ambitious goal setting throughout the life course (for a review, see Johnson and Roberts, 1995). Studies on self-esteem and related cognitive styles in bipolar disorder, however, have provided more differentiated insights. Patients with remitted BD, compared with healthy individuals, have reported lowered general self-esteem associated with lower levels of social adjustment, including work and leisure functioning (Blairy et al., 2004). A daily diary study found that mean levels of self-esteem in patients with remitted BD were similar to a healthy comparison group, although more variable over time, whereas their scores on the pragmatic inference task, an implicit measure of attributional style, revealed more negative self-evaluations (Knowles et al., 2007). Alloy et al., (2009, page 217) reviewed studies on specific cognitive styles in individuals with bipolar spectrum disorders and concluded that these individuals ". . . frequently exhibit maladaptive cognitive styles, even in the euthymic state, as negative as those seen in unipolar depressed persons .. . However, a growing number of studies suggest that it is cognitive styles involving perfectionism, excessive goal striving, self-criticism, and autonomy ... that are uniquely characteristic of risk for bipolar disorder." The authors also reviewed evidence that both negative and positive cognitive styles predict subsequent bipolar mood symptoms and episodes alone or in interaction with life events. A recent study investigated maladaptive cognitive biases (based on schema theory) in patients with remitted BD and comparison groups of healthy individuals, patients with unipolar depression and patients with anxiety disorders. Compared with the other patient groups, schemas related to high achievement and goal striving were particularly elevated in BD, but compared to healthy individuals the BD patients reported high scores on a wide range of maladaptive schemas, related to positive as well as negative self-esteem (Hawke and Provencher, 2012). Another study on patients with remitted BD, using the same instrument, revealed that negative self-schemas (perceived lack of own capability, fearful expectations of future outcomes, social discomfort) were specifically associated with self-reported impairments, including deficits in work ability, social and leisure functioning (Nilsson, 2012).

Taken together, these studies support our suggestion that negative selfperceptions may contribute to functional impairments in remitted BD patients. At the same time, these studies show a paradoxical pattern of extreme (high as well as low) self-perceptions in bipolar patients, which may fluctuate over time, even during periods of remission. Future studies are needed to investigate how these self-perceptions may interact with daily hassles and uplifts in influencing daily functioning. Daily process designs such as ESM are particularly useful to 
disentangle these kinds of interactions. Future longitudinal studies should also explore how these interactions may differentially influence the risk of future depressive and manic episodes and related functional outcomes.

\section{Mood reactivity to daily events and the influence of clinical characteristics}

In both bipolar and comparison groups, negative events were associated with increases in NA and decreases in PA, whereas positive events were followed by decreases in NA and increases in PA. The magnitude of mood changes was strongly associated with the appraised stressfulness of events. The reactivity of negative and positive affect to daily hassles and uplifts in patients with remitted BD was similar to that of healthy individuals, although mean levels of negative affect were higher and mean levels of positive affect were lower (Chapter 3). Within the patient group, subsyndromal depressive symptoms were associated with increased negative mood reactivity. Analyses of the two-year follow-up data revealed that high mean levels of NA during the experience sampling week predicted a shorter time to recurrence of depressive episodes, whereas heightened PA reactivity to positive daily events predicted a shorter time to recurrence of manic episodes (Chapter 5).

Our findings are in line with the results of other studies that indicate that heightened NA reactivity in BD patients is present only when depressive symptoms are present (for reviews, see Chapter 3, and Gruber, 2011). Subsyndromal depressive symptoms in BD are associated with increased risk for depressive relapse (Perlis et al., 2006; Tohen et al., 2006), and we speculated that heightened reactivity to negative daily events might be a contributing factor. In the follow-up part of the present study we could not, however, demonstrate that NA reactivity predicted depressive recurrence in patients with remitted BD. It is important to note that we were unable with these naturalistic data to distinguish between various aspects of mood reactivity, such as the threshold for reactivity, the rise time to peak, the magnitude of the response, and the recovery time (Davidson, 1998). For example, in a recent laboratory study, bipolar patients showed a selective deficit in maintaining increases in NA following exposure to negatively valenced pictures. The authors suggested that this deficit might reflect a tendency to attend selectively to positive stimuli. These findings illustrate that the duration of a mood response may be a more salient component of negative mood dysregulation in BD than the magnitude of the immediate response (Gruber et al., 2012).

Our findings on positive mood reactivity and its relation to illness course are of interest in light of two current theories concerning dysregulation of PA and associated reward-related emotions in BD. According to the first theory, as originally formulated by Gray (1973), the behavioral activation system (BAS) regulates approach behavior and PA in response to cues of potential rewards. The BAS is thought to be inadequately regulated in $\mathrm{BD}$, with a trait-like hyperre- 
sponsivity to relevant environmental stimuli, making the individual vulnerable to extreme fluctuations of BAS activity: excessively high in the presence of hypomanic/manic symptoms and decreased in the presence of depressive symptoms (Depue and Iacono, 1989; Depue and Zald, 1993). In recent years the BAS dysregulation model of BD has been further refined and expanded, by depicting a causal chain of psychological processes (i.e., relevance and efficacy appraisals) leading to manic and depressive states (Urosevic et al., 2008). In addition, the expanded BAS model elaborates the specific nature of BAS-relevant environmental factors: BAS activation-relevant events (e.g., opportunities for attainment of pertinent desires/goals) that will trigger hypomania/mania, and BAS deactivation-relevant events (e.g., failing an exam) that will trigger depression in individuals with bipolar spectrum disorder. More recently, Gruber and colleagues have developed an alternative model of positive emotion disturbance in $\mathrm{BD}$, which posits that $\mathrm{BD}$ is associated with heightened and persistent positive emotions (reward and achievement specific) in response to a variety of contexts (Gruber, 2011b). This second theory, referred to as positive emotion persistence (PEP), further posits specific driving and maintaining mechanisms (i.e., positive rumination) for positive emotion disturbance in BD (Gruber, 2011a). PEP thus differs from the BAS model with respect to the specific psychological processes and the type of events that are thought to be involved.

Both the expanded BAS dysregulation and PEP models predict that increased responsivity of positive emotions to reward stimuli (BAS) or a variety of contexts (PEP) is (1) a trait-like marker of BD and will thus also be present in patients with remitted BD; and (2) predictive of future manic recurrence in these patients. Strong support for the BAS hypotheses comes from the Longitudinal Investigation of Bipolar Spectrum Disorders (LIBS) Project (Alloy et al., 2012a). This project used a behavioral high-risk research design, selecting adolescent participants with high versus low risk for bipolar disorder, based on high versus moderate levels of self-reported BAS sensitivity. Prospective findings showed that high BAS sensitivity and high reward responsiveness on a behavioral task at baseline predicted first onset of bipolar spectrum disorder; moreover, these characteristics were also associated with a greater likelihood of progressing from 'soft' bipolar spectrum disorder to a more severe bipolar (BD-I or BD-II) diagnosis (Alloy et al., 2012a; Alloy et al., 2012b). Additional support for the BAS hypotheses comes from studies on clinical patients with remitted BD. Although the results of cross-sectional studies demonstrate that patients with remitted BD differ from healthy individuals in some but not all measures of BAS sensitivity, several longitudinal studies have reported that high levels of self-reported BAS sensitivity in these patients were associated with greater risk of manic recurrence during follow up (for a review, see Alloy et al., 2009, pp. 215-216). Empirical support for the PEP hypotheses primarily comes from laboratory studies on high risk groups (defined according to responses on the Hypomanic Personality Scale), demonstrating elevated positive emotion in 
reaction to positive, negative, and neutral stimuli (e.g. Gruber et al., 2008). Findings for clinical BD patients, however, are limited (see Gruber, 2011b, for a review). For example, Gruber et al., (2009) reported higher levels of PA in patients with BD-I compared to a healthy comparison group in experimental memory tasks. This difference, however, only emerged when the analysis controlled for current depressive symptoms.

Our findings partially support the BAS and PEP model. In contrast with these models we found that responsivity of PA to daily events (both positive and negative) in remitted BD patients did not differ from healthy individuals. This underlines that findings in nonclinical populations cannot simply be extended to clinical samples of patients with BD. A clinical sample of middle-aged bipolar patients may have endured more psychosocial problems that reduce opportunities for reward and other positive experiences compared to a younger, nonclinical sample of undergraduates. An alternative explanation for the absence of heightened PA reactivity in our patient group is that we used a composite and dimensional measure of $\mathrm{PA}$, composed of feelings of both pleasure-displeasure and arousal, whereas both BAS and PEP models suggest that specific reward and achievement-related emotions are involved. Finally, most findings of heightened positive responsivity are based on laboratory studies or on retrospective selfreports and may not generalize to reactions to naturally occurring situations like those investigated in the present study. In support of the BAS and PEP models, the present study found that higher PA reactivity in patients with remitted BD was associated with shorter time to manic recurrence. The fact that PA reactivity did not predict depression adds to the growing evidence that manic and depressive recurrences are related to different risk factors and associated pathways. Future studies need to: (1) replicate these findings in a larger sample; (2) examine the various temporal parameters (e.g., rise time to peak, duration) of the affective response; (3) investigate whether heightened PA reactivity in daily life is related to specific positive (e.g. reward-related) events; and (4) explore possible underlying psychological mechanisms and neurobiological pathways that may be part of the causal chain leading to mania (Urosevic et al., 2008; Gruber, 2011a).

\section{Salivary cortisol levels and reactivity patterns}

Simultaneous with the experience sampling we conducted an intensive sampling of salivary cortisol, which allowed us to examine daytime levels and dynamics of cortisol secretion, including the reactivity of this hormone to negative daily events, its diurnal decline, and its degree of random variability. We also investigated whether individual differences in cortisol secretion in the patient group could be explained by the number of previous episodes and the presence of subsyndromal symptoms. Results of the present study indicate that daytime cortisol levels and reactivity to daily stressors in patients with remitted BD were 
not different from a comparison group of healthy individuals (Chapter 4). Within the patient group a larger number of previous episodes was related to higher overall cortisol levels and reduced cortisol reactivity to daily stressors, which suggests that these characteristics of HPA axis dysregulation are present only in a subgroup of patients.

Two recent studies investigating cortisol levels in larger samples of bipolar patients have confirmed that elevated cortisol levels are not a general characteristic of patients with remitted BD. In the first study, Kamali et al., (2012) compared levels of awakening and bedtime salivary cortisol in patients with BD with and without a history of attempted suicide, and a group of healthy individuals. The awakening cortisol level was not different between the three groups, and in the patient groups both cortisol measures were not influenced by symptomatic status. A past history of attempted suicide, however, was associated with a 7.4\% higher bedtime salivary cortisol level in bipolar individuals, whereas there was no significant difference between non-suicidal BD patients and healthy individuals in bedtime salivary cortisol. In the second study, Manenschijn et al., (2012) measured hair cortisol levels (reflecting long-term cortisol secretion) of patients with bipolar disorder and healthy individuals and found no difference between the two groups. The subgroup of patients with age of onset above 30 years, however, had elevated hair cortisol levels compared to the subgroup with age of onset below 30 years and to healthy controls.

In short, whereas some previous studies suggest that HPA axis hyperactivity is a trait characteristic of bipolar disorder (Daban et al., 2005), the results of more recent studies, including the present one, indicate that elevated cortisol levels as well as altered reactivity patterns are present only in particular subgroups of patients with BD. Studies do, however, differ with respect to the specific subgroup that is thought to be involved, and replication therefore is needed before firm conclusions can be drawn. Nevertheless, our finding that a higher number of previous episodes is related to elevated cortisol levels and blunted cortisol responses is interesting in light of the kindling and sensitization theory; this postulates that prior episodes contribute to neurobiological abnormalities, including HPA axis hyperactivity, which in turn increase liability to recurrence (for a recent review, see Post et al., 2012). Evidence that high levels of cortisol and heightened reactivity to daily stressors in patients with remitted $\mathrm{BD}$ are associated with future recurrence would support this hypothesis. The two-year follow-up design of the present study allowed us to examine this. Results of the Cox regression analyses revealed that neither mean cortisol levels nor individual estimates of cortisol reactivity were significantly related to time to manic (mean levels: $p=0.28$; reactivity: $p=0.27$ ) or depressive recurrence (mean levels: $p=0.77$; reactivity: $p=0.73$ ). This suggests that these aspects of HPA axis functioning may be consequences of previous episodes but do not form part of the mechanism underlying vulnerability to recurrence, although the limited sample size does not allow firm conclusions. It is also possible that some 
pre-existing vulnerability, stemming for example from genetic factors or childhood adversity, leads to both HPA axis abnormalities and a pernicious illness course, through independent mechanisms.

In addition to the normal levels and reactivity patterns, bipolar patients in the present study did show some flattening of the diurnal cortisol slope compared to healthy individuals, especially in individuals with many previous episodes or current depressive symptoms. Although the effect we observed was subtle, this may indicate a partial loss of regulatory control over the normal circadian rhythmicity in cortisol secretion. A limitation of our study is that we were able to measure only daytime cortisol levels and thus could only investigate part of the circadian pattern. Patients also had lower mean autocorrelations, indicating that cortisol secretion was less stable over successive measurements. The pathophysiological significance of this pattern of cortisol secretion remains to be determined. More information is needed, for example, about patterns of cortisol pulsatility in this disorder; the sampling frequency in the present study was too low for this level of analysis.

In summary, this and other recent studies reveal that heightened levels of cortisol are not generally present in patients remitted BD and thus are not a trait characteristic of bipolar disorder. Our study adds to these findings by demonstrating normal patterns of cortisol reactivity to naturally occurring daily stressors. In these respects, the HPA axis in remitted bipolar patients appears to be functionally intact. Increased basal cortisol levels and blunted responses to daily stressors were demonstrated only in patients with many previous episodes. Longitudinal studies in a larger sample are needed to determine whether these HPA characteristics are part of the vulnerability to recurrence and mediate the influence of prior episodes on illness course. Future studies should also explore whether other relevant parameters of HPA axis functioning, such as a delayed recovery of cortisol levels following experimental psychosocial stressors (Burke et al., 2005), disturbed response to DEX/CRH tests (Watson et al., 2004), disturbed circadian rhythms (present study), or a more fluctuating pattern of cortisol secretion (present study) are more sensitive indicators of HPA axis dysregulation in patients with BD.

\section{Concluding remarks}

Participants recruited for this project were told that the results of the study would provide a more complete description of the daily life of bipolar patients, would provide better understanding of the mechanisms that are involved in episode recurrence, and might even generate ideas for improving their treatment. Did we fulfil these expectations? Although more research is clearly needed, we believe this question can be answered affirmatively. 
First, the high levels of NA and the low levels of PA, in combination with a withdrawn and passive lifestyle observed in the patient group, add to the picture that the remitted state is not really euthymic, but associated with suboptimal mood, residual symptoms, and sustained impairments. The fact that these characteristics have a negative impact on the quality of life and the future course of BD supports the principle that the optimal goal of treatment is to achieve a sustained state of full remission and restore good psychosocial functioning. At the same time, the present study showed bipolar patient's affect are influenced by daily hassles and uplifts in much the same way as in healthy individuals. This underlines that self-management strategies and rehabilitation techniques aimed at improving mastery of daily living circumstances, may be an important integral part of treatment of BD.

Second, the predictive value of PA reactivity and NA levels with regard to future manic and depressive episodes, respectively, may contribute to better and more differentiated prediction of recurrences. If replicated in a study with a sample large enough to allow controlling for other variables that may influence the risk of recurrences, such as treatment compliance, major life events, and dysfunctional cognitive schemas, these results would help clinicians provide appropriate personalized treatment.

Third, recent studies including the present one have begun to unravel the psychological and physiological mechanisms by which environmental factors may exert their influences on the course of bipolar disorder. The evidence presented suggests that clinical characteristics, such as prior episodes or current depressive symptoms, are associated with specific disturbances in affect regulation and cortisol secretion. These findings can stimulate and direct further research that will help us to better understand how these clinical characteristics make the individual more vulnerable to future relapse. Although this study has focused exclusively on mood and cortisol responses, it is crucial to bear in mind that other pathways such as dysfunctional cognitive schemas, disruptions of daily routines, and sleep loss may also play an important role in the generation of episode recurrences.

Finally, the present study confirms that ESM is a valuable research tool. Recent technical advances have made this method more feasible for use in clinical practice (Wichers et al., 2011). With the help of ESM, clinicians as well as patients themselves can obtain a much more precise picture of daily life experiences and their impact on affect regulation and psychopathological symptoms. Such information could help to improve current psychosocial treatments aimed at improving the course of bipolar disorders (Johnson and Fulford, 2009; Nusslock et al., 2009). 


\section{References}

Alloy, L. B., L. Y. Abramson, S. Urosevic, R. E. Bender and C. A. Wagner (2009). Longitudinal Predictors of Bipolar Spectrum Disorders: A Behavioral Approach System (BAS) Perspective. Clin Psychol (New York) 16: 206-226.

Alloy, L. B., R. E. Bender, W. G. Whitehouse, C. A. Wagner, R. T. Liu, D. A. Grant, S. Jager-Hyman, A Molz, J. Y. Choi, E. Harmon-Jones and L. Y. Abramson (2012a). High Behavioral Approach System (BAS) sensitivity, reward responsiveness, and goal-striving predict first onset of bipolar spectrum disorders: a prospective behavioral high-risk design. J. Abnorm. Psychol. 121: 339-51.

Alloy, L. B., S. Urosevic, L. Y. Abramson, S. Jager-Hyman, R. Nusslock, W. G. Whitehouse and M. Hogan (2012b). Progression along the bipolar spectrum: a longitudinal study of predictors of conversion from bipolar spectrum conditions to bipolar I and II disorders. J. Abnorm. Psychol. 121: 1627.

Blairy, S., S. Linotte, D. Souery, G. N. Papadimitriou, D. Dikeos, B. Lerer, R. Kaneva, V. Milanova, A. Serretti, F. Macciardi and J. Mendlewicz (2004). Social adjustment and self-esteem of bipolar patients: a multicentric study. J. Affect. Disord. 79: 97-103.

Burke, H. M., M. C. Davis, C. Otte and D. C. Mohr (2005). Depression and cortisol responses to psychological stress: a meta-analysis. Psychoneuroendocrinology 30: 846-856.

Coyne, J. C., S. M. Gallo, M. S. Klinkman and M. M. Calarco (1998). Effects of recent and past major depression and distress on self-concept and coping. J. Abnorm. Psychol. 107: 86-96.

Daban, C., E. Vieta, P. Mackin and A. H. Young (2005). Hypothalamic-pituitary-adrenal axis and bipolar disorder. Psychiatr. Clin. North Am. 28: 469-480.

Davidson, R. J. (1998). Affective style and affective disorders: perspectives from affective neuroscience. Cognition and Emotion 12: 307-330.

Depue, R. A. and W. G. Iacono (1989). Neurobehavioral aspects of affective disorders. Annu. Rev. Psychol. 40: 457-492.

Depue, R. A. and D. H. Zald (1993). Biological and environmental processes in nonpsychotic psychopathology: a neurobehavioral perspective. Basic Issues in Psychopathology. C. G. Costello. New York, The Guilford Press: 127-237.

Gray, J. A. (1973). Causal theories of personality and how to test them. Multivariate analysis and psychological theory. J. R. Royce. New York, Academic Press: 409-463.

Gruber, J. (2011a). Can feeling too good be bad? Positive emotion persistence (PEP) in bipolar disorder. Curr. Dir. Psychol. Sci. 20: 217-221.

Gruber, J. (2011b). A review and synthesis of positive emotion and reward disturbance in bipolar disorder. Clinical Psychology and Psychotherapy 18: 356-65.

Gruber, J., A. G. Harvey and S. L. Johnson (2009). Reflective and ruminative processing of positive emotional memories in bipolar disorder and healthy controls. Behav. Res. Ther. 47: 697-704.

Gruber, J., S. L. Johnson, C. Oveis and D. Keltner (2008). Risk for mania and positive emotional responding: too much of a good thing? Emotion 8: 23-33.

Gruber, J., A. L. Purcell, M. J. Perna and J. A. Mikels (2012). Letting go of the bad: deficit in maintaining negative, but not positive, emotion in bipolar disorder. Emotion: advance online publication. doi: $10.1037 / \mathrm{a} 0029381$.

Hawke, L. D. and M. D. Provencher (2012). Early maladaptive schemas among patients diagnosed with bipolar disorder. J. Affect. Disord. 136: 803-11.

Johnson, S. L. and D. Fulford (2009). Preventing mania: a preliminary examination of the GOALS Program. Behav Ther 40: 103-13.

Johnson, S. L. and J. E. Roberts (1995). Life events and bipolar disorder: implications from biological theories. Psychol. Bull. 117: 434-449.

Kamali, M., E. F. Saunders, A. R. Prossin, C. B. Brucksch, G. J. Harrington, S. A. Langenecker and M. G. McInnis (2012). Associations between suicide attempts and elevated bedtime salivary cortisol levels in bipolar disorder. J. Affect. Disord. 136: 350-8. 


\section{CHAPTER 6}

Knowles, R., S. Tai, S. H. Jones, J. Highfield, R. Morriss and R. P. Bentall (2007). Stability of self-esteem in bipolar disorder: comparisons among remitted bipolar patients, remitted unipolar patients and healthy controls. Bipolar Disord. 9: 490-5.

Manenschijn, L., A. T. Spijker, J. W. Koper, A. M. Jetten, E. J. Giltay, J. Haffmans, E. Hoencamp and E. F. van Rossum (2012). Long-term cortisol in bipolar disorder: Associations with age of onset and psychiatric co-morbidity. Psychoneuroendocrinology.

Nilsson, K. K. (2012). Early maladaptive schemas and functional impairment in remitted bipolar disorder patients. J. Behav. Ther. Exp. Psychiatry 43: 1104-8.

Nusslock, R., L. Y. Abramson, E. Harmon-Jones, L. B. Alloy and J. A. Coan (2009). Psychosocial Interventions for Bipolar Disorder: Perspective from the Behavioral Approach System (BAS) Dysregulation Theory. Clin Psychol (New York) 16: 449-469.

Perlis, R. H., M. J. Ostacher, J. K. Patel, L. B. Marangell, H. Zhang, S. R. Wisniewski, T. A. Ketter, D. J. Miklowitz, M. W. Otto, L. Gyulai, N. A. Reilly-Harrington, A. A. Nierenberg, G. S. Sachs and M. E. Thase (2006). Predictors of recurrence in bipolar disorder: primary outcomes from the Systematic Treatment Enhancement Program for Bipolar Disorder (STEP-BD). Am. J. Psychiatry 163: 217-24.

Post, R. M., J. Fleming and F. Kapczinski (2012). Neurobiological correlates of illness progression in the recurrent affective disorders. J. Psychiatr. Res. 46: 561-73.

Tohen, M., C. L. Bowden, J. R. Calabrese, D. Lin, T. D. Forrester, G. S. Sachs, A. Koukopoulos, L. Yatham and H. Grunze (2006). Influence of sub-syndromal symptoms after remission from manic or mixed episodes. Br. J. Psychiatry 189: 515-9.

Urosevic, S., L. Y. Abramson, E. Harmon-Jones and L. B. Alloy (2008). Dysregulation of the behavioral approach system (BAS) in bipolar spectrum disorders: review of theory and evidence. Clin. Psychol. Rev. 28: 1188-205.

Watson, S., P. Galagher, J. C. Ritchie, I. N. Ferrier and A. H. Young (2004). Hypothalamic-pituitaryadrenal axis function in patients with bipolar disorder. Br. J. Psychiatry 184: 496-502.

Wichers, M., C. J. Simons, I. M. Kramer, J. A. Hartmann, C. Lothmann, I. Myin-Germeys, A. L. van Bemmel, F. Peeters, P. Delespaul and J. van Os (2011). Momentary assessment technology as a tool to help patients with depression help themselves. Acta Psychiatr. Scand. 124: 262-72. 


\section{Appendix}

\section{The influence of environmental factors on the course of bipolar disorder}

(Adapted and translated from: Rob Havermans en Manon Hillegers (2008) Omgevingsfactoren. In: R.W. Kupka, E.A.M. Knoppert - van der Klein, W.A. Nolen (Eds.) Handboek Bipolaire Stoornissen. Hoofdstuk 10. De Tijdstroom, Utrecht. 


\section{Introduction}

The majority of patients with a bipolar disorder, clinicians, and researchers report that genetic and other biological factors only partially explain the large variability in the course of bipolar disorders. Moreover, research and clinical practice reveal that many patients, despite having optimal pharmacological treatment, show repetitive manic and depressive recurrences, frequent occurrence of interepisodic subsyndromal symptoms, and persistent functional and social disabilities. Research from the past 20 years on the role of environmental factors has mainly focused on the influence of stressful events, social support, and the emotional climate within a family, on the risk of episode recurrence. This research contributes to better insights into the course of bipolar disorders and suggests possible targets for psychosocial treatments.

This chapter covers, in succession, the methodological aspects and the results of recent research concerning the influence of environmental factors on the course of bipolar disorders. Due to the limited scope of this chapter, it is impossible to cover all relevant studies separately. The discussion will concentrate on recently published reviews, which summarize the most important research results (Alloy et al., 2005; Johnson, 2005a). A brief discussion of questions that have not yet been answered and that provide direction for future research, will be followed by a discussion of the relevance of the research results for daily clinical practice.

\section{Methodological aspects}

A number of methodological aspects are essential to the interpretation of research findings concerning the influence of environmental factors on the course of bipolar disorders. These aspects can be exemplified by studies addressing the question of whether a major life event is a risk factor for the recurrence of a mood episode. Similar issues also apply, however, to other factors than life events, and to other outcomes.

A first methodological aspect is the distinction between a risk factor and a cause. To establish that a life event is a risk factor for the recurrence of a mood episode, the presence of a life event has to be statistically correlated with the probability of a mood episode, and the event must precede it. Such a correlation, however, does not imply that the life event is also the cause of the mood episode. For that, it must be demonstrated that manipulation of the life event influences the probability of recurrence. On top of that, it has to be plausible that the correlation found cannot be better explained by the influence of a third variable. This requires experimental studies, which are, however, understandably unethical. The results of psychosocial treatments may provide indirect 
support for the assumption that a life event is of causal influence. These treatments aim to reduce the probability of a recurrence, partially through influencing the occurrence of life events and other environmental factors, as well as changing the way they are coped with. Such a prophylactic treatment provides indirect support for the assumption that these environmental factors are part of the causal chain that leads to episode recurrence.

A second methodological aspect is the unreliability of memory. In many studies, particularly older ones, patients are asked about life events and illness episodes that took place in the past, sometimes in the distant past. However, we know that people more frequently forget life events and episodes the further back in the past they took place. In addition to that, the ability to recall life events takes place in a selective manner. Understandably, many patients have a need to explain the recurrence by attributing it to a stressful event. This tendency, which the literature refers to as effort after meaning, results in people assigning an incorrect date to the events, or reporting mainly the events which they presume played a role in triggering the recurrence. Events that the person thinks are a less relevant for the recurrence are forgotten more quickly or are understated.

A third aspect involves the fact that life events and symptoms mutually influence each other. A problem with retrospective research is that it is difficult to discern whether a life event truly precedes a recurrence or results from the symptoms, or first signs, of a mania or depression. For example, the symptoms of a depressive or manic episode can lead to a conflict with the partner, which the patient then in retrospect unjustifiably sees as the eliciting factor for the recurrence. Even when it is evident that the patient was not in a depressive or manic episode at the time of the conflict, it is difficult to determine retrospectively if the conflict was independent of symptoms, because patients with a remitted bipolar disorder frequently have subsyndromal symptoms that influence daily functioning and interactions with the social environment. This suggests that retrospective research is unable to establish in a reliable way whether a life events is a risk factor of episode recurrence.

A fourth aspect involves the individual differences in the assessment of life events. In many studies, the survey of life events relies on patients' self-report and is carried out using a checklist. The descriptions of the life events portrayed are, however, applicable to very diverse situations and provide much room for subjective interpretation. For example, if someone reports that there was a severe illness in the family, for one person that can mean a partner had a heart attack, whereas for another person it means a nephew had a serious cold.

These and other methodological aspects have led to the use of a longitudinal design in more recent research. This design follows a group of patients over a longer timeframe and the symptomatic course and possible recurrences are registered using standardised interviews. A semi-structured interview is carried out to register the life events periodically. The most commonly used interview 
method is the Life Events and Difficulties Schedule (LEDS) (Brown \& Harris, 1978). Based on a guidebook containing an extensive description of possible life events, this method systematically verifies which life events have taken place, when they took place, and the degree to which they were independent of the disorder itself. The severity of a life event is also assessed as objectively as possible, based on its nature and circumstances. In the present review of studies on the influence of environmental factors on the course of bipolar disorders we shall mainly focus on longitudinal studies that applied standardised life event interviews.

\section{Life events and the course of bipolar disorder}

In the past 20 years, several longitudinal studies have investigated if there is a correlation between the presence of a life event and the probability of an episode recurrence. In these studies, the symptomatic course in a group of patients with a bipolar disorder was followed consistently for a number of years. They also included a detailed structured interview carried out recurrently (usually every three months) to check if any life event had occurred during the previous interval.

Most of the studies were confined to negative life events that are stressful or are generally accompanied by negative emotional reactions. Examples are: the death of a loved one, the loss of a job, having an accident, or a severe illness of a family member. The results of these studies confirm the hypothesis that negative life events are associated with an increased probability of an episode recurrence. For example, it was found that the probability of a recurrence is more than four times as great if a life event had taken place in the preceding period, compared with a period in which that was not the case (Ellicott et al., 1990). Conversely, it was also reported that the probability of the presence of a life event in periods preceding a recurrence is four times as great compared to periods in which no recurrence occurred (Hunt et al., 1992). Another study has reported that an independent, negative life event was a predictor of a slower recovery in patients who were admitted to a psychiatric hospital for a mania or a bipolar depression (Johnson \& Miller, 1997). Patients who experienced a negative life event during the episode had a recovery time that was three times longer than patients who did not experience such an event. Further analysis also showed that the correlation between life events and the pace of recovery could not be explained by the degree to which medication was used effectively. Although effective treatment with medication most certainly influenced the course, it did not protect against the negative influence of life events. 


\section{Life events and mania versus depression}

Most studies on the relationship between life events and the probability of a recurrence unfortunately do not distinguish between a manic episode and a depressive episode. The relevant question is whether bipolar depressions and manias are associated with different types of life events. An obvious hypothesis is that bipolar depressions are related to negative life events such as the experience of loss, because studies on patients with unipolar depressions have consistently found that these types of life events are a significant risk factor for a recurrence. In support of this hypothesis, patients with a bipolar depression report just as many independent, negative life events over the period that precedes the depression as do patients with a unipolar depression. Other studies, however, report no difference in frequency of life events in the period preceding bipolar depression compared with a control period (that was not followed by a bipolar depression) (for an overview, see Johnson 2005a).

Hence, research on the relationship between negative life events and the risk for a bipolar depression does not provide consistent findings. The reason may be that such a relation is only present in certain subgroups. In one study a correlation was found between negative life events and bipolar depressions, but only in female patients (Christensen et al., 2003). It was also reported that life events are only a risk factor for a bipolar depression in people who have a negative cognitive style, making them disproportionately susceptible to reacting depressively. Another possible reason for the absence of a clear correlation is that most of the depressive episodes are not brought about by a negative life event, but by other factors such as daily events, medication changes, lack of social support, chronic stressors, and physical causes. If a life event is one of the many risk factors, it can be expected that it only contributes to the probability of a depressive recurrence to a limited degree. In many of these studies, the number of patients is too small to provide evidence of such a correlation. It is less obvious that negative life events result in the occurrence of manic episodes, certainly in the case of 'classical' manias that are accompanied by euphoria, elevated self-confidence, and increased energy and productivity. Several longitudinal studies have indeed shown that negative life events do not occur more often prior to a mania than they do after a manic episode (Johnson, 2005a). This makes it improbable that negative life events play an important role in triggering a manic episode. No direct relation was found even in studies that analysed if the occurrence of a negative life event exacerbates already present manic symptoms (Johnson, 2005a).

Based on theoretical assumptions, it has been postulated that disruption of sleep is the common mechanism (final common pathway) of a large variety of factors that could possibly induce a mania, such as emotional events (the breakup of a relationship), events that are accompanied by changes in the circadian rhythm (jetlag, birth of a child, working night shifts) or events with physical 
effects (surgery, drug use) (Wehr et al., 1987). Case studies in the literature indeed suggest that sleep deficiency can induce manic symptoms. It is also known that treatment with sleep deprivation leads to the occurrence of hypomania or manic symptoms in more than $10 \%$ of the patients with a bipolar depression. Conversely, it was reported that in a patient with a rapid cycling bipolar disorder, the probability of the occurrence of manias could be reduced by extending the duration of bedrest artificially (Wehr et al., 1998).

A second category of life events assumed to play a role in triggering manias are events that disrupt daily routines, such as the break-up of a relationship, moving house, or changing jobs. This is known as the social zeitgeber hypothesis, which postulates that disruption of daily routines induces a manic episode through dysregulation of biorhythms (Grandin et al., 2006). A disturbance of the internal biological clock in the suprachiasmatic nucleus could also contribute to such a dysregulation in patients with a bipolar disorder. Retrospective research has shown that events that disrupt daily routines are reported more frequently in periods preceding a mania than preceding a depression (Malkoff-Schwartz et al., 2000). The problem with this research, however, is that a disruption of routines is quickly forgotten. The difference that was found could therefore also be explained by the fact that in general depressive episodes last longer than manic episodes, so that the chance of forgetting a preceding disruption of daily routines is greater. This underlines the need for properly designed longitudinal research that includes weekly or even daily measurements.

A third category of events which are thought to be associated with an increased probability of inducing manias are specific positive events that involve the attainment of personal goals. Examples are the prospect for a promotion at work, earning a diploma, or winning an award. This hypothesis is based on the idea that in patients with a bipolar disorder there is a dysregulation of a neurophysiological system that is referred to as the behavioural activation system (BAS), also known as the behavioural approach system. This system is sensitive to incentives that provoke an increase of activities directed at the attainment of personal goals, and regulates the associated cognitions, emotions, and behaviour. A pronounced activation of this system manifests symptoms similar to mania, such as expansive mood and increased motivation, activity, and energy. This led to the hypothesis that (hypo-)mania is characterized by a hypersensitive BAS-system (Johnson, 2005b; Nusslock et al., 2007). Conversely, as a reaction to loss or failure, bipolar patients react with an extremely negative mood, reduced energy, and anhedonia. This hypothesis is empirically supported by the results of two longitudinal studies which found that achieving a personal goal or the prospect thereof (but not the experience of a positive event in general) is a risk factor for a mania (and not for a depression) in patients with a bipolar disorder (Johnson et al., 2000a; Nusslock et al., 2007). 


\section{Social support}

The presence of social support of family and friends is a known predictor of the course of depressive disorders and other psychiatric conditions (Johnson et al., 1999). It is thus plausible that in bipolar disorders, social support either directly or indirectly (for example as a protection against the influence of negative life events) can promote the recovery from an episode and can reduce the probability of a recurrence. In recent years, a number of longitudinal studies investigated the influence of social support on the course of bipolar disorders. The results of these studies show that the lack of social support is a predictor of a more delayed recovery and a predictor of a greater probability for recurrence (for an overview, see Alloy et al., 2005). An interesting finding is that the influence of social support on the recovery from an episode was found for bipolar depressions but not for manic episodes. Just as with the influence of life events, it appears that depressions and manias differ from each other with regard to the influence of social support also. An interesting question is in what way social support influences the recovery of a depression. A possible mechanism is that social support protects against the negative influence of life events. Research, however, has not supported this. In one study it turned out that the presence of a negative life event as well as the degree of social support were mutually independent predictors of the duration of depressive episodes (Johnson et al., 1999). Another study found that sufficient social support possibly promoted the recovery of a depression because it had a positive effect on selfesteem (Johnson et al., 2000b).

\section{Expressed emotion}

Expressed emotion (EE) is a concept related to the emotional climate within a family, and is well-known in clinical practice and scientific research. A high level of EE is defined as a strongly critical attitude or an excessively emotional involvement of a close family member with regard to the patient. A high EE is a known predictor of an unfavourable course in patients with a schizophrenic disorder. A number of prospective studies have shown that a high EE also increases the probability of a recurrence in patients with a bipolar disorder (for an overview, see Alloy et al., 2005). A high EE turns out to be mainly present if manic symptoms are present in the patient and the family member involved believes that the patient has self-control over his own behaviour. Observations in the laboratory have also shown that a high EE is associated with a negative style of interaction between the patient and his family (Simoneau et al., 1998). According to the authors, the influence of EE on the course of bipolar disorders can best be regarded as an interactive process in which the presenting symp- 
toms of the patient and a high EE in a family member mutually reinforce each other.

\section{Conclusion and further research}

In summary, it may be concluded that the results of several properly designed longitudinal studies suggest that life events, social support, and expressed emotion influence the course of bipolar disorders. Investigation as to whether mania and depression are associated with different types of life events has been less extensive. There are indications that a negative life event and an absence of social support are risk factors for a bipolar depression, but not for mania. There is also empirical support for the hypothesis that risk factors for the occurrence of manic symptoms - but not for depressive symptoms - are specific life events related to sleep deficiency, disruption of daily routines, or the prospect of attaining personal goals. However, the numbers of patients in these studies were small and in general the results have not been replicated. If larger studies could confirm that specific events are a risk factor for specific symptoms, this would motivate the development of targeted psychosocial interventions.

There is little research on the role of naturally occurring daily events in the course of bipolar disorders. Although they are less stressful, they are much more numerous than life events. The experience-sampling method, which has already been used in other populations, is a method for researching the daily events in everyday life in a valid way. In the author's own experience-sampling method it was found that patients with a bipolar disorder in remission did not differ from healthy controls in the quantity and severity of daily hassles (Havermans et al., 2007). Within the patient group, however, those patients with current depressive symptoms and more previous depressive episodes experienced negative events as more stressful.

Now that we know that specific life events, absence of social support, and a high level of expressed emotion are risk factors for a recurrence, research should probably focus more on identifying variables that influence this relationship. This may also provide a more specific answer to the question as to which subgroups of patients are vulnerable to the influence of environmental factors. An often-mentioned influencing variable is the number of previous episodes. According to the kindling and sensitization hypothesis (Post, 1992), the role of life events as a trigger of a recurrence gradually reduces with an increasing number of episodes, and eventually the course of the disorder becomes more autonomous. If proven, this hypothesis would imply that interventions focused on dealing with life events are particularly useful in patients who have yet undergone only a few episodes. This hypothesis also underlines that a prophylactic treatment would have to start as early as possible in the course of the disorder, so that the progressive vulnerability induced by the repetitive occur- 
rence of mood episodes is restricted to a minimum. Research on this hypothesis, however, has thus far not provided unequivocal results. Future research should also be directed at the possible mechanisms by which identified risk factors influence the probability of a recurrence. Besides being theoretically interesting, better insight into these mechanisms is also important for clinical practice, because it may reveal possible targets for therapeutic interventions. Examples that follow from studies reviewed above include research on the effect of disruption of sleep and daily routine on biorhythms (circadian sleep-wake rhythm, cortisol, neurotransmitters) and the effect of a lack of social support on self-esteem. Research on these topics, however, is scarce and often not replicated.

\section{Clinical implications}

Many of the theoretical ideas and mpirical research findings that are covered in this chapter have found their way to clinical practice. An example of this is the application of the Life Chart Method, which systematically charts the retrospective as well as the prospective symptomatic pathogenesis in relation to medication use together with environmental factors. Another example is the use of interventions that teach patients to recognise and manage early warning signs and symptoms of impending manic or depressive episodes. Examples of preventive measures applied when early warning signs of a mania are present are promotion of sufficient sleep, maintaining regular daily routines, and the reduction of goal-attainment activities. The rationale for such interventions is described in this chapter. These instruments are suitable for application in daily clinical practice and their use is supported by the availability of forms and manuals. In recent years, various systematic forms of psycho-education and psychotherapy have been developed and described in which attention is given to the role of environmental factors. These instruments and treatments have gained a fixed place in national and international guidelines, although there use in everyday clinical practice lags behind. In recent years, however, to an increasing degree mental health institutions have adopted the principles of evidence based medicine and started specialised treatment programs that facilitate the implementation of these guidelines. It is expected that this will lead to increased attention for the targeted modulation of environmental factors in clinical practice. 


\section{References}

Alloy, L.B., Abramson, L.Y., Urosevic, S., Walshaw, P.D., Nusslock, R., \& Neeren, A.M. (2005). The psychosocial context of bipolar disorder: environmental, cognitive, and developmental risk factors. Clinical Psychology Review, 25, 1043-1075.

Brown, G.W., \& Harris, T. (1978). Social origins of depression: a study of psychiatric disorder in women. London: Tavistock Publications.

Christensen, E.M., Gjerris, A., Larsen, J.K., Bendtsen, B.B., Larsen, B.H., Rolff, H., et al. (2003). Life events and onset of a new phase in bipolar affective disorder. Bipolar Disorders, 5, 356-361.

Ellicott, A., Hammen, C., Gitlin, M., Brown, G., \& Jamison, K. (1990). Life events and the course of bipolar disorder. The American Journal of Psychiatry, 147, 1194-1198.

Grandin, L.D., Alloy, L.B., \& Abramson, L.Y. (2006). The social zeitgeber theory, circadian rhythms, and mood disorders: review and evaluation. Clinical Psychology Review, 26, 679-694.

Havermans, R., Nicolson, N.A., \& deVries, M.W. (2007). Daily hassles, uplifts, and time use in individuals with bipolar disorder in remission. The Journal of Nervous and Mental Disease, 195, 745-751.

Hunt, N., Bruce-Jones, W., \& Silverstone, T. (1992). Life events and relapse in bipolar affective disorder. Journal of Affective Disorders, 25, 13-20.

Johnson, S.L., \& Miller, I. (1997). Negative life events and time to recovery from episodes of bipolar disorder. Journal of Abnormal Psychology, 106, 449-457.

Johnson, S.L., Winett, C.A., Meyer, B., Greenhouse, W.J. \& Miller, I. (1999). Social support and the course of bipolar disorder. Journal of Abnormal Psychology, 108, 558-566.

Johnson, S.L., Sandrow, D., Meyer, B., Winters, R., Miller, I., Solomon, D., et al. (2000a). Increases in manic symptoms after life events involving goal attainment. Journal of Abnormal Psychology, 109, 721-727.

Johnson, S.L., Meyer, B., Winett, C.A., \& Small, J. (2000b). Social support and self-esteem predict changes in bipolar depression but not mania. Journal of Affective Disorders, 58, 79-86.

Johnson, S.L. (2005a). Life events in bipolar disorder: towards more specific models. Clinical Psychology Review, 25, 1008-1027.

Johnson, S.L. (2005b). Mania and dysregulation in goal pursuit: a review. Clinical Psychology Review, 25, 241-262.

Malkoff-Schwartz, S., Frank, E., Anderson, B.P., Hlastala, S.A., Luther, J.F., Sherill, J.T., et al. (2000). Social rhythm disruption and stressful life events in the onset of bipolar and unipolar episodes. Psychological Medicine, 30, 1005-1016.

Nusslock, R., Abramson, L.Y., Harmon-Jones, E., Alloy, L.B., \& Hogan, M.E. (2007). A goal-striving life event and the onset of hypomanic and depressive episodes and symptoms: perspective from the behavioral approach system (BAS) dysregulation theory. Journal of Abnormal Psychology, 116, 105-115.

Post, R.M. (1992). Transduction of psychosocial stress into the neurobiology of recurrent affective disorder. The American Journal of Psychiatry, 149, 999-1010.

Simoneau, T.L., Miklowitz, D.J., \& Saleem R. (1998). Expressed emotion and interactional patterns in the families of bipolar patients. Journal of Abnormal Psychology, 107, 497-507.

Wehr, T.A., Sack, D.A., \& Rosenthal, N.E. (1987). Sleep reduction as a final common pathway in the genesis of mania. The American Journal of Psychiatry, 144, 201-204.

Wehr, T.A., Turner, E.H., Shimada, J.M. Lowe, C.H., Barker, C., \& Leibenluft, E. (1998). Treatment of a rapidly cycling bipolar patient by using extended bed rest and darkness to stabilize the timing and duration of sleep. Biological Psychiatry, 43, 822-828. 


\section{Samenvatting}

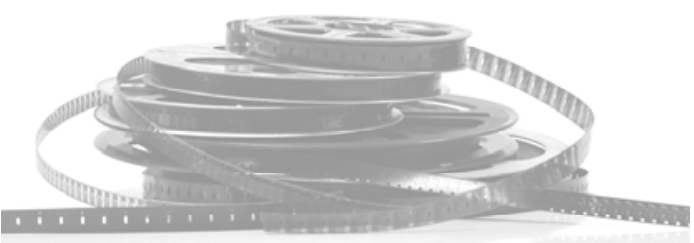


De bipolaire stoornis, ook wel manisch-depressieve stoornis genoemd, is gekenmerkt door extreme stemmingswisselingen, waarbij recidiverende episoden van depressie, manie en hypomanie, worden afgewisseld met perioden van remissie waarin weinig of geen symptomen aanwezig zijn. Het beloop van de stoornis is zeer variabel. Sommige patiënten herstellen goed na het doormaken van vaak ernstige episoden en slagen erin gedurende langere perioden stabiel te blijven, met behoud van een acceptabel nivo van sociaal en maatschappelijk functioneren. Bij veel patiënten is het beloop echter meer chronisch met frequent recidiverende episoden, onvolledig herstel met subsyndromale restsymptomen, en aanhoudende functionele beperkingen. Het is daarom belangrijk onderzoek te doen naar factoren die van invloed zijn op het beloop van de stoornis en naar de mechanismen die daar mogelijk een rol in spelen. In de afgelopen 20 jaar hebben meerdere cohort studies aangetoond dat psychosociale omgevingsfactoren, zoals ingrijpende gebeurtenissen (major life events), sociale steun, en het emotionele klimaat binnen het gezin, de kans op het optreden van nieuwe episoden gedurende het verdere beloop van de bipolaire stoornis beïnvloeden. Een overzicht van deze studies, eerder gepubliceerd als een boekbijdrage, is als bijlage aan dit proefschrift toegevoegd. Een belangrijke beperking van dergelijke studies is dat ze ons weinig leren over de directe psychologische en fysiologische effecten van omgevingsfactoren, terwijl informatie daarover inzicht kan geven in de wijze waarop deze factoren de kans op het optreden van nieuwe episoden in de toekomst beïnvloeden. Het onderzoek beschreven in dit proefschrift is opgezet om hieraan een bijdrage te leveren.

Hoofdstuk 1 beschrijft de theoretische achtergronden, de doelen en de onderzoeksmethode van de studie. Het belangrijkste doel van het onderzoek was de beschrijving van de ervaring van dagelijkse gebeurtenissen en de effecten hiervan op fluctuaties in stemming en cortisol, bij een groep patiënten met een bipolaire stoornis tijdens een periode van remissie. De resultaten werden vergeleken met een groep gezonde proefpersonen die wat betreft leeftijd en geslacht met de patiëntengroep overeenkwamen. In het onderzoek werd gebruik gemaakt van de Experience Sampling Methode (ESM), waarmee op een intensieve manier (tien metingen per dag gedurende zes dagen) informatie werd verzameld over stemming, bezigheden en gebeurtenissen tijdens het normale dagelijkse leven van de proefpersonen. Bij de analyse van de stemmingsvariabelen konden twee dimensies worden onderscheiden: negatief affect (NA) en positief affect (PA). Gelijktijdig met de ESM-metingen werden ook speekselmonsters verzameld, waarin op een later moment de concentratie van het stresshormoon cortisol werd gemeten. De patiëntengroep werd na afloop van de ESM-week gedurende twee jaar opgevolgd, waarbij herhaaldelijk werd geëvalueerd of en wanneer in de tussenliggende periode een recidief van een depressieve of manische episode was opgetreden. Doel van deze follow-up was na te gaan of de gemeten niveaus en reacties van NA en PA een betere voorspeller zijn van een recidief dan bekende risicofactoren, 
zoals een groot aantal eerder doorgemaakte episoden en de aanwezigheid van subsyndromale restsymptomen.

Hoofdstuk 2 beschrijft de aard, de frequentie en de subjectieve beleving (appraisals) van negatieve en positieve dagelijkse gebeurtenissen bij patiënten en gezonde proefpersonen. Ook werd onderzocht of individuele verschillen in de ervaring van deze gebeurtenissen samenhangen met verschillen in tijdsbesteding. Tegen de verwachting in bleken patiënten en gezonde proefpersonen niet te verschillen in het totale aantal gerapporteerde negatieve en positieve gebeurtenissen en ook niet in de appraisals van deze gebeurtenissen. Er werden wel verschillen in tijdsbesteding gevonden: patiënten besteedden gemiddeld minder tijd aan werk, meer tijd aan passieve vormen van ontspanning, en brachten meer tijd binnenshuis door. Een dergelijke tijdsbesteding bleek samen te hangen met verminderde blootstelling aan zowel negatieve als positieve gebeurtenissen. Echter, ook na controle voor verschillen in tijdsbesteding, bleken patiënten en gezonde proefpersonen niet van elkaar te verschillen in de ervaring van gerapporteerde dagelijkse gebeurtenissen. Vervolgens is gekeken of verschillen binnen de patiëntengroep in de ervaring van dagelijkse gebeurtenissen, samenhingen met bepaalde klinische kenmerken. Uit de analyses bleek dat patiënten negatieve gebeurtenissen als meer stressvol werden ervaren naarmate zij meer actuele depressieve symptomen hadden en meer depressieve episoden hadden doorgemaakt. Deze bevindingen ondersteunen bestaande theorieën dat subsyndromale depressieve symptomen en doorgemaakte episoden, stressvolle gebeurtenissen genereren of de neiging versterken om gebeurtenissen negatief te interpreteren.

In hoofdstuk 3 worden de niveaus van NA en PA en de veranderingen die hierin optreden na het optreden van negatieve en positieve gebeurtenissen bestudeerd. Patiënten vertoonden een gemiddeld hogere score op NA en lagere score op PA vergeleken met gezonde proefpersonen. Zoals verwacht gingen negatieve gebeurtenissen gepaard met een toename van NA en een afname van PA, terwijl positieve gebeurtenissen waren geassocieerd met een afname van NA en een toename van PA. Patiënten en gezonde proefpersonen verschilden echter niet in de grootte van deze effecten. Binnen de patiëntengroep bleek de aanwezigheid van subsyndromale depressieve symptomen samen te hangen met een sterkere stijging van NA in reactie op negatieve gebeurtenissen. Dergelijke symptomen zijn een bekende risicofactor voor een recidief, geopperd wordt dat de verhoogde reactiviteit van NA daarbij een rol speelt.

In hoofdstuk 4 worden de cortisolgehaltes in het speeksel en de invloed daarop van dagelijkse gebeurtenissen bij patiënten en gezonde proefpersonen geanalyseerd. In eerdere studies bij patiënten met een bipolaire stoornis waren verstoringen van de hypothalamus-hypofyse-bijnieras gevonden, waaronder een 
verhoogde cortisolproductie, tijdens manische en depressieve episoden. Minder duidelijk was of deze verstoringen ook aanwezig zijn tijdens perioden van remissie. De resultaten van het huidige onderzoek lieten zien dat een negatieve dagelijkse gebeurtenis gepaard gaat met een stijging van het cortisolgehalte. Patiënten en gezonde proefpersonen verschilden echter niet van elkaar in de gemiddelde concentratie van cortisol en ook niet in de cortisolreactie op negatieve gebeurtenissen. Patiënten lieten wel een iets vlakkere curve over de dag zien en ook sterkere fluctuaties in het cortisolgehalte over opeenvolgende meetmomenten. Patiënten met veel doorgemaakte episoden hadden gemiddeld hogere cortisolgehaltes, vlakkere dagcurven, en een minder sterke stijging van cortisol na negatieve gebeurtenissen dan patiënten met weinig doorgemaakte episoden. Deze resultaten vormen een aanwijzing dat bij patiënten met een bipolaire stoornis, ook tijdens een fase van remissie, subtiele veranderingen in cortisolproductie aanwezig zijn, die meer uitgesproken zijn bij patiënten met veel doorgemaakte episoden.

In hoofdstuk 5 staat de vraag centraal of binnen de patiëntengroep, de niveaus en reacties van NA en PA, gemeten tijdens de ESM-week, voorspellers zijn van de kans op een recidief depressie of manie gedurende de follow-up periode van twee jaar. Bij deze analyse werd gecontroleerd voor de mogelijke invloed van eerdere episoden en aanwezige subsyndromale depressieve symptomen op de recidiefkans. De resultaten laten zien dat een hogere gemiddelde score van NA een voorspeller is van een korter interval tot de eerstvolgende recidief depressie. Ook werd gevonden dat een sterkere stijging van PA na een positieve dagelijkse gebeurtenis een voorspeller is van een korter interval tot de eerstvolgende recidief manie. Deze laatste bevinding sluit aan bij recente theorievorming over de mogelijk belangrijke rol van een stoornis in de regulatie van positief affect bij het ontstaan en het beloop van de bipolaire stoornis.

In hoofdstuk 6 zijn de belangrijkste resultaten van het onderzoek samengevat en besproken. Daarbij worden voorstellen gedaan voor toekomstig onderzoek en wordt ook ingegaan op de mogelijke betekenis voor de klinische praktijk. Concluderend wordt gesteld dat het ESM-onderzoek beschreven in dit proefschrift heeft bijgedragen aan een meer gedetailleerde beschrijving van de fenomenologie van het dagelijks leven van de patiënten met een bipolaire stoornis. Het onderzoek heeft ook een beter inzicht gegeven in de directe psychologische en fysiologische effecten van dagelijkse gebeurtenissen, en aangetoond dat subsyndromale depressieve symptomen en eerder doorgemaakte episoden samenhangen met specifieke verstoringen in de regulatie van affect en cortisol. Deze bevindingen geven richting aan verder onderzoek met het doel beter te begrijpen hoe omgevingsfactoren en klinische variabelen de kwetsbaarheid voor een recidief kunnen beïnvloeden. Indien gerepliceerd in een grotere studie, toont het huidige onderzoek ook aan dat experience sam- 
pling kan bijdragen aan een betere en meer gedifferentieerde voorspelling van het toekomstige beloop van de bipolaire stoornis. Recente technische ontwikkelingen maken de ESM-methode meer geschikt voor de dagelijkse klinische praktijk. De toepassing hiervan kan behandelaren en patiënten met een bipolaire stoornis helpen een nauwkeuriger beeld te krijgen van de wijze waarop aanwezige klachten en symptomen samenhangen met dagelijkse gebeurtenissen en activiteiten, en daarmee een waardevolle bijdrage leveren aan de verbetering van psychosociale behandelingen en zelfmanagementinterventies. 



\section{Verantwoording en dankwoord}

Het heeft lang geduurd maar nu is het klaar. Als psychiater en manager zorg in een voortdurend veranderende GGZ-omgeving, en vader in een gezin met drie opgroeiende kinderen, had het promotieonderzoek weinig prioriteit. Dat het uiteindelijk toch is afgerond heb ik te danken aan Nancy Nicolson, een fantastische co-promotor. Altijd constructief in het overleg en op tijd de druk opvoerend. Nancy, ik vermoed dat het gebrek aan voortgang voor jou soms ook frustrerend was, maar het is je gelukt het tot een goed einde te brengen. Mijn promotor, Marten deVries, bedank ik voor de gelegenheid die hij me heeft geboden om promotieonderzoek te doen. Ik heb je oproep om de klinische relevantie van het onderzoek voor ogen te houden ter harte genomen.

Ik heb veel te danken aan Lex van Bemmel die mij op zijn slaaplab in Vijverdal, waar ik als gewetensbezwaarde dienstplichtige werd tewerkgesteld, liet kennismaken met het wetenschappelijk onderzoek binnen de psychiatrie. Hij heeft me geïnspireerd om de opleiding tot psychiater te volgen en na afronding daarvan patiëntenzorg te combineren met het doen van promotieonderzoek. Samen met Nancy was hij betrokken bij de opzet van het studie. Na zijn vertrek uit Maastricht zijn we elkaar uit het oog verloren, gelukkig hebben we elkaar onlangs weer ontmoet. Hans Berkhof was onmisbaar als statisticus, ik bedank hem voor zijn geduld bij het beantwoorden van mijn vragen en zijn bereidheid om de multilevel analyses opnieuw te draaien als we weer eens van mening waren veranderd over de te includeren variabelen.

Er zijn meer mensen die ik wil bedanken. Zonder de hulp van Anneke Zaad en Mieke Vossen had ik de meeste patiënten nooit zover gekregen dat ze wilden meewerken aan dit onderzoek. Cristel Achterberg, Lilly Finders, Truda Driesen en Frieda van Goethem hebben op een zeer prettige en nauwkeurige wijze zorg gedragen voor de dataverzameling en -invoer. Philip Delespaul leverde een belangrijke bijdrage aan het managen van het databestand. Frenk Peeters bedank ik voor zijn bijdrage aan de werving van een gemeenschappelijke groep gezonde proefpersonen, en de collegiale samenwerking sindsdien. Miranda Reijnders ontwierp de fraaie omslag. Dit is ook een goed moment om de vele 
mensen met wie ik dagelijks samenwerk te bedanken, waaronder de verpleegkundigen op KC 1.1., de secretaresses, de behandelaren binnen het team, de PITverpleegkundigen, de arts-assistenten, de psychiaters binnen en buiten de instelling, Rob Beurskens en de dames van de prikdienst, de arts-assistenten en de collega-managers. De proefpersonen bedank ik voor de deelname aan het onderzoek en het gestelde vertrouwen. Ook al geldt Experience Sampling onderzoek als niet belastend, het was best intensief om 60 keer een vragenlijstje in te vullen en wat speeksel af te staan, en daarnaast een aantal keren naar de kliniek te komen voor interviews.

Hans Peerden en Benjamin Richartz, ik ben blij met jullie steun als paranimf. Hans, ik ken je al vanaf het begin van onze geneeskunde studie, ik waardeer onze vriendschap die standhoudt ondanks de afstand. Die wandeltochten waarbij we alle belangrijke levensvragen doornemen, daar moeten we mee doorgaan, het is mijn beurt om het initiatief te nemen. Benjamin, we werken al heel wat jaren samen aan verbetering van de kwaliteit van de patiëntenzorg, ik waardeer je betrokkenheid en eerlijkheid. Via jou bedank ik ook je vader, Mark Richartz, die mij destijds heeft aangenomen voor de opleiding tot psychiater.

Mam, jij en Pap hebben me altijd de steun en het vertrouwen gegeven om mijn eigen toekomst te bepalen. Een belangrijke regel daarbij was, dat je moest doorzetten als je aan iets begon. Die regel gold voor school, voor hobby's, en heb ik ook nageleefd bij het schrijven van dit proefschrift. Het is jammer dat ons Pap, overleden kort voor de afronding, de verdediging van mijn proefschrift niet meer heeft kunnen bijwonen. Hij zou erg trots geweest zijn, maar ik weet dat hij dat ook al was zonder die promotie.

Mijn lieve kinderen Malou, Céline en Luc. Jullie vonden het wel interessant dat ik een boekje aan het schrijven was. De afgelopen maanden heb ik heel wat uren op zolder doorgebracht achter de computer. We gaan nu weer wat vaker leuke dingen doen. Laura, mijn lieve vrouw, bedankt voor je steun en voor je stimulans om het proefschrift af te ronden, ook al waren er genoeg andere dingen te doen. 


\section{Curriculum vitae}

Rob Havermans werd op 27 juli 1961 geboren in Bergen op Zoom. In 1979 behaalde hij het VWO diploma aan het Rythoviuscollege te Eersel, waarna hij aan de Katholieke Universiteit Nijmegen geneeskunde (artsexamen 1988) en filosofie (doctoraalexamen 1987) studeerde. Na zijn vervangende dienstplicht als onderzoeksassistent op het PMS Vijverdal te Maastricht, werkte hij een jaar als arts-assistent op een opnameafdeling in het Psychiatrisch Centrum Nijmegen. Van 1991 tot 1995 volgde hij de opleiding tot psychiater in Maastricht, aansluitend werkte hij als psychiater en universitair docent bij de vakgroep Psychiatrie en Neuropsychologie van de Universiteit Maastricht en bij het PMS Vijverdal te Maastricht. Zijn huidige functie is psychiater en manager zorg bij Mondriaan, binnen het behandelprogramma PsyQ Depressie Maastricht en Heerlen. Rob Havermans is getrouwd met Laura Dreessen, samen hebben ze drie kinderen. 